\title{
Computational Fluid Dynamics Modeling of Scaled Hanford Double Shell Tank Mixing - CFD Modeling Sensitivity Study Results
}

\author{
V. Jackson \\ Washington River Protection Services, LLC \\ Richland, WA 99352 \\ U.S. Department of Energy Contract DE-AC27-08RV14800

$\begin{array}{lll}\text { EDT/ECN: } & \text { DRF } & \text { UC: N/A } \\ \text { Cost Center: } & \text { 2GBD00 } & \text { Charge Code: } 200495 \\ \text { B\&R Code: } & \text { N/A } & \text { Total Pages: } 66\end{array}$ \\ Key Words: WRPS, Small Scale Mixing Demonstration, SSMD, \\ CFD Modeling, Sensitivity Report
}

Abstract: The primary purpose of the tank mixing and sampling demonstration program is to mitigate the technical risks associated with the ability of the Hanford tank farm delivery and certification systems to measure and deliver a uniformly mixed high-level waste (HLW) feed to the Waste Treatment and Immobilization Plant (WTP) Uniform feed to the WTP is a requirement of 24590-WTP-ICD-MG-01-019, ICD-19 - Interface Control Document for Waste Feed, although the exact definition of uniform is evolving in this context. Computational Fluid Dynamics (CFD) modeling has been used to assist in evaluating scaleup issues, study operational parameters, and predict mixing performance at full-scale..

TRADEMARK DISCLAIMER. Reference herein to any specific commercial product, process, or service by trade name, trademark, manufacturer, or otherwise, does not necessarily constitute or imply its endorsement, recommendation, or favoring by the United States Government or any agency thereof or its contractors or subcontractors.
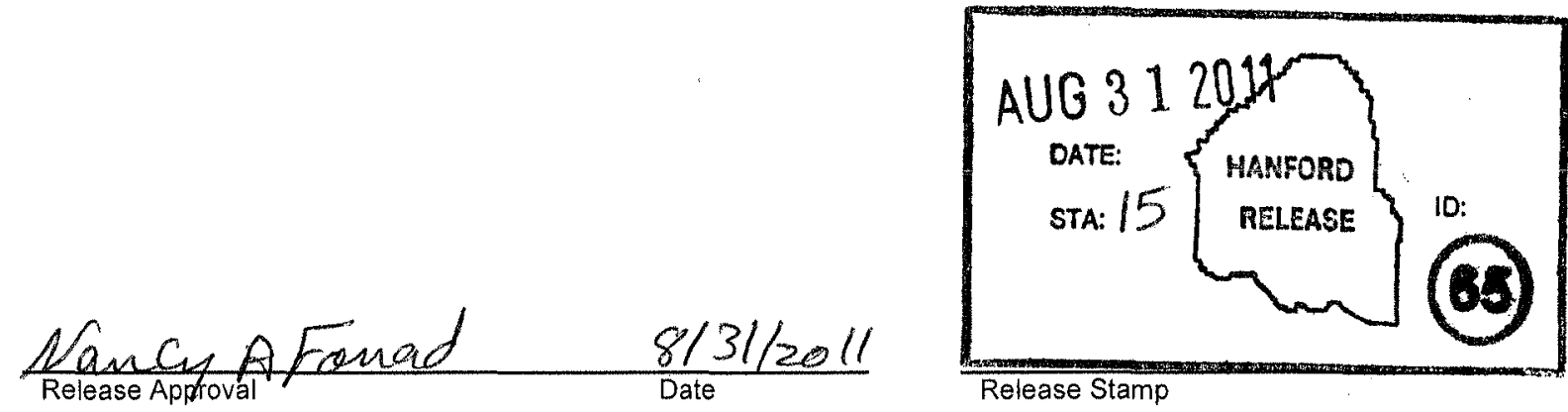

Release Stamp

\section{Approved For Public Release}


Computational Fluid Dynamics Modeling of Scaled Hanford Double Shell Tank Mixing

\section{CFD Modeling Sensitivity Study \\ Results}

Revision: $\quad 0$

Issue Date: August, 20 I I

Approved By:

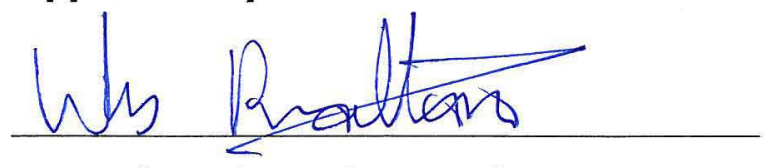

Dr. Wesley Bratton, Project Manager

Prepared for:

washington river Washington River Protection Solutions

protectionsolutions PO Box 850, MSIN H6-16

Richland, WA 99352

Prepared by:

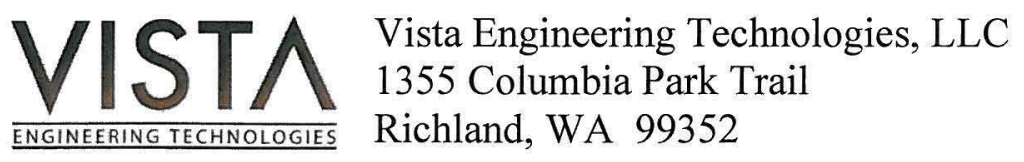




\section{EXECUTIVE SUMMARY}

The primary purpose of the tank mixing and sampling demonstration program is to mitigate the technical risks associated with the ability of the Hanford tank farm delivery and certification systems to measure and deliver a uniformly mixed high-level waste (HLW) feed to the Waste Treatment and Immobilization Plant (WTP). Uniform feed to the WTP is a requirement of 24590-WTP-ICD-MG-01-019, ICD-19-Interface Control Document for Waste Feed, although the exact definition of uniform is evolving in this context. Computational Fluid Dynamics (CFD) modeling has been used to assist in evaluating scale-up issues, study operational parameters, and predict mixing performance at full-scale.

To accomplish this goal, the following three objectives for the CFD modeling were established:

1. Demonstrate that the modeled jet velocities are equivalent to the jet velocities measured in the small scale mixing demonstration (SSMD) 120-inch tank.

2. Evaluate the impact of the jet, in terms of its flow rate and rotational rate, on the mixing performance at each of the three tank scales: 43.2-inch, 120-inch, and full-scale.

3. Evaluate the correlations that occur among the various tank scales for a defined particle suspension range of 0.2 to $0.4 \mathrm{~m} / \mathrm{s}$, as well as the parameter's impacts on mixing performance.

A single full-scale CFD mesh was initially prepared to match the characteristics of Tank AY-102. From this mesh, scaled models for both of the physical models developed by the SSMD were prepared using geometrically-scaled dimensions for all the tank parameters (such as diameter and depth), as well as mixer pump nozzle diameter and locations. Therefore, the CFD models are consistent at all three scales as constructed. Details of the model are documented in RPP-48055, Computational Fluid Dynamics Modeling of Scaled Hanford Double Shell Tank Mixing, Fiscal Year 2010 Model Development Results. Since the model development work presented in RPP-48055, the CFD model has been adjusted using actual jet velocity measurements made in the 120-inch SSMD tank by the SSMD contractor. These measurements utilized an impellor flow meter and were used to fine-tune the turbulence parameters in the CFD model to match the jet velocities from the SSMD program. A good correlation between the measured velocities and the computed velocities was obtained and provides confidence in the model parameters.

To accomplish the objective of studying the operational parameters of mixer pump flow rate and rotation rate at the three scales (43.2-inch tank, 120-inch tank and full-scale), and their impacts on mixing performance, a test matrix of six runs was conducted using the 120 -inch scale tank. The test matrix consisted of three different mixer pump flow rates and two pump rotational rates. The three flow rates for the 120 -inch scaled model consisted of 58, 78, and 98 gallons per minute (GPM), which corresponds to jet velocities of $18.5,24.9$, and $31.3 \mathrm{ft} / \mathrm{s}$ respectively. The two rotational rates that were studied for the 120 -inch scale model were 0.77 and 0.48 pump-head revolutions per minute (RPM). Two additional runs were also completed -- one at the 43.2-inch tank scale and other at the 900-inch (full) tank scale. These were done to verify the tank scaling theory so the results from the 120 -inch runs could be translated to both the 43.2-inch scale and full-scale.

A test matrix reduction using only the 120 -inch tank scale was possible since the CFD models contained only fluids, and the fluid constitutive model scales uniformly over the three scales considered. This scaling was demonstrated and confirmed using the results from a high flow rate and high rotational rate test case in each of the three tank sizes. Comparison of the results clearly shows that fluid velocities and 
associated mixing performance can be simulated at all scales using the given scaling relationships and the CFD results from 120 -inch tank.

Using the mixing performance results from the test matrix, the CFD results show that the pump flow rate (jet face velocity) has a larger impact on mixing performance than pump-head rotational rate within the defined particle suspension range of 0.2 to $0.4 \mathrm{~m} / \mathrm{s}$. For the 120-inch scale, changes in flow rate from 58 to $98 \mathrm{GPM}$ at a constant pump-head rotational rate produced between 25 and $70 \%$ increase in the mixing iso-surface area for the defined particle suspension range of 0.2 to $0.4 \mathrm{~m} / \mathrm{s}$. Likewise a change from 0.77 RPM to 0.48 RPM in pump-head rotational rate produced changes between $-20 \%$ and $+6 \%$ depending on the flow rate. For the lower flow rates, it is beneficial to reduce the rotational rate to allow the jet velocity additional time to fully expand and penetrate.

Comparison across the three scales indicates that rotational rate has a slightly larger influence at the larger scales. More importantly, the areas with fluid velocities of interest related for solids suspension are relatively larger as the scale increases. This finding is partly due to the higher jet velocities utilized in the large scales, but does suggest that mixing performance and distribution of solids can be expected to improve as scales get larger as long as fluid flow is the dominant mode of solid movement. The influence of actual solid particles in these fluid-only simulation streams should be considered when predicting mixing performance. 
REVISION HISTORY

\begin{tabular}{|l|l|}
\hline \multicolumn{1}{|c|}{ Revision } & \multicolumn{1}{c|}{ Change Description } \\
\hline 0 & Initial Release \\
\hline & \\
\hline & \\
\hline & \\
\hline & \\
\hline & \\
\hline & \\
\hline & \\
\hline & \\
\hline & \\
\hline & \\
\hline & \\
\hline & \\
\hline & \\
\hline
\end{tabular}




\section{TABLE OF CONTENTS}

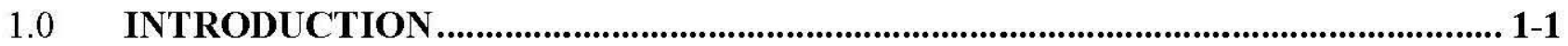

1.1 Fiscal Year 2011 CFD Modeling Objectives ............................................................. 1-2

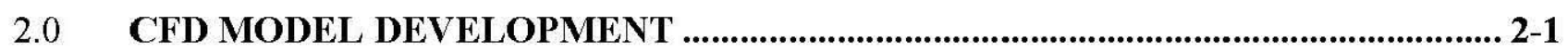

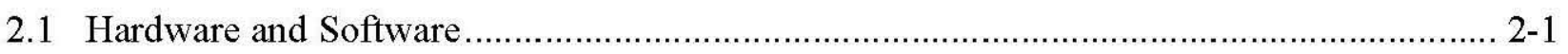

2.2 Model Geometry and Key Characteristics ................................................................... 2-1

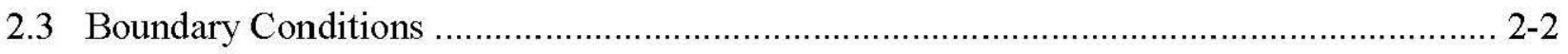

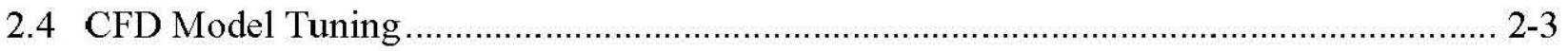

$3.0 \quad 120-I N C H$ TANK SCALE SENSITIVITY ST UDIES ..................................................... 3-1

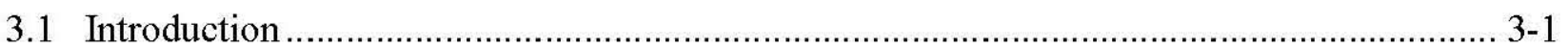

3.2 Iso-Value Surface Area .......................................................................................

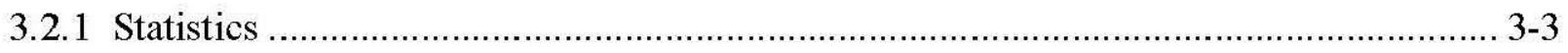

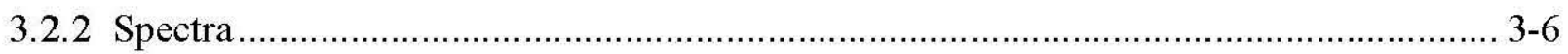

3.3 120-Inch Comparisons ..................................................................................... 3-11

3.3.1 Effect of Changes in Flow Rate …………………............................................. 3-11

3.3.2 Effect of Changes in Rotation Rate................................................................... 3-14

4.0 SCALING RELATIONSHIPS AMONG THE THREE SCALES ................................ 4-1

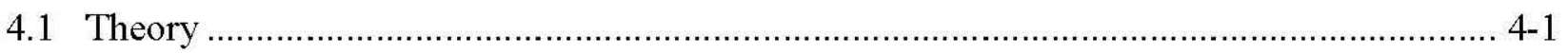

4.1.1 Power per Unit Volume...................................................................................... 4-2

4.2 Full, 120-Inch, and 43.2-Inch Scale Comparison ...................................................... 4-2

4.3 Scaling 120-Inch Cases to Full-Scale and 43.2-Inch Scales ........................................... 4-10

C.0 CONCLUSIONS............................................................................................................. 5-1

6.0 REFERENCES ..................................................................................................... 6-1

\section{APPENDICES}

Appendix A: Process Movie on CD. 1

\section{LIST OF FIGURES}

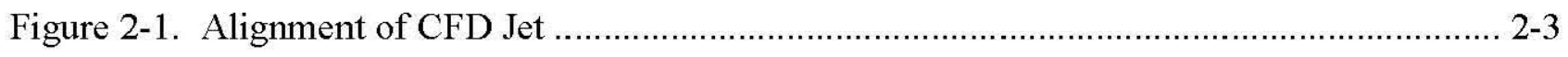

Figure 2-2. Control Rod with Bottom Foot...................................................................... 2-4

Figure 2-3. Jet Velocity Data for the 120-Inch Tank (Velocity Matched) .................................... 2-7

Figure 3-1. FS-120-vmp7-upp3-dnp1-p1to3vm.mp4 ………............................................... 3-3 
Figure 3-2. Typical Time Series for Two Full Rotations................................................... 3-4

Figure 3-3. Relative Standard Deviation All Cases (\%). ................................................... 3-5

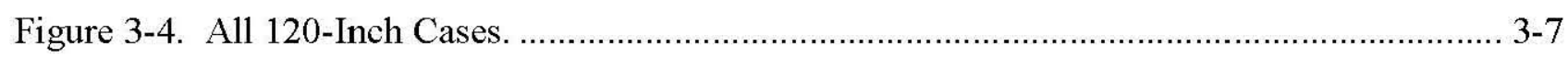

Figure 3-5. Phase Shift with Ad-Hoc 0.9590 and 0.8663 Factors.......................................... 3-10

Figure 3-6. Comparison of 120-Inch Cases at Constant RPM.............................................. 3-12

Figure 3-7. Comparison of 120-Inch Cases at Constant GPM................................................ 3-15

Figure 4-1. Comparison Cases for each of the Scales (actual simulations). ............................. 4-3

Figure 4-2. Comparison Cases for All Models ........................................................... 4-7

Figure 4-3. Distribution of Differences Three Cross-Cases................................................ 4-9

Figure 4-4. Results at Maximum GPM and Maximum RPM Case (Consistent with Sect. 4.2)... 4-11

Figure 4-5. Extrapolated versus Simulated. .............................................................. 4-15

Figure 4-6. Maximum GPM and Minimum RPM Case...................................................... 4-16

Figure 4-7. Medium GPM and Maximum RPM Case ................................................... 4-17

Figure 4-8. Medium GPM and Minimum RPM Case ...................................................... 4-18

Figure 4-9. Minimum GPM and Maximum RPM Case................................................... 4-19

Figure 4-10. Minimum GPM and Minimum RPM Case. ..................................................... 4-20

Figure 4-11. Results from 120-inch Cases Presented in Full-Scale Units. .............................. 4-26

Figure 4-12. Results from 120-inch Cases Presented in 43.2-Inch Units. .............................. 4-27

\section{LIST OF TABLES}

Table 3-1. Fiscal Year 2011 Simulations.

Table 3-2. Relative Standard Deviation of Iso-Value Surface Area (sq. m. and \%) Versus Iso-Value Relative Magnitude (2 pages) ...................................................................... 3-5

Table 3-3. Iso-Value Surface Area versus Velocity Magnitude (2 pages)................................ 3-8

Table 3-4. Iso-Value Surface Area (scaled) versus Velocity Magnitude (scaled) (2 pages). ....... 3-10

Table 3-5. Percent Change between Comparison Cases, Constant RPM (\%) (2 pages)............. 3-13

Table 3-6. Percent Change between Comparison Cases, Constant GPM (\%) (2 pages). ............ 3-15

Table 4-1. Iso-Value Surface Area (scaled) versus Velocity Magnitude (3 pages)..................... 4-4

Table 4-2. Iso-Value Surface Area (scaled) versus Velocity Magnitude (scaled) (2pages). ......... 4-7

Table 4-3. Percent Change between Comparison Cases (\%) (2 pages). ................................... 4-9

Table 4-4. Iso-Value Surface Area (scaled) versus Velocity Magnitude (4 pages)................... 4-11

Table 4-5. Iso-Value Surface Area (scaled) versus Velocity Magnitude (4 pages)................... 4-21 


\section{LIST OF TERMS}

$\begin{array}{ll}\text { ADMP } & \text { Advanced Design Mixer Pump } \\ \text { ALC } & \text { Air Lift Circulator } \\ \text { CFD } & \text { Computational Fluid Dynamics } \\ \text { DST } & \text { Double-shell Tank } \\ \text { FY-2011 } & \text { Fiscal Year 2011 } \\ \text { GPM } & \text { Gallons per Minute } \\ \text { HLW } & \text { High Level Waste } \\ \text { OTS } & \text { Off the Shelf } \\ \text { PJM } & \text { Pulsed-jet Mixer } \\ \text { Q3 } & \text { Third quartile } \\ \text { RPM } & \text { Revolutions per Minute } \\ \text { SRNL } & \text { Savannah River National Laboratory } \\ \text { SRS } & \text { Savannah River Site } \\ \text { SSMD } & \text { Small-scale Mixing Demonstration } \\ \text { UDF } & \text { User Defined Function } \\ \text { V\&V } & \text { Validation and Verification } \\ \text { Vista Engineering } & \text { Vista Engineering Technologies, LLC } \\ \text { WTP } & \text { Waste Treatment and Immobilization Plant }\end{array}$

\section{UNITS OF MEASURE}

$\begin{array}{ll}\mathrm{dB} & \text { Decibel } \\ \mathrm{ft} & \text { Feet } \\ \text { in } & \text { Inch } \\ \mathrm{GB} & \text { Gigabyte } \\ \mathrm{GHz} & \text { Gigahertz } \\ \mathrm{GPM} & \text { Gallons per Minute } \\ \mathrm{m} & \text { Meters } \\ \mu \mathrm{m} & \text { micrometers } \\ \mathrm{mHz} & \text { Megahertz } \\ \mathrm{mm} & \text { Millimeter } \\ \% & \text { Percent } \\ \mathrm{RPM} & \text { Revolutions per Minute } \\ \mathrm{s} & \text { Second } \\ \mathrm{sq} . \mathrm{m} & \text { Square meters }\end{array}$




\subsection{INTRODUCTION}

The primary purpose of the tank mixing and sampling demonstration program is to mitigate the technical risks associated with the ability of the tank farms delivery and certification systems to measure and deliver uniformly mixed, high-level waste (HLW) feed to the Waste Treatment and Immobilization Plant (WTP). Uniform feed to the WTP is a requirement of 24590-WTP-ICD-MG01-019, ICD-19 - Interface Control Document for Waste Feed, although the exact definition of uniform is evolving in this context. Computational Fluid Dynamics (CFD) modeling has been used in conjunction with the small-scale mixing demonstration (SSMD) measurements to assist in evaluating scale-up issues, study operational parameters and predict mixing performance at fullscale.

One of the major reasons for conducting the CFD modeling as part of the double-shell tank (DST) mixing program was to develop scale-up relationships and full-scale predictions of the mixing performance. The CFD modeling approach is being accomplished using a graded project approach that begins fairly simply and increases in complexity with each step of the project. Prior to progressing forward on each step, a strong comparison of the CFD model results to the mixing demonstration results must occur to ensure that the model is progressing as planned and the desired project end objectives can be reached.

As demonstrated in Section 2.4 of this report, water velocities calculated within the CFD model domain along the jet centerline in the 120-inch tank scale was compared with data measured in the SSMD 120 -inch tank. The model results and the measurements sufficiently match, providing confidence in the jet velocities and turbulence parameters selected for the CFD modeling. Based on sufficient water velocity matching, the next modeling step was to conduct a series of sensitivity studies to evaluate the influence of various operational parameters on the mixing behavior. This step was accomplished using three flow rates (i.e. jet velocities) and two rotational rates. All the work was conducted at the 120 -inch tank scale, and scaling relationships were utilized to calculate the influences for the 43.2-inch scale and the full-scale model. Although the CFD simulations and the SSMD mixing results were not compared as described in the RPP-44619, Computational Fluid Dynamics Modeling for Double-Shell Tank Mixing Demonstration Project Work Plan, due to evaluation differences, the results in terms of comparisons with other tank mixing modeling scenarios are considered valid due to the internal consistencies of the comparisons.

The single-fluid CFD models have been used to facilitate understanding of mixing phenomena that occur within the tank based on the key assumption that the solid's mixing characteristics are a function of fluid velocities. Evaluation of the mixing phenomena can take many different forms, as there are various approaches to measuring and mixing performance. Given that this CFD study only considers a single fluid phase, mixing performance can only be postulated in terms of fluid velocities. Due to the complexities of the actual tank waste particle combinations, some general bounding velocity assumptions based upon previous Savannah River Site (SRS) results have been used to define a reference point of interest. The SRS results consist of a velocity of $0.3 \mathrm{~m} / \mathrm{s}$ that is necessary to suspend a particle within the tank environment, as well as a velocity of $0.7 \mathrm{~m} / \mathrm{s}$ to erode a pile of settled solids and mobilize that material. Based upon these SRS velocity ranges, the major focus has been upon the 0.2 to the $0.4 \mathrm{~m} / \mathrm{s}$ range for the mixing performance of Hanford particles located in the tanks. 
Based upon these basic constitutive assumptions, which should be confirmed or improved by the SSMD test results for Hanford-specific wastes, the CFD modeling can evaluate the scaling and performance impacts of various operational scenarios. To accomplish this evaluation, a sensitivity study using various mixer pump jet face velocities and rotational rates was established and studied using CFD models for a test matrix of six different operational scenarios. The test matrix consisted of three different jet velocities and two rotational rates. The three jet velocities for the 120 -inch scaled model consisted of 58,78, and 98 gallons per minute (GPM) flow rates which translate into jet velocities of $18.5,24.9$, and $31.3 \mathrm{ft} / \mathrm{s}$ respectively. The two rotational rates that were studied for the 120 -inch scale model were 0.77 and 0.48 revolutions per minute (RPM).

The test matrix was primarily executed using the 120 -inch scale model. The model only contains fluids and does not simulate particles. Since all kinematics follow the constitutive model for the fluid, all aspects of the model will scale uniformly for the characteristics affected by the assumed scaling over the size ranges considered. These constitutive relationships allow the results from the 120 -inch model to be either scaled down to the 43.2 -inch or scaled up to the full-scale 900 -inch model. To demonstrate and validate this assumption, one CFD calculation for each of the 43.2-inch and full-scale scenarios were executed. These results are also compared to demonstrate that kinematic scaling holds.

This report presents the CFD model results from the sensitivity studies that evaluated the effects of a range of jet velocities and rotation rates of the jet nozzles. The basic premises are that the amount of mixing that occurs within the tank is related to jet's fluid velocity within the tank, which begins with jet penetration into the tank contents. As the jet velocity is increased, the distance the jet is able to penetrate into the tank contents increases. As the jet's rotational rate increases, the jet's penetration into the tank contents decreases. To evaluate the influence of these two parameters, a test matrix consisting of three jet velocities and two rotational rates was analyzed using the CFD model.

This report is structured such that Section 1.0 provides an introduction to the goals and objectives of the CFD studies that were conducted. Section 2.0 discusses the CFD model and the calibration of the turbulence parameters using a series of jet velocity measurements from the SSMD program. Section 1.0 presents the CFD iso-surface-area theory, and presents the 120 -inch tank scale results. Section 4.0 recaps scaling theory and uses results from Section 3.0 to determine the scaled results for both the 43.2-inch and full-scale tank. The validity of the extrapolation of the 120-inch scale results is compared to direct simulations at the other two scales. This data is then used to examine the mixing performance results between the three tank scales. Finally, a series of project recommendations are presented in Section 5.0 and references are listed in Section 6.0.

\subsection{Fiscal Year 2011 CFD Modeling Objectives}

The work presented in this report is a continuation of the work conducted and documented in the RPP-48055, Computational Fluid Dynamics Modeling of Scaled Hanford Double Shell Tank Mixing, Fiscal Year 2010 Model Development Results. The three major objectives of this work continuation were:

1. Demonstrate that the modeled jet velocities are equivalent to the jet velocities measured in the SSMD 120-inch tank;

2. Evaluate the impact of the jet, in terms of its flow rate and rotational rate, on the mixing performance at each of the three scales -- 43.2-inch, 120-inch, and full-scale; 
3. Evaluate the correlations that occur among the various scales for a defined particle suspension range of 0.2 to $0.4 \mathrm{~m} / \mathrm{s}$, as well as the parameters' impacts on mixing performance.

Each of these objectives has been addressed and is documented in this report. The CFD model turbulence parameters were tuned based upon the impellor velocity measurements conducted in the 120 -inch tank. Three jet velocities and two jet rotational rates were studied at the 120 -inch tank scale. The 120 -inch tank was scaled using the power-per-unit-volume scaling relationship. This scaling was shown to be in agreement with the 43.2 and full-scale model runs. The mixing performance curves for a selected particle suspension velocity range of 0.2 to $0.4 \mathrm{~m} / \mathrm{s}$ at each tank scale are presented to display the mixing performance. Recommendations for further development and implementation of the CFD modeling techniques are also provided. 


\subsection{CFD MODEL DEVELOPMENT}

Advanced, commercial CFD codes are highly capable tools that are suited to a variety of unique and sophisticated problems. FLUENT ${ }^{\circledR 1}$ is a commercial, off-the-shelf (OTS) CFD software from ANSYS $^{\circledR 2}$, that has been used to model solid suspension in both stirred and pulse-jet-mixer (PJM)agitated tanks. The SSMD program approach will combine CFD modeling with physical testing at two scales to develop sufficient data to evaluate the tank mixing phenomena. Keeping in mind that stirring and sluicing are chaotic processes, general approximations of the actual system's behavior are appropriate. This section summarizes the model development of the single-phase velocity models only.

\subsection{Hardware and Software}

The CFD modeling described in this report was executed on a Dell ${ }^{\circledR 3}$ Precision ${ }^{\circledR}$ PWS 690 64-bit computer running Microsoft ${ }^{\circledR 4}$ Windows $\mathrm{XP}^{\circledR}$ Professional x64 Edition, Version 2003, Service Pack 2. ANSYS FLUENT 12.1 software was used for all model executions. The software and hardware system underwent a validation and verification $(\mathrm{V} \& \mathrm{~V})$ process that is documented, along with additional details concerning the computing system, in RPP-48055.

\subsection{Model Geometry and Key Characteristics}

A single full-scale CFD mesh was initially prepared. From this mesh, scaled models of both of the physical models developed by the SSMD were prepared using geometrically scaled dimensions for all the tank parameters (such as diameter and depth), as well as nozzle diameter and locations from full-scale drawings. Therefore, the models are consistent at all three scales as constructed. As-built documentation from the SSMD contractor was used for both the small-scale and the full-scale tanks. The geometry models of the full-size tank and the two scaled test beds were created separately to allow for individual deviations in the test beds. Therefore, the resulting meshes are similar in the number of computational nodes, but are not exact duplicates.

The air lift circulators (ALCs), transfer pump, and heater coil are modeled as vertical cylinders. The jet pumps are also modeled as vertical cylinders, with the nozzle faces appearing on the lower surface of the cylinder. There are 16 nozzle faces on each jet pump surface, separated by 22.5 degrees, which are coordinated to simulate a rotating pump head.

The geometric models are relatively complicated in comparison to typical fluid tanks in other industries. Legacy items such as the ALCs, heater, and many smaller features not included in the CFD model interrupt and redirect the flow path of the actual jet. Features smaller than the transfer line were not modeled.

The two physical tank sizes developed for SSMD testing are a small-scale (43.2-inch diameter) and a large-scale (120-inch diameter) tank. Since the full-scale tank has a diameter of 75 feet $(900$ inches), the scaling ratios for the small- and large-scale test tanks are 1/20.8 (0.048) and 1/7.5 $(0.133)$, respectively. The key geometric features of the tanks were linearly scaled from the

\footnotetext{
${ }^{1}$ FLUENT is a registered trademark of ANSYS, and SAS IP, Inc., of Canonsburg, Pennsylvania.

${ }^{2}$ ANSYS is a registered trademark of SAS IP Inc of Canonsburg, Pennsylvania.

${ }^{3}$ Dell and all of its products are registered trademarks pf Dell, Inc of Plano, Texas.

${ }^{4}$ Microsoft products are registered trademarks of Microsoft Corporation of Redmond, Washington.
} 
Hanford Site drawings for the AY-102 DST, to establish the design basis. The drawing references are H-2-34690: Dome Plan Penetration Tank-102-AY; H-2-64447: Tank Plan and Penetration Schedule; and H-2-34669: Coil Assembly. A dimensional drawing of the test apparatus provided by the SSMD contractor was reviewed to ensure that any differences between the Tank AY-102 drawings and the test platform were captured and documented for use with the CFD model. For each model, the nominal drawing values were used. Additional information on the tank geometry can be found in Section 2.2 of RPP-48055.

\subsection{Boundary Conditions}

Several of the boundary conditions in Hanford's DSTs are challenging (jet face parameters, suction inlet parameters, free surface boundary), and the knowledge of them is limited. Therefore, the CFD model utilizes a simplified domain, as discussed in Section 2.2 of RPP-48055. Statistically valid results were obtained by evolving the initial conditions with several rotations of the mixer jets. Starting with simple cases allowed the CFD model to be developed over time by increasing its complexity. The initial primary boundary conditions were walls and obstructions, for example.

The computational domain of the CFD model ends at the walls, where the flow transitions to laminar flow before reaching the wall - e.g. the no-slip boundary condition. The CFD model, using FLUENT, was designed to prevent laminar and turbulent flow in the same domain, since full implementation of CFD was not required, as solution of the full set of equations is an active topic in advanced research. The FLUENT program solves this issue using various known assumptions to eliminate the duality. A wall function therefore uses some experimental correlation to apply a boundary layer in the last tiny fraction of the computational cell adjacent to the wall. For this model, the standard wall function has been selected and used on the tank wall, tank floor, and ALC and heating coil obstructions until other data motivates the use of something more computationally complex.

The top of the computational domain is a free surface where fluid phases separate into air and fluid. The air in the top of the tank is not modeled, and because there is no separate phase on the bottom of the tank, the top and bottom can be modeled as walls. The stresses at the top air-fluid boundary are set to be frictionless, causing flow to approach the boundary and slide across it instead of penetrating or bouncing off it. The stress tensor at the top does not have to be zero, and in channelflow applications, for example, a special boundary-layer function is imposed to simulate the action of the free surface. This degree of sophistication was not included at this time in the model. For now, the CFD model represents the top surface using a slip boundary condition.

In the flow domain, nozzles and intakes are surface boundaries with refined meshes. These boundary conditions are where mass, velocity vectors, turbulence, etc., appear or disappear. Flow coming into the tank from a jet nozzle that penetrates under laminar to slightly turbulent conditions will travel further into the tank than will flow with a lot of swirl, turbulent intensity, or divergent velocity vectors, which will increase the velocity's spread. For the model used in this study, a simple combination of pressure boundary outlet (jet pump "inlet"), and specified flow-velocity inlet (jet pump "outlet nozzle") is used in lieu of a more complex pump function to simulate the jet pump, which is deferred until a solid phase is added..

At this stage, with only a single-phase system being modeled, the velocity, turbulence intensity and hydraulic diameter are set at the nozzle face (pump outlet, CFD inlet), and the intake face is set to hold constant gage pressure (pump inlet, CFD outlet). Thus, mass flow in and mass flow out float a 
bit. After a few time steps, mass is adequately conserved, producing reasonable results for the interior flow at low computational cost.

The average velocity over the face of the pump nozzles for each scale is taken from Table 4.2 in PL-SSMD-EG-001, RPP-44620, Waste Feed Delivery Small Scale Mixing Demonstration Plan. The turbulence intensity was initially $10 \%$ for each of the scales (a conservative value), and the hydraulic diameter was the nozzle diameter at each scale. Well-known correlations within FLUENT are used to obtain the two turbulence parameters ( $k$ and epsilon) on the boundary of the flow domain, using the local average velocity (which is different for each scale). This method introduces a kind of scaling such that each of the models has similar relative amounts of turbulence introduced by the pump faces. Additional work presented in Section 2.4 of this report describes the tuning adjustments made to the CFD model using the SSMD actual jet velocity measurements.

The suction return for each of the jet pumps was modeled as a uniform velocity profile across the face of the suction inlet boundary leaving the domain. The jets and suction returns were treated as boundary conditions in the bulk liquid. Therefore, mass can enter and leave the model only at these locations. Since mass is conserved, mass in will equal mass out such that mass brought out of the model domain through the pump suction inlet will equal the mass returned to the model domain through the two jets on each pump. In more complex situations, this condition is handled by a User Defined Function (UDF). In the present case, balance is achieved by a simple pressure boundary condition. For the water-only cases, only the volumetric flow rate and temperature is needed for each jet pump (i.e. pair of nozzles).

Additional detail of the modeling of the jet pumps, nozzles, and associated turbulence can be found in RPP-48055, which provides the details of the jet nozzle orientation and the modeling of the rotational aspects of the jet.

\subsection{CFD Model Tuning}

The CFD model was calibrated using a series of water-only velocity measurements that were made in the 120-inch SSMD tank, and not as described in RPP-44619, but as described later in this report. The actual measurements were made using a flow impeller to collect a limited dataset from only the 120-inch SSMD tank. This dataset was collected to aid in tuning and the development of theoretical models. The 120 -inch tank flow velocity measurements were collected with the ALCs raised up out of the way, but not completely out of the tank.

The CFD model used for comparison to the experimental results was created with the ALCs in place (and is identical to the regular 120-inch scale CFD model configured to simulate one jet pump at a fixed angle). The rotational jet angle chosen for the experimental measurements was selected such that the centerline of the jet was

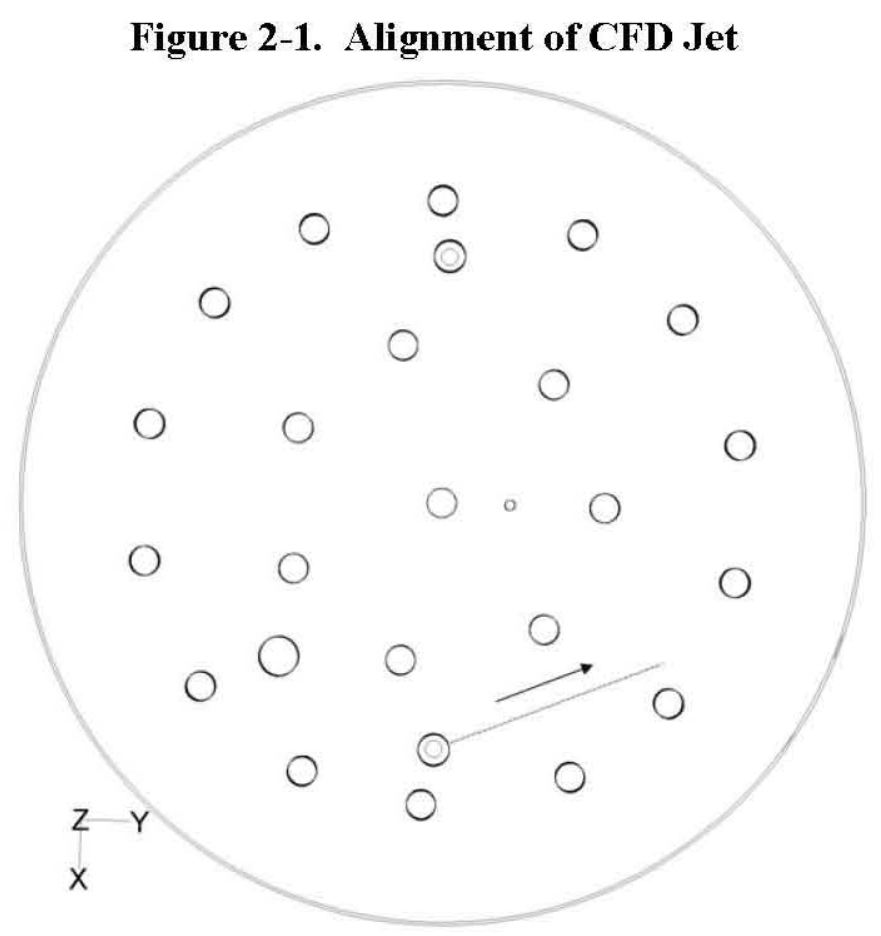


oriented between ALCs, to minimize both the flow interference from the ALC's in the tank as well as the simulation (22.5 degrees counterclockwise from the $y$-axis). Figure 2-1 shows the alignment of the jet pump used in the CFD simulations (only the section sampled is shown, and the arrow indicates the flow direction of the jet). The DVD in Appendix A has video of the actual tank with the flow meter in operation. For the SSMD measurements, the jets rotation was held stationary, but both mixing jets (4 nozzles) were operating.

The impellor flowmeter was a SWOFFER ${ }^{\circledR 5}$ Model 3000-1514 (serial \#8604). The impellor centerline was mounted 2.5 inches above the base of the foot unit (see Figure 2-2 for a photo of the impellor). The foot unit provided stability to the flow meter during velocity measurements. It allowed the flow meter's control rod to press firmly against the tank bottom. This pressure reduced the deflection of the rod that occurs due to the high velocity flow field coming out of the jet. The control rod was used to control the meter from the top of the tank. At each measurement location, the flowmeter was Figure 2-2. Control Rod with Bottom Foot. centered at the measurement point and then rotated to achieve the maximum velocity reading, indicating that the flow meter was generally aligned with the flow direction. These measurements were conducted at a series of locations along the centerline of the jet flow. A video of the measurement process for one location is provided on the DVD in Appendix A of this report. This video indicates the difficulty of precisely positioning the measurement device in the high flow stream immediately coming out of one of the jet nozzles.

Two volumetric flow rates were tested: 90 and 110 GPM. The 98 GPM CFD model data at the rotational angle that matched the measurements was used to compare with the average SSMD measured results from the two-flow rates after normalizing by jet velocity and nozzle diameter. The CFD model calculated the velocity along a series of vertical straight lines arranged along the centerline of the jet at various nozzle-diameter distances as show in Figure 2-1. This dataset allowed the jet to be tracked as it dropped towards the bottom of the tank (and to neutralize the impact of the non-uniform mesh along the jet). It should be noted that the CFD results are cell velocities using the existing gridding and represent an average velocity over an area much smaller than that of the impellor flow meter (the cell size opens up more towards the wall away from the pump and ALCs), which averages the velocities within the diameter of the impellor (1.975 inch). This difference in representative areas represents one of the major differences in the two measurements that must be considered as the data are compared.

The velocities in Figure 2-3 have been normalized by the average velocity at the jet face. The distance from the jet face has also been normalized by the jet diameter to create a normalized nondimensional plot. In Figure 2-3, the dataset corresponding to the directional line identified in Figure 2-1 was used to represent the CFD calculated velocities along that line from the jet face towards the tank wall. The data points on the plots are the average normalized velocities from the SWOFFER 3100 flowmeter. Each location was measured twice. Error bars of $+/-15 \%$ have been added to the data points to suggest uncertainty in these measurements.

${ }^{5}$ SWOFFER is a registered trademark of Swoffer Instruments, Inc., Seattle, Washington. 
The CFD calculations and measured data show good agreement away from the nozzle face. However, there are several factors that should be considered when evaluating this comparison. The physics of the measurement apparatus and devices as well as the key boundary conditions should be considered. When a turbulent jet of fluid is discharged from a nozzle into a stagnant fluid medium, it both entrains fluid and expands. The fluid domain for a large-scale tank has solid wall boundaries on the side(s) and bottom, and often internal components, e.g. ALCs and a free surface boundary on top. The jet expands into the downstream region, but then ultimately returns to the suction on the bottom of the pump, interfering with the jet in the process.

The spreading fluid is retarded by the interaction with the walls, and part of the flow that attaches to the floor after a certain distance may be expected to look like a kind of boundary layer.

Entrainment of quiescent fluid and solids occurs near the outer edges of the flow, and accordingly resembles a free jet in these regions (The Theory of Turbulent Jets, Abramovich 1963). Most mixing action and entrainment occurs in the region of fully developed flow, which begins at a distance of about eight nozzle diameters from the exit plane (Abramovich 1963). When a turbulent jet of fluid is discharged from a nozzle with a diameter, $d_{0}$, into a quiescent fluid, the nondimensional velocity, $V_{n}$, distribution along the jet axis for a homogeneous fluid is approximated by a constant $(B)$ times the inverse of the non-dimensional distance $\mathrm{x}$ along the axis:

$$
V_{n}=B\left(x / d_{0}\right)^{-1} \quad E Q 1
$$

For a free jet, the constant, $B$, is found in Abramovich 1963, to be 6.32. This value does not have effects from nearby walls or floors and is the solution in an infinite half space. For SRS, Tank 18, the constant $(B)$ was found to be 4.874 . This number compared well with both our data as well as the measured test data for the Advanced Design Mixer Pump (ADMP) in an 85-foot diameter tank with 70 inches of water using a six-inch nozzle diameter located 27 inches above the tank floor with a flow rate of 5,200 GPM and a nozzle velocity of $17.98 \mathrm{~m} / \mathrm{s}$ ("Mixing in Large Scale Tanks - Part I - Flow Modeling of Turbulent Mixing Jets," Lee et al 2004).

For the Hanford DST mixing scenario, where the floor boundary is very near the jet centerline and the suction return is in this same region, the constant can be expected to be even lower than 4.87 . The SSMD measured data raises concerns because it shows an almost linear decay that continues to decrease even at points beyond 30 nozzle diameters. According to the standard fluid dynamics theory, the decay rate at this distance should be less than it is at closer distances. Possible explanations for linear decay of the SSMD measured data include the large diameter of the impellor creating an average of the jet velocity as it tends to the tank floor and the return suction also traveling along the floor bottom. The CFD results do not show this linear decay, and better match the theoretical slope as shown in Figure 2-3.

Other factors that affect the degree of fit between the CFD results and the measured data include the location of the measurement points along the centerline. Although every attempt was made to ensure that the meter was located along the centerline of the jet, the jet itself was in a fixed positioned 2.5 inches above the tank floor and directed at an angle to reduce any ALC influence. This fact may explain some of the error because the probe may not have been positioned directly in the jet centerline flow. The video in Appendix A, showing the measurement process, clearly demonstrates that the flow is moving very swiftly out of the jet nozzles and positioning the meter in this high flow field is difficult. Although spots were marked and observed on the bottom, exact positioning of the probe in this environment was very difficult. Finally, the rotational alignment of the impellor flow meter was performed by rotating the flow meter to obtain the maximum velocity. 
The flow meter may or may not align with the jet, depending on the positioning previously described. The impellor flow meter converts rotation rate to velocity with built-in software that is proprietary, and the probe was not calibrated in a channel flow prior to use. However, the factory calibration represents sufficient accuracy for these types of measurements.

The turbulence parameters, $\mathrm{k}$ and epsilon, in the CFD model were specified with the option to use turbulence intensity and hydraulic diameter (from the jet nozzle size). The range of turbulence intensity tested was from $1 \%$ to $10 \%$. A typical value used in other applications, as a ballpark starting value, is $4 \%$. Unfortunately, the turbulence in the CFD simulations was dominated by grid dispersion, so changing the turbulence intensity had limited effects. However, the decision was made not to make the grid finer just for this purpose because the current cell count was already large (the complete model was used and not refined to better define the jet shape). If the ALCs and other tank obstructions were not modeled, it is believed that a better approximation of the near pump region could have been obtained because the mesh would be more uniform near the jet pumps. This study was focused on the region beyond 20 jet-nozzle diameters, which was adequately modeled with a turbulence intensity of $10 \%$ as can be seen in Figure 2-3. In this region, a good comparison between the measured data and the CFD model results was obtained.

The nozzle functions were also modified to attempt control of grid dispersion and obtain a better fit to the measured data. The nozzle function was utilized to create better penetration of the jet by focusing the flow at a point approximately five nozzle diameters in front of the nozzle face. This affected the early portions of the curve out to a distance of approximately nine nozzle diameters. Beyond this distance, the mesh coarseness began to influence the model results, as shown by the curve dip at 15 nozzle diameters. Since the majority of the work being performed by the mixing jet within the tank is done away from the jet nozzle, refining the mesh to improve the model's representation of the early part of the curve was not considered to be extremely important. It was assumed that matching the curve at 20 nozzle diameters and beyond in a conservative manner was more important, and the matching was accomplished.

Another factor in the comparison was the different boundary conditions on which the theoretical equations and solution are based. The Hanford jet is not a true free jet as postulated in EQ 1. Fluid can be entrained behind, on top and below the jet. It is not just a boundary with fluid that must transition from static to dynamic. In addition, the suction inlet at the bottom of the jet is a major influence. The suction inlet produces fluid motion in the opposite direction to that of the jet. This motion will create additional drag on the jet as the fluid has to move against fluid moving in the opposite direction. For these reasons, the centerline velocity in the CFD models decays faster than the theoretical wall jet scenario.

Computational Fluid Dynamics, using FLUENT has met with success, fits within expectations and follows established trends. The final CFD model data agrees reasonably well with the actual measured data from the 120-inch tank, using the average 90 and 110 GPM flow rates as shown in Figure 2-3. There is room for improvement, but given the various other uncertainties, such as final design of the mixer pump and knowledge of its turbulence factors, actual jet velocity and rotational rates, the values provide sufficient confidence in the reasonableness of the CFD model results.

Since the CFD results are used and compared against themselves in this report, the results are all consistent and any possible error in tuning of the turbulence parameters will be consistent across all the results. 
Figure 2-3. Jet Velocity Data for the 120-Inch Tank (Velocity Matched).

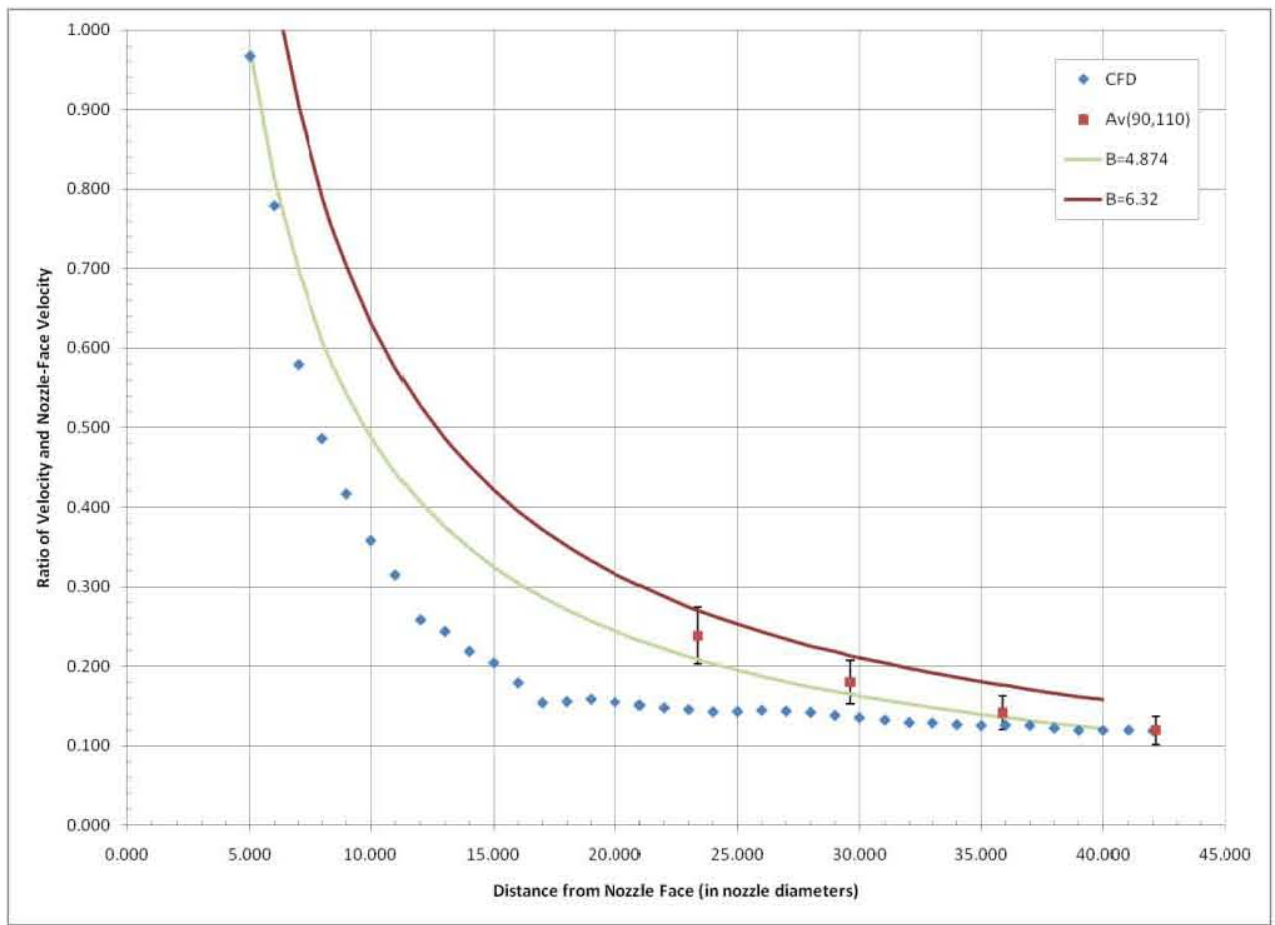




\section{$3.0 \quad 120-I N C H$ TANK SCALE SENSITIVITY STUDIES}

\subsection{Introduction}

A table of simulations to perform in fiscal year (FY)-2011 was provided, encompassing nine computer runs from three scaled flow rates, measured in GPM, crossed with two pump rotational speeds, measured in RPM. The completed runs are shown in Table 3-1, where seven of the nine have at least three complete rotations, and all obtained adequate statistics for analysis.

Table 3-1. Fiscal Year 2011 Simulations.

\begin{tabular}{|c|c|c|c|c|c|c|c|}
\hline Model Name & GPM & RPM & $\begin{array}{l}\text { First Restart } \\
\text { Written }\end{array}$ & Last Restart Written & $\begin{array}{l}\text { Days } \\
\text { Elapsed }\end{array}$ & Rotations & $\begin{array}{l}\text { Days per } \\
\text { Rotation }\end{array}$ \\
\hline 120-Inch & 98 & 0.77 & $12 / 13 / 20104: 05$ & $12 / 25 / 20108: 55$ & 12.20 & 4.00 & 3.05 \\
\hline 120-Inch & 98 & 0.48 & $12 / 27 / 201013: 51$ & $1 / 5 / 201116: 06$ & 9.09 & 3.11 & 2.92 \\
\hline 120-Inch & 78 & 0.48 & $4 / 11 / 201112: 32$ & $4 / 19 / 20115: 58$ & 7.73 & 3.00 & 2.58 \\
\hline 120-Inch & 78 & 0.77 & $4 / 4 / 201112: 36$ & $4 / 10 / 2011 \quad 19: 54$ & 6.30 & 3.00 & 2.10 \\
\hline 120-Inch & 58 & 0.77 & 1/19/2011 16:07 & $1 / 25 / 20112: 06$ & 5.42 & 3.00 & 1.81 \\
\hline 120-Inch & 58 & 0.48 & $1 / 5 / 201118: 06$ & $1 / 13 / 20118: 44$ & 7.61 & 3.33 & 2.29 \\
\hline 43.2-Inch & 8.6 & 1.51 & $3 / 23 / 201121: 34$ & $3 / 31 / 20118: 09^{*}$ & 7.44 & 0.55 & 13.61 \\
\hline 43.2-Inch & 8.6 & 1.51 & $4 / 23 / 20113: 50$ & $4 / 25 / 201117: 23^{*}$ & 2.56 & 0.30 & 8.64 \\
\hline Full-Scale & 10400 & 0.2 & $1 / 27 / 201117: 50$ & $2 / 9 / 201121: 21$ & 13.15 & 3.00 & 4.38 \\
\hline
\end{tabular}

Note: *Last pump index not included, stalled.

Using the current CFD model results, it has been demonstrated that FLUENT can adequately handle problems in tanks with complex internal configurations. However, each application is different, and a new approach is needed to address the specific operating conditions in question. A similar effort was conducted at SRS for the ADMP (Lee et al 2004). At SRS, a full-scale mixing pump was fabricated and tested in a partially filled, full-scale tank as described in Section 3.0 of RPP-48055. In addition to the full scale testing, a CFD model was created of the mixing pump and the resulting jet flows. The data for SRS, (Lee et al 2004) along with others, have indicated that fluid velocity, particle size, specific gravity of the particle and tank liquid level are key parameters associated with particle suspension. When erosion begins, it is dependent on the critical shear stress. The critical shear stress of the cohesive sludge materials depends on the composition of the sludge material, the particle-size distribution, particle shape and packing. A minimum fluid velocity for suspending cohesive sludge at SRS was established and confirmed as $0.7 \mathrm{~m} / \mathrm{s}(2.27 \mathrm{ft} / \mathrm{s})$ (Lee et al 2004). This velocity will erode the sludge layer for particle sizes larger than clay material (about $5 \mu \mathrm{m}$ ). The velocity required to maintain such particles in suspension within the tank environment was $0.3 \mathrm{~m} / \mathrm{s}$ $(0.98 \mathrm{ft} / \mathrm{s})$. Establishing these characteristic velocities for SRS sludge allowed SRS to find the local fluid velocity at any distance from the nozzle (with CFD) and use it as a measure of the capability of the jet submerged in the sludge bank to form a slurry and carry that slurry around the tank.

Estimations of minimum suspension velocity, particle-settling rate and incipient erosion velocity have been performed at Savannah River National Laboratory (SRNL) to support the use of a CFD approach to understanding this problem. (See "Analysis of Turbulent Mixing Jets in a Large Scale 
Tank," Lee et al 2008, for details.) For visualization purposes, a velocity range of 0.2 to $0.4 \mathrm{~m} / \mathrm{s}$ $(0.66$ to $1.31 \mathrm{ft} / \mathrm{s})$ has been utilized in this project. While this value may not be precisely equivalent to velocities necessary to produce equal results with Hanford waste solids, it does provide a useful reference point to judge the relative tank performance changes that occur as varying tank conditions are modeled.

\subsection{Iso-Value Surface Area}

Various key parameters have been studied in this report as well as the previous report (RPP-48055) to define and evaluate mixing performance based on a power-per-unit-volume scaling approach for the jet velocities. Based on these defined jet velocities, the velocity time history at a given point (i.e. the transfer pump location) scales appropriately between the tank sizes and represents the flow and corresponding mixing performance at this point (or other points). Velocity time histories are not really good measures of mixing performance, which is characteristic of the entire tank at any given time. Taking another approach, the velocities within the tank that exceed a lower value, which is required to suspend a specific sized particle and provide transport, can also be utilized to estimate mixing performance. Since particle size was not scaled, using these same velocities in each tank, and then normalizing to the full-scale tank and surface-area unit (for the iso-surface area), improved understanding of the percentage of the tank that was being mixed at a given point in time or after several rotations of the jet pump. Considering the process, measures of the area of an iso-value surface equal to a velocity magnitude commensurate with either suspension or erosion velocities could indicate when the jets are doing the most work possible. Assuming that the isovalue surfaces are mostly potato-shaped and not extremely fragmented, the relative areas of surfaces of differing velocity magnitude can be an integral measure of system performance at the different scales. The surface areas offer the primary comparison technique that is used to compare mixing performance. An example of an iso-velocity surface is shown in Figure 3-1.

In Figure 3-1, the picture on the left-hand side is the 120-inch model and on the right-hand side is the full-scale model. The scale is in absolute velocity magnitude (not scaled), so the smaller model is energizing flow to the lower intensity and comparable velocity magnitudes are confined to the volume most directly influenced by the pump. 
Figure 3-1. FS-120-vmp7-upp3-dnp1-p1to3vm.mp4.

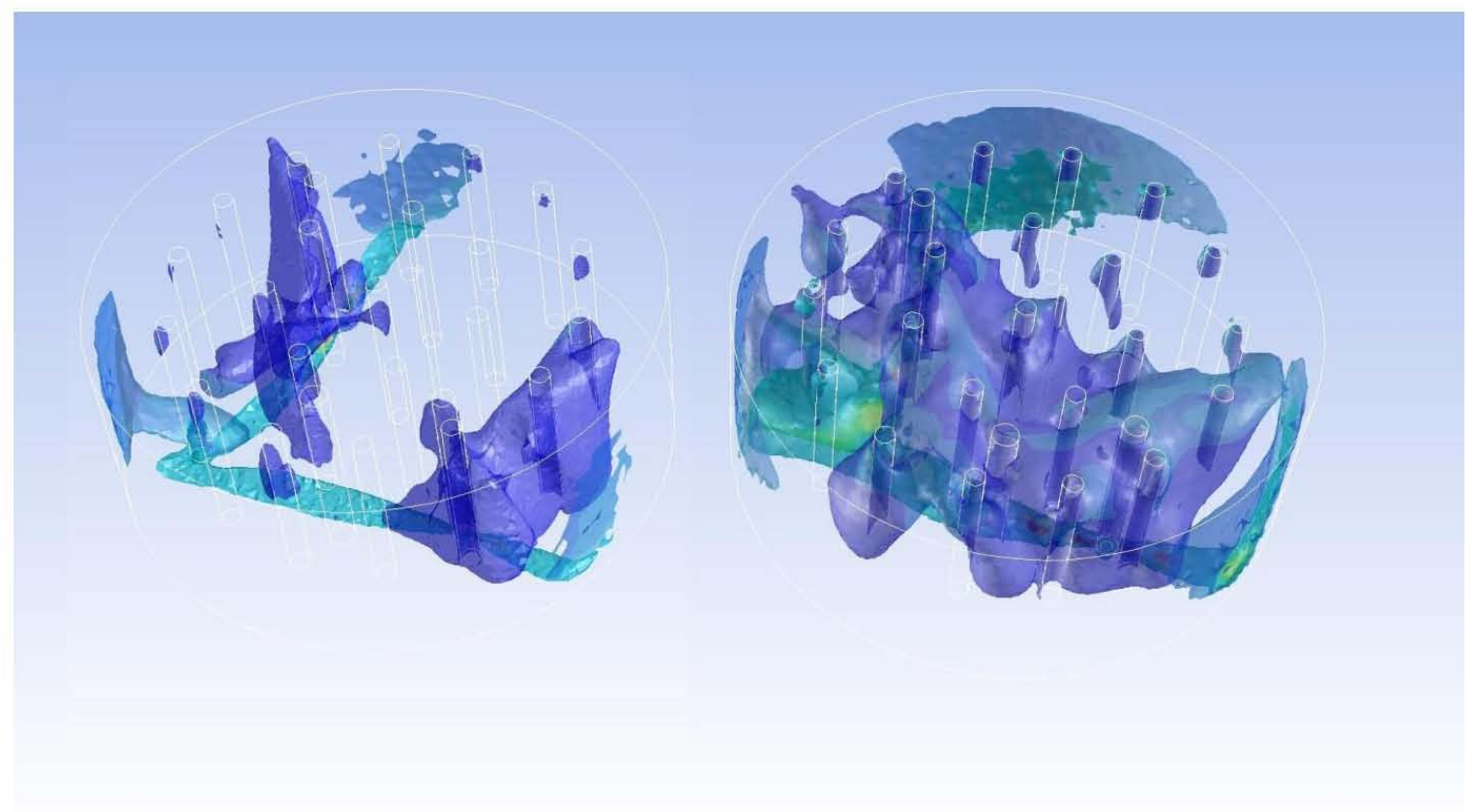

\subsubsection{Statistics}

Figure 3-2 shows time histories for typical iso-value velocity magnitudes during the last two full rotations of the 120 -inch model. Using the last full rotations allows any variation due to start-up or flow-rate changes to settle down. By inspection, the jet-mixing process reaches a repetitive cycle as the areas fluctuate with time and jet position, and are generally steady around the mean. Quartiles, taken over a large enough time, become steady enough to use as a single value to represent the results of the simulation. 
Figure 3-2. Typical Time Series for Two Full Rotations.

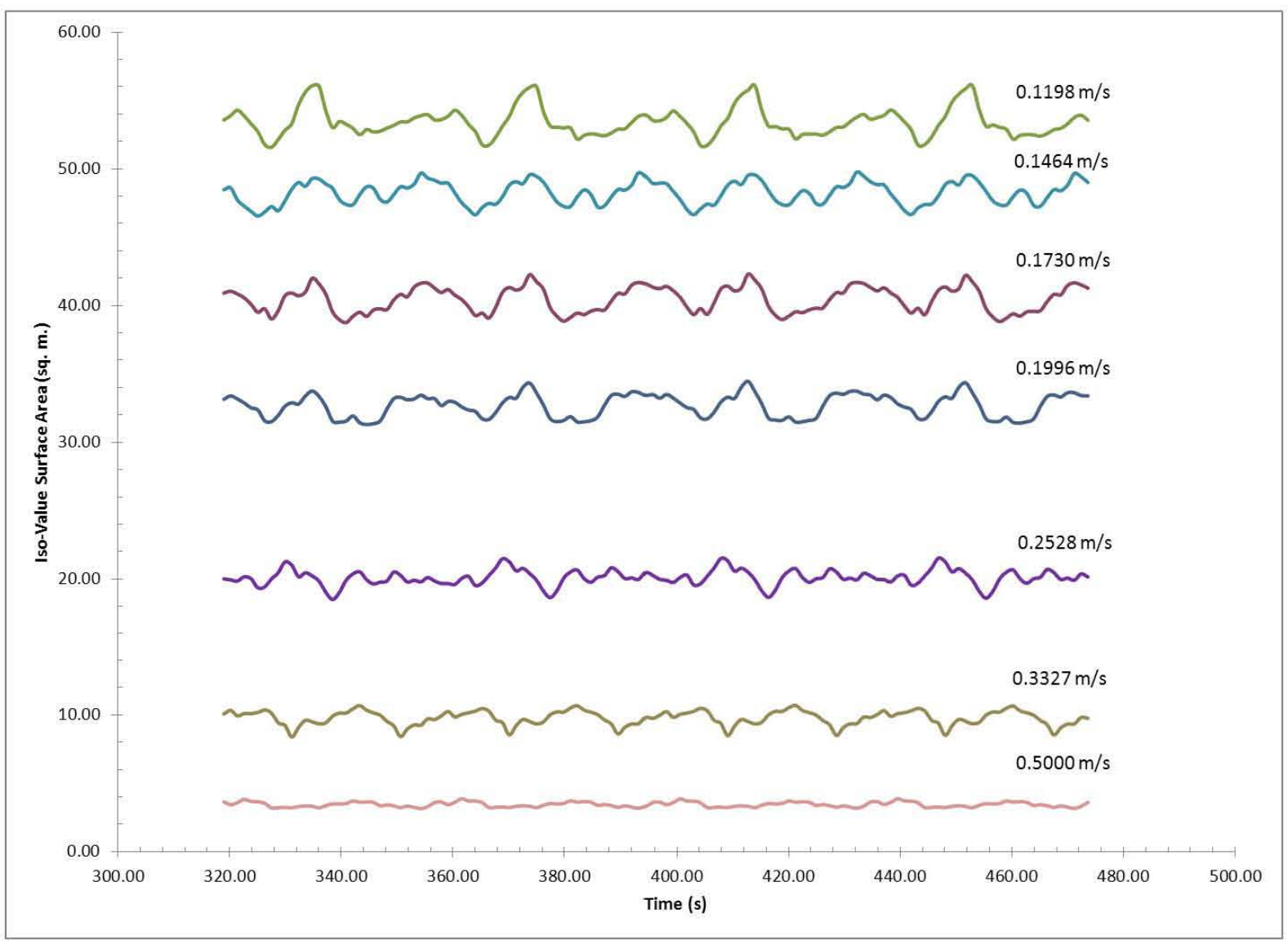

Statistical values presented in the result tables and plots were taken from the last two full rotations of the jet-mixer pumps. The only exception was for the 43.2 -inch scaled simulations, where the entire range of stable values was used (repeated twice because the simulations kept stalling). A rotation of steady-state solutions at each index point of the pumps was used as an initial condition for the simulation of the 43.2-inch model. Therefore, the partial results for the 43.2-inch model are better than partial results from a cold start for collecting statistics. The normalized standard deviation of the iso-value velocity magnitude (scaled) over the time series is shown in Figure 3-3. As expected, the 43.2-inch model shows the most variation due to its limited dataset. All cases have a standard deviation below $10 \%$ over the range of 0.2 to 0.4 scaled velocity magnitudes (i.e. full-scale range mapped to the appropriate scale). This standard deviation was believed to be acceptable for comparison purposes in Section 4.2. The highest scaled velocity magnitudes showed the most variation since they surround the jets as they interact with the fluid during the pump rotation, hitting the ALCs, etc. The third quartile (Q3), as computed by Microsoft Excel, is shown in Figure 3-4 as an example. Besides Q3, the mean, Q2, is used to scale values when comparing the statistics between scales (Figure 3-3). The Q3 quartile is chosen to simplify presentation by choosing one value to plot for each simulation case. 
Figure 3-3. Relative Standard Deviation All Cases (\%).

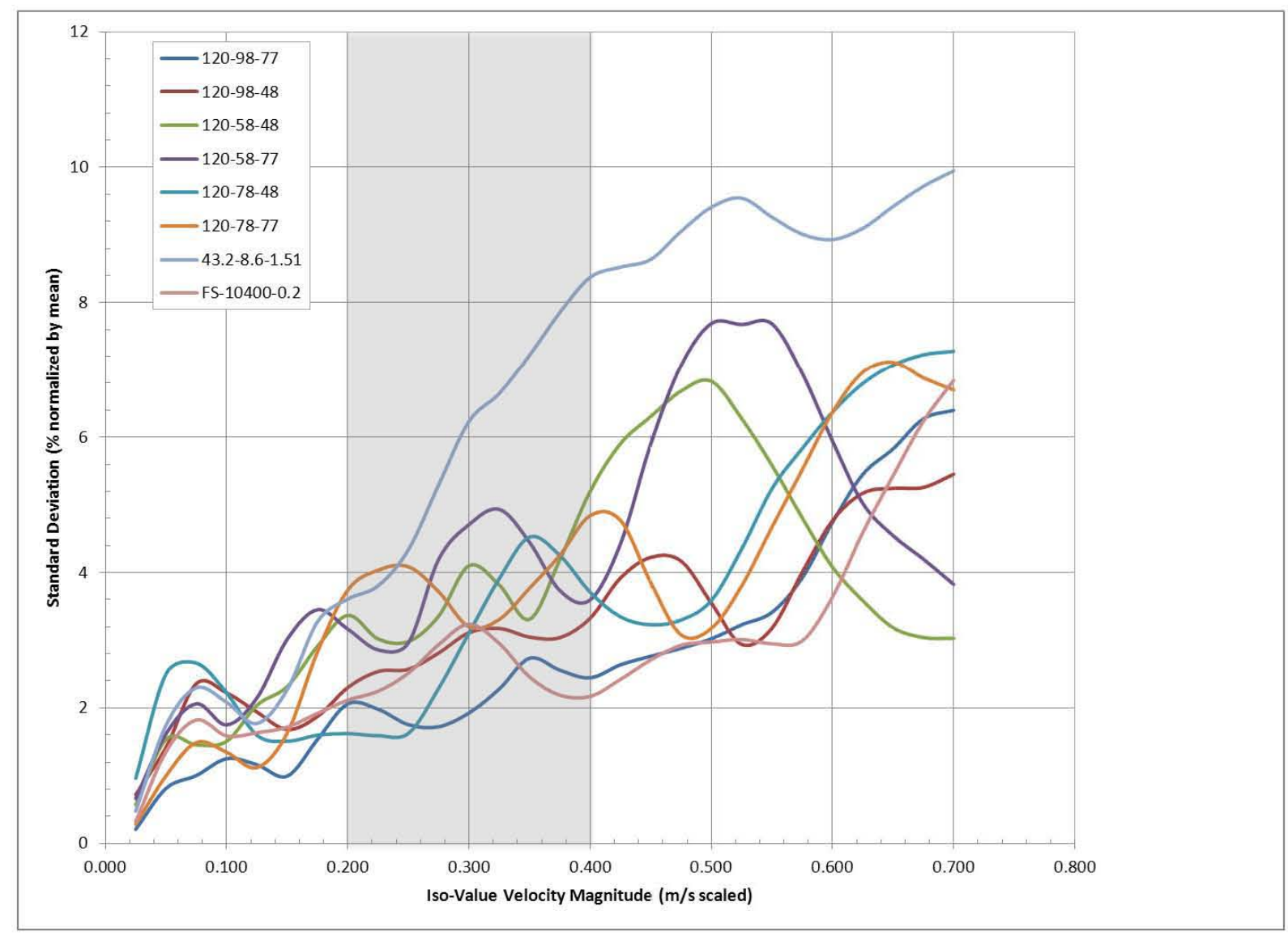

Table 3-2. Relative Standard Deviation of Iso-Value Surface Area (sq. m. and \%) Versus Iso-Value Relative Magnitude (2 pages).

\begin{tabular}{|c|c|c|c|c|c|c|c|c|}
\hline \multicolumn{9}{|l|}{ All Simulations } \\
\hline \multirow{3}{*}{$\begin{array}{c}\text { Velocity } \\
\text { Magnitude } \\
\text { (scaled) }\end{array}$} & 120-Inch & 120 -Inch & 120-Inch & 120-Inch & 120 -Inch & 120-Inch & 43.2-Inch & Full-Scale \\
\hline & GPM=98 & GPM=98 & GPM=58 & GPM $=58$ & GPM=78 & GPM=78 & $\mathrm{GPM}=8.6$ & $\mathrm{GPM}=10400$ \\
\hline & $\mathrm{RPM}=0.77$ & $\mathrm{RPM}=0.48$ & $\mathrm{RPM}=0.48$ & $\mathrm{RPM}=0.77$ & $\mathrm{RPM}=0.48$ & $\mathrm{RPM}=0.77$ & $\mathrm{RPM}=1.51$ & $\mathrm{RPM}=0.2$ \\
\hline 0.0250 & 0.2068 & 0.7190 & 0.5683 & 0.6626 & 0.9633 & 0.2798 & 0.4766 & 0.3208 \\
\hline 0.0500 & 0.8126 & 1.4194 & 1.5359 & 1.6199 & 2.5042 & 0.9979 & 1.7460 & 1.3560 \\
\hline 0.0750 & 1.0016 & 2.3582 & 1.4547 & 2.0612 & 2.6621 & 1.4885 & 2.2963 & 1.8219 \\
\hline 0.1000 & 1.2497 & 2.2227 & 1.5070 & 1.7489 & 2.2217 & 1.3459 & 2.0815 & 1.5861 \\
\hline 0.1250 & 1.1602 & 1.9395 & 2.0398 & 2.1486 & 1.5958 & 1.1185 & 1.7700 & 1.6340 \\
\hline 0.1500 & 0.9923 & 1.6804 & 2.3149 & 3.0144 & 1.5083 & 1.6278 & 2.2702 & 1.7166 \\
\hline 0.1750 & 1.5355 & 1.8755 & 2.9117 & 3.4510 & 1.5976 & 2.8310 & 3.2748 & 1.9215 \\
\hline 0.2000 & 2.0600 & 2.3017 & 3.3673 & 3.1632 & 1.6206 & 3.7425 & 3.6075 & 2.1156 \\
\hline 0.2250 & 1.9794 & 2.5386 & 3.0195 & 2.8573 & 1.5906 & 4.0342 & 3.8037 & 2.2471 \\
\hline 0.2500 & 1.7532 & 2.5713 & 2.9818 & 2.9617 & 1.6246 & 4.0854 & 4.3372 & 2.5153 \\
\hline
\end{tabular}


Table 3-2. Relative Standard Deviation of Iso-Value Surface Area (sq. m. and \%) Versus Iso-Value Relative Magnitude ( 2 pages).

\begin{tabular}{|c|c|c|c|c|c|c|c|c|}
\hline \multicolumn{9}{|l|}{ All Simulations } \\
\hline Velocity & 120-Inch & 120-Inch & 120 -Inch & 120 -Inch & 120-Inch & 120-Inch & 43.2-Inch & Full-Scale \\
\hline \multirow{2}{*}{$\begin{array}{l}\text { Magnitude } \\
\text { (scaled) }\end{array}$} & GPM=98 & $\mathrm{GPM}=98$ & GPM=58 & GPM=58 & GPM=78 & GPM=78 & GPM=8. 6 & GPM $=10400$ \\
\hline & $\mathrm{RPM}=0.77$ & $\mathrm{RPM}=0.48$ & $\mathrm{RPM}=0.48$ & $\mathrm{RPM}=0.77$ & $\mathrm{RPM}=0.48$ & $\mathrm{RPM}=0.77$ & $\mathrm{RPM}=1.51$ & $\mathrm{RPM}=0.2$ \\
\hline 0.2750 & 1.7221 & 2.8120 & 3.3571 & 4.1947 & 2.2900 & 3.7179 & 5.2955 & 2.9355 \\
\hline 0.3000 & 1.9261 & 3.1114 & 4.1013 & 4.7076 & 3.1085 & 3.1983 & 6.2334 & 3.2362 \\
\hline 0.3250 & 2.2799 & 3.1737 & 3.8147 & 4.9332 & 3.9112 & 3.3076 & 6.6476 & 2.9509 \\
\hline 0.3500 & 2.7347 & 3.0467 & 3.3098 & 4.4457 & 4.5239 & 3.7703 & 7.2209 & 2.4572 \\
\hline 0.3750 & 2.5577 & 3.0383 & 4.1911 & 3.7334 & 4.2516 & 4.2561 & 7.8546 & 2.1882 \\
\hline 0.4000 & 2.4447 & 3.3249 & 5.1996 & 3.5953 & 3.7094 & 4.8409 & 8.3734 & 2.1708 \\
\hline 0.4250 & 2.6371 & 3.9202 & 5.9051 & 4.4248 & 3.3447 & 4.7697 & 8.5244 & 2.4220 \\
\hline 0.4500 & 2.7627 & 4.2235 & 6.3040 & 5.9007 & 3.2280 & 3.8511 & 8.6385 & 2.7083 \\
\hline 0.4750 & 2.8804 & 4.1691 & 6.6828 & 7.0665 & 3.2987 & 3.0785 & 9.0511 & 2.9249 \\
\hline 0.5000 & 3.0212 & 3.5487 & 6.8274 & 7.6898 & 3.5874 & 3.1754 & 9.4091 & 2.9714 \\
\hline 0.5250 & 3.2279 & 2.9388 & 6.2752 & 7.6760 & 4.3456 & 3.8009 & 9.5436 & 3.0121 \\
\hline 0.5500 & 3.4119 & 3.1774 & 5.5831 & 7.6856 & 5.2372 & 4.6713 & 9.2620 & 2.9477 \\
\hline 0.5750 & 3.9208 & 4.0050 & 4.8088 & 6.9468 & 5.8323 & 5.5189 & 9.0107 & 2.9904 \\
\hline 0.6000 & 4.7415 & 4.7671 & 4.0791 & 5.9412 & 6.3715 & 6.3702 & 8.9311 & 3.6386 \\
\hline 0.6250 & 5.4501 & 5.1717 & 3.5851 & 5.0207 & 6.7963 & 6.9624 & 9.0976 & 4.5908 \\
\hline 0.6500 & 5.8269 & 5.2437 & 3.1847 & 4.5444 & 7.0714 & 7.1137 & 9.4202 & 5.4310 \\
\hline 0.6750 & 6.2712 & 5.2574 & 3.0392 & 4.1973 & 7.2262 & 6.8781 & 9.7187 & 6.2362 \\
\hline 0.7000 & 6.3973 & 5.4515 & 3.0269 & 3.8241 & 7.2806 & 6.6997 & 9.9461 & 6.8408 \\
\hline
\end{tabular}

\subsubsection{Spectra}

Once the variations with time were reduced by calculating the third quartile (Q3) for the area of each iso-value surface area, a smooth curve could be calculated for each simulation run. This curve looked like an energy spectrum and behaved analogously with changes in flow rate (i.e. energy input) in the simulations. Thus, a curve of iso-value surface area versus iso-value velocity magnitude is referred to as a spectrum (plural spectra) in the remainder of the report. However, this descriptive explanation of the spectra curves is only an analogy. See Figure 3-4 for an example.

The shape of this curve approximately represents the energy dissipated by the jet-mixing process. Higher jet velocities and flow rates will change the peak location and magnitude. This excess energy will spread out over the spectrum represented by the curve. Changes in rotational rate also change the peak, but in the region of interest (shaded section) changes in flow rate are more significant as most of the rotational effect happens at lower velocity magnitudes.

Changes in rotation rate will also shift the location where the energy is dissipated. The effect is probably only significant at lower velocities, as can be seen in the sensitivity studies of the 120 -inch 
model shown in Figure 3-4. The small changes in rotational rate do not significantly affect the tracking of high-velocity tails of the spectra against each other. Changing the rotation rate does not affect the iso-area peak height within the velocity range of interest. For the 78 and 98 GPM cases, the high RPM (0.77) produces the highest peak iso-area, whereas the 58 GPM has the highest isoarea peak at 0.48 RPM. These GPM rates are all at a velocity below the region of interest. Table 3-3 lists the data used in Figure 3-4.

Figure 3-4. All 120-Inch Cases.

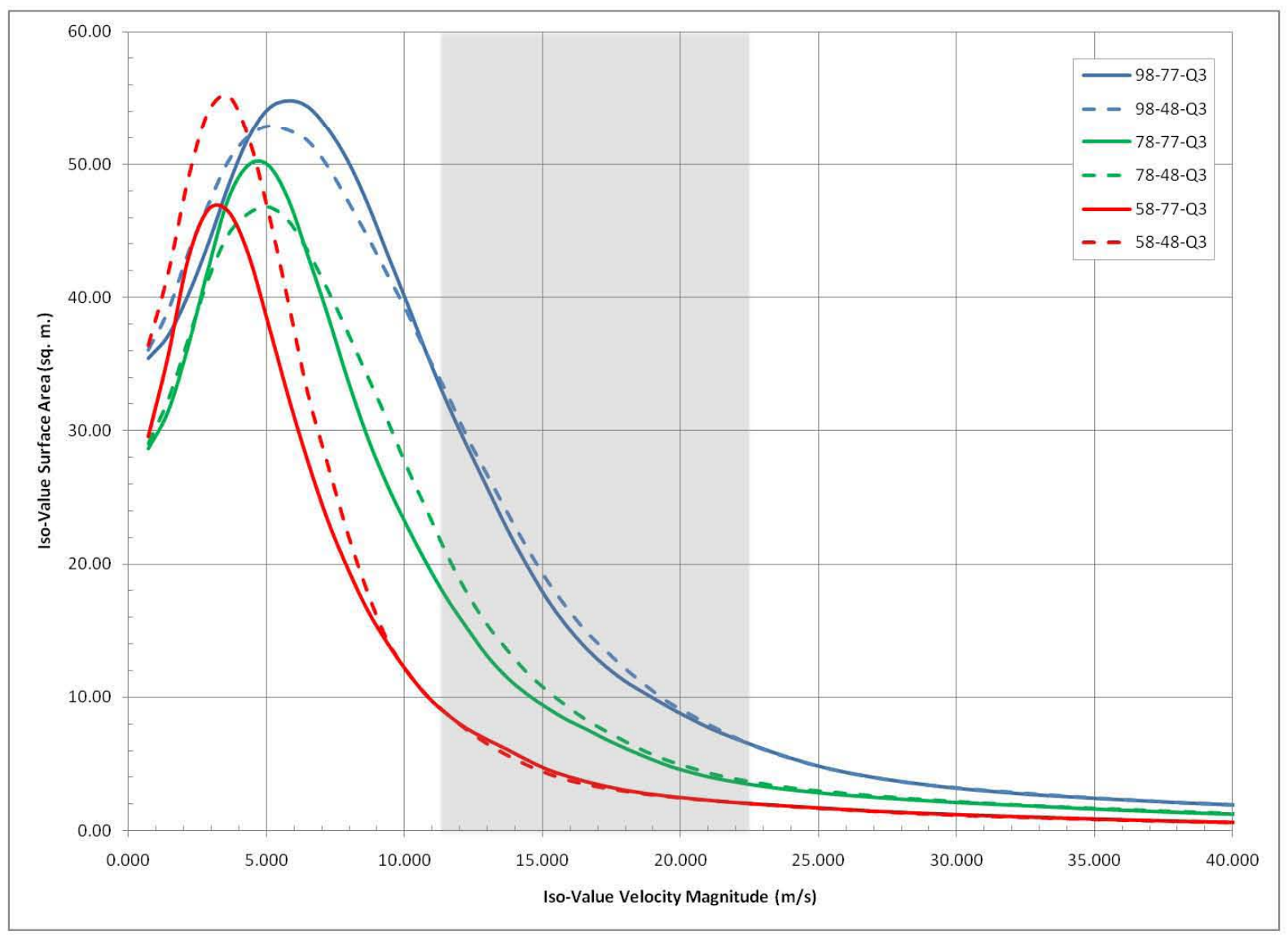


Table 3-3. Iso-Value Surface Area versus Velocity Magnitude (2 pages).

\begin{tabular}{|c|c|c|c|c|c|c|}
\hline \multicolumn{7}{|c|}{ All 120-Inch Runs } \\
\hline $\begin{array}{c}\text { Velocity } \\
\text { Magnitude } \\
(\mathrm{m} / \mathrm{s})\end{array}$ & $\begin{array}{c}120-\text { Inch } \\
\text { GPM }=98 \\
\text { RPM }=0.77 \mathrm{Q} 3 \\
\text { (sq. m.) }\end{array}$ & $\begin{array}{c}120-\text { Inch } \\
\text { GPM=98 } \\
\text { RPM=0.48Q3 } \\
\text { (sq. m.) }\end{array}$ & $\begin{array}{c}120-\text { Inch } \\
\text { GPM }=78 \\
\text { RPM }=0.77 \mathrm{Q} 3 \\
\text { (sq. m.) }\end{array}$ & $\begin{array}{c}120-\text { Inch } \\
\text { GPM }=78 \\
\text { RPM }=0.48 Q 3 \\
\text { (sq. m.) }\end{array}$ & $\begin{array}{c}120 \text {-Inch } \\
\text { GPM=58 } \\
\text { RPM }=0.77 \mathrm{Q} 3 \\
\text { (sq. m.) }\end{array}$ & $\begin{array}{c}120-\mathrm{Inch} \\
\mathrm{GPM}=58 \\
\mathrm{RPM}=0.48 \mathrm{Q} 3 \\
\text { (sq. m.) }\end{array}$ \\
\hline 0.013 & 35.449 & 36.066 & 28.649 & 29.031 & 29.554 & 36.433 \\
\hline 0.026 & 37.163 & 39.033 & 31.460 & 32.321 & 35.618 & 41.863 \\
\hline 0.038 & 40.203 & 43.317 & 36.330 & 36.820 & 42.857 & 48.907 \\
\hline 0.051 & 43.999 & 46.913 & 42.085 & 41.305 & 46.539 & 53.962 \\
\hline 0.064 & 48.316 & 50.174 & 47.317 & 44.667 & 46.459 & 55.237 \\
\hline 0.077 & 51.945 & 52.078 & 49.894 & 46.268 & 43.325 & 52.210 \\
\hline 0.089 & 54.193 & 52.887 & 49.950 & 46.789 & 38.146 & 46.631 \\
\hline 0.102 & 54.845 & 52.583 & 47.466 & 45.796 & 32.706 & 39.891 \\
\hline 0.115 & 54.409 & 51.783 & 43.194 & 43.500 & 27.752 & 32.914 \\
\hline 0.128 & 52.747 & 49.868 & 38.721 & 40.601 & 23.316 & 27.554 \\
\hline 0.140 & 50.341 & 47.291 & 33.898 & 37.410 & 19.712 & 22.399 \\
\hline 0.153 & 47.126 & 44.604 & 29.551 & 34.108 & 16.569 & 17.959 \\
\hline 0.166 & 43.324 & 41.742 & 25.930 & 30.795 & 14.085 & 14.318 \\
\hline 0.179 & 39.588 & 38.877 & 22.814 & 27.220 & 11.917 & 11.949 \\
\hline 0.191 & 35.738 & 35.723 & 19.969 & 23.985 & 10.100 & 10.148 \\
\hline 0.204 & 32.138 & 32.810 & 17.399 & 20.697 & 8.735 & 8.781 \\
\hline 0.217 & 28.902 & 29.582 & 15.213 & 17.833 & 7.661 & 7.586 \\
\hline 0.230 & 25.801 & 26.758 & 13.141 & 15.475 & 6.846 & 6.549 \\
\hline 0.242 & 22.710 & 23.955 & 11.508 & 13.580 & 6.112 & 5.699 \\
\hline 0.255 & 19.961 & 21.281 & 10.250 & 11.872 & 5.325 & 4.956 \\
\hline 0.268 & 17.453 & 18.839 & 9.227 & 10.524 & 4.620 & 4.335 \\
\hline 0.281 & 15.384 & 16.770 & 8.327 & 9.349 & 4.108 & 3.840 \\
\hline 0.294 & 13.677 & 14.934 & 7.598 & 8.292 & 3.678 & 3.478 \\
\hline 0.306 & 12.284 & 13.473 & 6.825 & 7.434 & 3.322 & 3.195 \\
\hline 0.319 & 11.165 & 12.100 & 6.138 & 6.634 & 3.022 & 2.966 \\
\hline 0.332 & 10.261 & 10.877 & 5.507 & 5.905 & 2.793 & 2.758 \\
\hline 0.345 & 9.387 & 9.758 & 4.924 & 5.292 & 2.612 & 2.588 \\
\hline 0.357 & 8.585 & 8.906 & 4.460 & 4.817 & 2.450 & 2.440 \\
\hline 0.375 & 7.572 & 7.788 & 3.947 & 4.215 & 2.256 & 2.263 \\
\hline 0.400 & 6.425 & 6.415 & 3.427 & 3.628 & 2.021 & 2.044 \\
\hline 0.425 & 5.425 & 5.394 & 3.041 & 3.181 & 1.831 & 1.831 \\
\hline 0.450 & 4.616 & 4.626 & 2.740 & 2.875 & 1.655 & 1.653 \\
\hline 0.475 & 4.050 & 4.042 & 2.512 & 2.618 & 1.491 & 1.483 \\
\hline
\end{tabular}


Table 3-3. Iso-Value Surface Area versus Velocity Magnitude (2 pages).

\begin{tabular}{|c|c|c|c|c|c|c|}
\hline \multicolumn{7}{|c|}{ All 120-Inch Runs } \\
\hline $\begin{array}{l}\text { Velocity } \\
\text { Magnitude } \\
(\mathrm{m} / \mathrm{s})\end{array}$ & $\begin{array}{c}120-\text { Inch } \\
\text { GPM }=98 \\
\text { RPM }=0.77 \mathrm{Q} 3 \\
\text { (sq. m.) }\end{array}$ & $\begin{array}{c}120-\text { Inch } \\
\text { GPM }=98 \\
\text { RPM }=0.48 \mathrm{Q} 3 \\
\text { (sq. m.) }\end{array}$ & $\begin{array}{c}120 \text {-Inch } \\
\text { GPM }=78 \\
\text { RPM }=0.77 \mathrm{Q} 3 \\
\text { (sq. m.) }\end{array}$ & $\begin{array}{c}120-\text { Inch } \\
\text { GPM }=78 \\
\text { RPM }=0.48 Q 3 \\
\text { (sq. m.) }\end{array}$ & $\begin{array}{c}120-\text { Inch } \\
\text { GPM }=58 \\
\text { RPM }=0.77 \mathrm{Q} 3 \\
\text { (sq. m.) }\end{array}$ & $\begin{array}{c}120-\text { Inch } \\
\text { GPM }=58 \\
\text { RPM }=0.48 Q 3 \\
\text { (sq. m.) }\end{array}$ \\
\hline 0.500 & 3.606 & 3.595 & 2.314 & 2.393 & 1.353 & 1.331 \\
\hline 0.525 & 3.245 & 3.283 & 2.142 & 2.206 & 1.232 & 1.211 \\
\hline 0.550 & 2.975 & 3.032 & 1.997 & 2.035 & 1.130 & 1.103 \\
\hline 0.575 & 2.736 & 2.815 & 1.856 & 1.884 & 1.037 & 1.019 \\
\hline 0.600 & 2.559 & 2.608 & 1.714 & 1.750 & 0.946 & 0.927 \\
\hline 0.625 & 2.385 & 2.423 & 1.576 & 1.628 & 0.860 & 0.851 \\
\hline 0.650 & 2.240 & 2.260 & 1.463 & 1.513 & 0.782 & 0.782 \\
\hline 0.675 & 2.094 & 2.116 & 1.349 & 1.404 & 0.708 & 0.717 \\
\hline 0.700 & 1.966 & 1.980 & 1.250 & 1.306 & 0.642 & 0.656 \\
\hline 0.725 & 1.844 & 1.853 & 1.164 & 1.223 & 0.579 & 0.596 \\
\hline
\end{tabular}

Plots of the scaled iso-value area versus scaled velocity magnitude are used in Section 4.2 to show that a single peak of approximately the same magnitude is obtained for all three scales. The peak is located further left (smaller velocity magnitudes) as the size of the model decreases. The sharpness of the peak increases for the smaller scales as well. The iso-value areas for the smaller scales are divided by the square of the appropriate geometric scale factor so that all scales can be shown together on one plot for comparison purposes.

Figure 3-5 shows the effect of shifting the iso-value velocity magnitude mapping when the 120 -inch model is scaled to full-scale. The shape change is not apparent until the curves are plotted with both axes scaled. The location of the peak moves counter to the shift in the x-axis-i.e. mapping the full-scale values to smaller values at the 120 -inch scale causes the peak to shift right (toward higher full-scale iso-value velocity magnitudes). The far-left spectrum (green - 120-Hi-Hi Q3) is the matching curve used in the comparison shown in Figure 4-1 and Figure 4-2. The other two spectra represent ad-hoc shifts of 0.9590 and 0.8663 relative to the normal scaling (in other words, a different mapping of iso-value velocity magnitudes from full-scale to 120 -inch scale) as these FLUENT edits were available for use. These factors were chosen arbitrarily and are used only for discussion purposes.

The shift shown in Figure 3-5 shows the importance of correcting for as-is velocity variation when performing simulations and model testing. If the scaling is not exactly right for a particular set of conditions, it can be adjusted by changing the mapping of iso-value velocity magnitudes and rerunning the edit rather than rerunning the simulation or test. Values for Figure 3-5 are listed in Table 3-4. 
Figure 3-5. Phase Shift with Ad-Hoc 0.9590 and 0.8663 Factors.

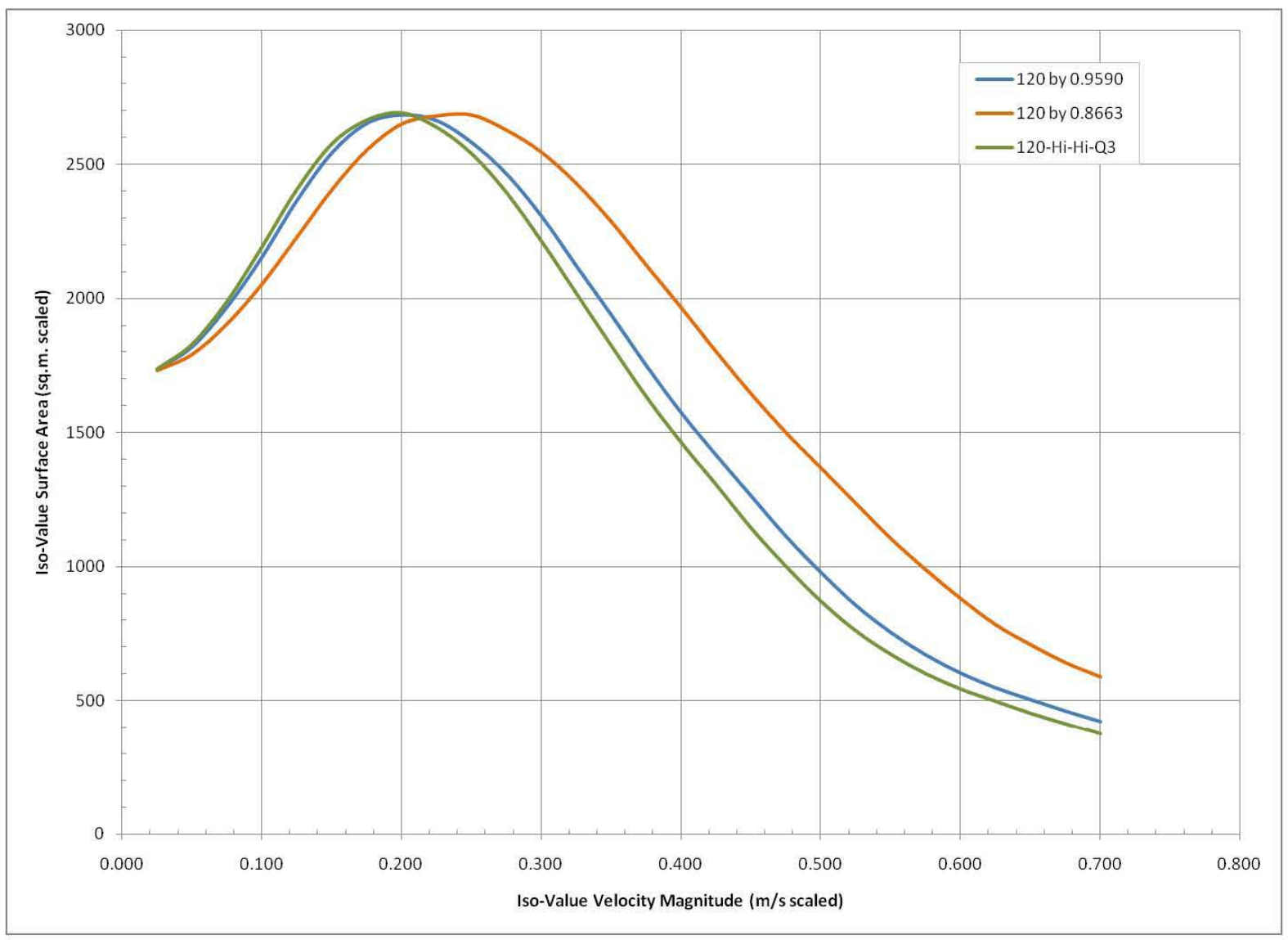

Table 3-4. Iso-Value Surface Area (scaled) versus Velocity Magnitude (scaled) (2 pages).

\begin{tabular}{|c|c|c|c|}
\hline \multicolumn{4}{|c|}{ Phase Shift in 120-Inch Simulations GPM=98 RPM=0.77 Q3 (sq. m.) } \\
\hline Velocity Magnitude $(\mathrm{m} / \mathrm{s})$ & $\begin{array}{c}\text { Actual Velocity Magnitude } \\
\text { Mapping }\end{array}$ & $\begin{array}{c}\text { Mapping Shifted } \\
0.9590\end{array}$ & $\begin{array}{c}\text { Mapping Shifted } \\
0.8663\end{array}$ \\
\hline 0.025 & 1738.17 & 1736.08 & 1730.08 \\
\hline 0.050 & 1830.80 & 1820.01 & 1789.99 \\
\hline 0.075 & 1990.33 & 1968.88 & 1903.89 \\
\hline 0.100 & 2193.37 & 2154.79 & 2052.41 \\
\hline 0.125 & 2407.49 & 2366.20 & 2227.10 \\
\hline 0.150 & 2576.89 & 2543.96 & 2403.88 \\
\hline 0.175 & 2666.18 & 2654.03 & 2551.68 \\
\hline 0.200 & 2692.52 & 2685.96 & 2649.35 \\
\hline 0.225 & 2639.10 & 2664.63 & 2679.51 \\
\hline 0.250 & 2540.59 & 2583.21 & 2682.81 \\
\hline 0.275 & 2395.46 & 2465.37 & 2626.09 \\
\hline 0.300 & 2214.42 & 2307.94 & 2544.09 \\
\hline
\end{tabular}


Table 3-4. Iso-Value Surface Area (scaled) versus Velocity Magnitude (scaled) (2 pages).

\begin{tabular}{|c|c|c|c|}
\hline Phase Shift in 120-Inch Simulations GPM=98 RPM=0.77 Q3 (sq. m.) & $\begin{array}{c}\text { Mapping Shifted } \\
0.8663\end{array}$ \\
\hline Velocity Magnitude (m/s) & $\begin{array}{c}\text { Actual Velocity Magnitude } \\
\text { Mapping }\end{array}$ & $\begin{array}{c}\text { Mapping Shifted } \\
0.9590\end{array}$ & 2427.09 \\
\hline 0.325 & 2019.66 & 2121.74 & 2284.69 \\
\hline 0.350 & 1824.75 & 1938.76 & 2122.89 \\
\hline 0.375 & 1635.10 & 1750.21 & 1964.52 \\
\hline 0.400 & 1463.80 & 1573.93 & 1800.23 \\
\hline 0.425 & 1306.91 & 1415.46 & 1643.30 \\
\hline 0.450 & 1145.59 & 1263.60 & 1498.06 \\
\hline 0.475 & 1002.21 & 1112.22 & 1366.93 \\
\hline 0.500 & 872.48 & 977.56 & 1234.70 \\
\hline 0.525 & 762.02 & 854.74 & 1103.47 \\
\hline 0.550 & 674.35 & 753.44 & 987.39 \\
\hline 0.575 & 602.60 & 669.80 & 879.42 \\
\hline 0.600 & 545.41 & 601.59 & 782.47 \\
\hline 0.625 & 499.48 & 546.79 & 707.84 \\
\hline 0.650 & 454.63 & 502.51 & 640.81 \\
\hline 0.675 & 414.62 & 459.74 & 587.96 \\
\hline 0.700 & 376.80 & 420.44 & \\
\hline
\end{tabular}

\subsection{0-Inch Comparisons}

Plots of energy-analog spectra are used to compare variations in flow rate and rotation rate for the 120 -inch scale at absolute values of iso-value velocity magnitude $(0.0$ to $0.7 \mathrm{~m} / \mathrm{s})$.

Figure 3-4 represents the energy dissipated by the jet-mixing process for all of the 120 -inch scale simulations. Higher jet velocities and flow rates change the peak location and magnitude. The increase in energy associated with higher flow rates spreads out over the spectrum represented by the curve.

Changes in rotational rate will also shift where the energy is dissipated, but the effect is only significant at lower energies, as can be seen in Figure 3-4. The small changes in rotation rate do not significantly affect how the high-energy tails of the spectra overlap in the area of interest, as shown by the sections of the curves in the shaded region of Figure 3-4.

\subsubsection{Effect of Changes in Flow Rate}

Inspection of Figure 3-6 demonstrates the effect of changing the pumping rate of the jet-mixer pumps. Figure 3-6 compares the percent difference between pairs of simulations at the same rotational rate. The legend of the figure indicates the flow rate and rotational rate values (GPM1, GPM2: RPM). In the key region of interest, 0.2 to $0.4 \mathrm{~m} / \mathrm{s}$, all of the curves are relatively flat and do not change dramatically, indicating that the mixing is relatively (but not in absolute terms) 
constant over this velocity range. For all cases the solid and dashed lines (i.e. differences in rotational rate) track relatively closely to each other, indicating that the rotational effect is minimal in this range. Past about $0.4 \mathrm{~m} / \mathrm{s}$ the absolute values of the iso-value surface areas become very small, so these percent changes are insignificant to the process. It is important to note that percentchange can be the same for both small and large absolute changes. Refer to the spectra plots for an indication of the magnitude changes. Note the smaller impact from rotation rate (maximum of $20 \%$ ) as compared to the larger impact from flow rate (approaching $80 \%$ ). The data used in Figure 3-6 are listed in Table 3-5.

Figure 3-6. Comparison of 120-Inch Cases at Constant RPM.

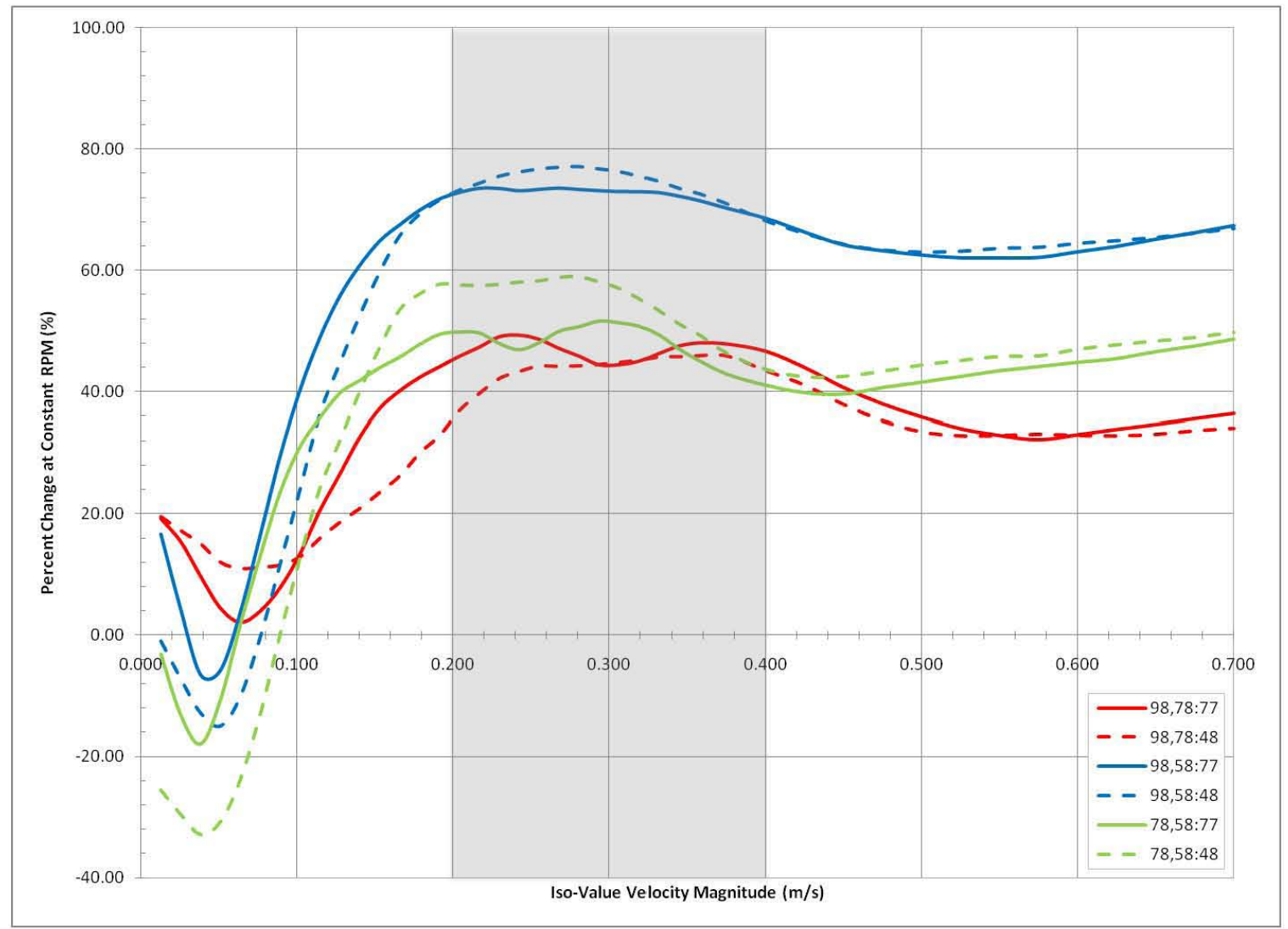


Table 3-5. Percent Change between Comparison Cases, Constant RPM (\%) (2 pages).

\begin{tabular}{|c|c|c|c|c|c|c|}
\hline \multicolumn{7}{|c|}{ Calculated from Iso-Value Surface Areas as $100^{*}$ (First-GPM - Second-GPM)/First-GPM } \\
\hline Velocity & 120 -Inch & 120-Inch & 120-Inch & $120-$ Inch & 120 -Inch & 120-Inch \\
\hline $\begin{array}{l}\text { Magnitude } \\
\qquad(\mathrm{m} / \mathrm{s})\end{array}$ & $\begin{array}{c}\text { GPM }=98, \\
\text { GPM }=78 \text { at } \\
\text { RPM }=0.77(\%)\end{array}$ & $\begin{array}{c}\mathrm{GPM}=98, \\
\mathrm{GPM}=58 \text { at } \\
\mathrm{RPM}=0.77(\%)\end{array}$ & $\begin{array}{c}\mathrm{GPM}=98, \\
\mathrm{GPM}=78 \text { at } \\
\mathrm{RPM}=0.48(\%)\end{array}$ & $\begin{array}{c}\mathrm{GPM}=98, \\
\mathrm{GPM}=58 \text { at } \\
\mathrm{RPM}=0.48(\%)\end{array}$ & $\begin{array}{c}\mathrm{GPM}=78, \\
\mathrm{GPM}=58 \text { at } \\
\mathrm{RPM}=0.77(\%)\end{array}$ & $\begin{array}{c}\mathrm{GPM}=78, \\
\mathrm{GPM}=58 \text { at } \\
\mathrm{RPM}=0.48(\%)\end{array}$ \\
\hline 0.013 & 19.183 & 16.629 & 19.508 & -1.018 & -3.161 & -25.499 \\
\hline 0.026 & 15.345 & 4.157 & 17.196 & -7.249 & -13.216 & -29.522 \\
\hline 0.038 & 9.633 & -6.602 & 14.999 & -12.906 & -17.965 & -32.829 \\
\hline 0.051 & 4.349 & -5.773 & 11.955 & -15.026 & -10.583 & -30.645 \\
\hline 0.064 & 2.067 & 3.842 & 10.976 & -10.092 & 1.812 & -23.666 \\
\hline 0.077 & 3.948 & 16.594 & 11.156 & -0.254 & 13.166 & -12.843 \\
\hline 0.089 & 7.830 & 29.610 & 11.531 & 11.830 & 23.631 & 0.337 \\
\hline 0.102 & 13.453 & 40.366 & 12.907 & 24.138 & 31.097 & 12.896 \\
\hline 0.115 & 20.612 & 48.994 & 15.995 & 36.438 & 35.751 & 24.335 \\
\hline 0.128 & 26.591 & 55.796 & 18.583 & 44.747 & 39.784 & 32.136 \\
\hline 0.140 & 32.663 & 60.842 & 20.895 & 52.636 & 41.848 & 40.125 \\
\hline 0.153 & 37.293 & 64.841 & 23.532 & 59.737 & 43.932 & 47.347 \\
\hline 0.166 & 40.148 & 67.490 & 26.224 & 65.699 & 45.682 & 53.506 \\
\hline 0.179 & 42.372 & 69.896 & 29.985 & 69.266 & 47.762 & 56.104 \\
\hline 0.191 & 44.123 & 71.740 & 32.860 & 71.594 & 49.424 & 57.691 \\
\hline 0.204 & 45.862 & 72.820 & 36.920 & 73.238 & 49.795 & 57.574 \\
\hline 0.217 & 47.366 & 73.493 & 39.717 & 74.356 & 49.639 & 57.461 \\
\hline 0.230 & 49.071 & 73.467 & 42.167 & 75.524 & 47.902 & 57.678 \\
\hline 0.242 & 49.328 & 73.087 & 43.311 & 76.208 & 46.888 & 58.031 \\
\hline 0.255 & 48.651 & 73.323 & 44.216 & 76.712 & 48.048 & 58.254 \\
\hline 0.268 & 47.130 & 73.529 & 44.139 & 76.992 & 49.932 & 58.811 \\
\hline 0.281 & 45.874 & 73.300 & 44.253 & 77.105 & 50.671 & 58.930 \\
\hline 0.294 & 44.446 & 73.106 & 44.477 & 76.713 & 51.590 & 58.059 \\
\hline 0.306 & 44.436 & 72.956 & 44.823 & 76.286 & 51.329 & 57.022 \\
\hline 0.319 & 45.026 & 72.929 & 45.173 & 75.489 & 50.757 & 55.293 \\
\hline 0.332 & 46.328 & 72.775 & 45.713 & 74.640 & 49.275 & 53.285 \\
\hline 0.345 & 47.552 & 72.180 & 45.764 & 73.481 & 46.958 & 51.104 \\
\hline 0.357 & 48.047 & 71.460 & 45.919 & 72.603 & 45.066 & 49.341 \\
\hline 0.375 & 47.871 & 70.209 & 45.875 & 70.948 & 42.852 & 46.325 \\
\hline 0.400 & 46.659 & 68.539 & 43.449 & 68.131 & 41.019 & 43.647 \\
\hline 0.425 & 43.957 & 66.260 & 41.040 & 66.064 & 39.797 & 42.443 \\
\hline 0.450 & 40.654 & 64.148 & 37.849 & 64.272 & 39.589 & 42.514 \\
\hline 0.475 & 37.975 & 63.196 & 35.227 & 63.309 & 40.663 & 43.355 \\
\hline
\end{tabular}


Table 3-5. Percent Change between Comparison Cases, Constant RPM (\%) (2 pages).

\begin{tabular}{|c|c|c|c|c|c|c|}
\hline \multicolumn{7}{|c|}{ Calculated from Iso-Value Surface Areas as $100^{*}$ (First-GPM - Second-GPM)/First-GPM } \\
\hline Velocity & $120-\operatorname{lnch}$ & 120-Inch & 120-Inch & 120 -Inch & 120 -Inch & $120-\operatorname{lnch}$ \\
\hline $\begin{array}{l}\text { Magnitude } \\
(\mathrm{m} / \mathrm{s})\end{array}$ & $\begin{array}{c}\text { GPM }=98, \\
\text { GPM }=78 \text { at } \\
\text { RPM }=0.77(\%)\end{array}$ & $\begin{array}{c}\mathrm{GPM}=98, \\
\mathrm{GPM}=58 \text { at } \\
\mathrm{RPM}=0.77(\%)\end{array}$ & $\begin{array}{c}\mathrm{GPM}=98, \\
\mathrm{GPM}=78 \text { at } \\
\mathrm{RPM}=0.48(\%)\end{array}$ & $\begin{array}{c}\mathrm{GPM}=98, \\
\mathrm{GPM}=58 \text { at } \\
\mathrm{RPM}=0.48(\%)\end{array}$ & $\begin{array}{c}\mathrm{GPM}=78, \\
\mathrm{GPM}=58 \text { at } \\
\mathrm{RPM}=0.77(\%)\end{array}$ & $\begin{array}{c}\mathrm{GPM}=78, \\
\mathrm{GPM}=58 \text { at } \\
\mathrm{RPM}=0.48(\%)\end{array}$ \\
\hline 0.500 & 35.840 & 62.491 & 33.447 & 62.985 & 41.538 & 44.383 \\
\hline 0.525 & 33.984 & 62.029 & 32.811 & 63.130 & 42.482 & 45.124 \\
\hline 0.550 & 32.878 & 62.027 & 32.883 & 63.619 & 43.427 & 45.794 \\
\hline 0.575 & 32.180 & 62.091 & 33.079 & 63.779 & 44.104 & 45.875 \\
\hline 0.600 & 33.013 & 63.033 & 32.896 & 64.434 & 44.814 & 46.999 \\
\hline 0.625 & 33.895 & 63.926 & 32.819 & 64.877 & 45.430 & 47.718 \\
\hline 0.650 & 34.689 & 65.105 & 33.061 & 65.411 & 46.570 & 48.327 \\
\hline 0.675 & 35.590 & 66.185 & 33.657 & 66.114 & 47.500 & 48.923 \\
\hline 0.700 & 36.447 & 67.352 & 34.049 & 66.881 & 48.628 & 49.783 \\
\hline 0.725 & 36.833 & 68.580 & 34.008 & 67.839 & 50.259 & 51.265 \\
\hline
\end{tabular}

\subsubsection{Effect of Changes in Rotation Rate}

In contrast to the constant rotation rate case in Section 3.3.1, where the impact was greater at higher velocity, the constant flow rate case shows differences that are more significant at lower velocities, especially at lower flow rates. Figure 3-7 shows this effect by the spread of the curves, where negative values mean that the lower rotation value has a larger response in those regions.

Remember that percent-change does not indicate the magnitude of the change. Refer to the spectra plots for magnitude changes. Over the region of interest, between 0.2 and $0.4 \mathrm{~m} / \mathrm{s}$, there is a large percent change in the 78 GPM case. This swing indicates that at the $0.2 \mathrm{~m} / \mathrm{s}$ velocity the mixing performance is more sensitive to rotational rate than at the $0.4 \mathrm{~m} / \mathrm{s}$ velocity. The lowest flow rate ( $58 \mathrm{GPM}$ ) goes through a similar transition at lower velocity (in the range of 0.1 to $0.2 \mathrm{~m} / \mathrm{s}$ ), while the highest flow rate (98 GPM) never shows this transition.

The influence of rotation rate is limited at the lower energy levels in the 43.2-inch and 120-inch models because the solid is not scaled. It will respond to absolute velocity levels when added to the CFD model. It is possible that, in real operations at the full-scale, a lower jet velocity with a different rotational rate could be more efficient, assuming that the maximum performance of the jetmixer pumps is more than is needed. The data for Figure 3-7 is listed in Table 3-6. 
Figure 3-7. Comparison of 120-Inch Cases at Constant GPM.

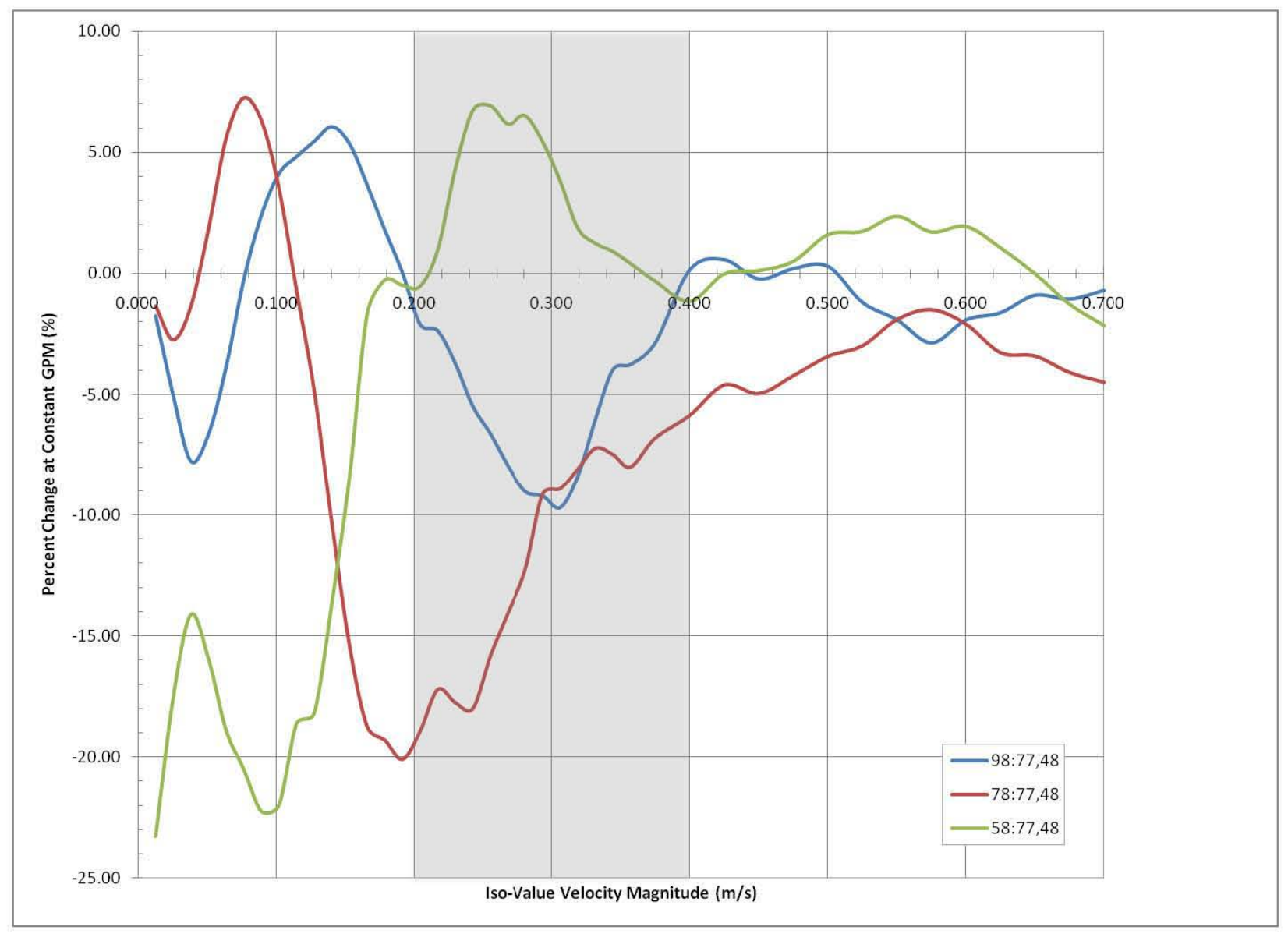

Table 3-6. Percent Change between Comparison Cases, Constant GPM (\%) (2 pages).

\begin{tabular}{|c|c|c|c|}
\hline \multicolumn{4}{|c|}{ Calculated from Iso-Value Surface Areas as $100^{*}($ First-RPM - Second-RPM)/First-RPM } \\
\hline $\begin{array}{l}\text { Velocity Magnitude } \\
\qquad(\mathrm{m} / \mathrm{s})\end{array}$ & $\begin{array}{c}120-\operatorname{Inch} \mathrm{RPM}=0.77, \\
\mathrm{RPM}=0.48 \text { at } \mathrm{GPM}=98(\%)\end{array}$ & $\begin{array}{c}\text { 120-Inch RPM=0.77, RPM=0.48 } \\
\text { at GPM=78 (\%) }\end{array}$ & $\begin{array}{c}120-\text { Inch RPM=0.77, } \\
\text { RPM }=0.48 \text { at } G P M=58(\%)\end{array}$ \\
\hline 0.013 & -1.741 & -1.332 & -23.275 \\
\hline 0.026 & -5.033 & -2.737 & -17.532 \\
\hline 0.038 & -7.746 & -1.348 & -14.119 \\
\hline 0.051 & -6.624 & 1.854 & -15.951 \\
\hline 0.064 & -3.846 & 5.601 & -18.894 \\
\hline 0.077 & -0.256 & 7.268 & -20.508 \\
\hline 0.089 & 2.409 & 6.328 & -22.242 \\
\hline 0.102 & 4.123 & 3.518 & -21.968 \\
\hline 0.115 & 4.827 & -0.708 & -18.602 \\
\hline 0.128 & 5.458 & -4.856 & -18.174 \\
\hline 0.140 & 6.057 & -10.361 & -13.632 \\
\hline
\end{tabular}


Table 3-6. Percent Change between Comparison Cases, Constant GPM (\%) (2 pages).

\begin{tabular}{|c|c|c|c|}
\hline \multicolumn{4}{|c|}{ Calculated from /so-Value Surface Areas as $100^{*}$ (First-RPM - Second-RPM)/First-RPM } \\
\hline $\begin{array}{l}\text { Velocity Magnitude } \\
\qquad(\mathrm{m} / \mathrm{s})\end{array}$ & $\begin{array}{c}120-\operatorname{Inch} \mathrm{RPM}=0.77, \\
\mathrm{RPM}=0.48 \text { at } \mathrm{GPM}=98(\%)\end{array}$ & $\begin{array}{c}120 \text {-Inch RPM }=0.77, \mathrm{RPM}=0.48 \\
\text { at } \mathrm{GPM}=78(\%)\end{array}$ & $\begin{array}{c}120-\operatorname{Inch} \mathrm{RPM}=0.77, \\
\mathrm{RPM}=0.48 \text { at } \mathrm{GPM}=58(\%)\end{array}$ \\
\hline 0.153 & 5.352 & -15.420 & -8.389 \\
\hline 0.166 & 3.653 & -18.761 & -1.654 \\
\hline 0.179 & 1.794 & -19.315 & -0.261 \\
\hline 0.191 & 0.041 & -20.108 & -0.476 \\
\hline 0.204 & -2.090 & -18.952 & -0.522 \\
\hline 0.217 & -2.353 & -17.227 & 0.981 \\
\hline 0.230 & -3.708 & -17.767 & 4.332 \\
\hline 0.242 & -5.480 & -18.006 & 6.752 \\
\hline 0.255 & -6.614 & -15.822 & 6.931 \\
\hline 0.268 & -7.945 & -14.051 & 6.176 \\
\hline 0.281 & -9.009 & -12.273 & 6.524 \\
\hline 0.294 & -9.196 & -9.134 & 5.448 \\
\hline 0.306 & -9.680 & -8.916 & 3.824 \\
\hline 0.319 & -8.373 & -8.082 & 1.875 \\
\hline 0.332 & -6.006 & -7.222 & 1.254 \\
\hline 0.345 & -3.949 & -7.492 & 0.911 \\
\hline 0.357 & -3.743 & -7.992 & 0.412 \\
\hline 0.375 & -2.860 & -6.798 & -0.309 \\
\hline 0.400 & 0.151 & -5.860 & -1.143 \\
\hline 0.425 & 0.573 & -4.604 & -0.006 \\
\hline 0.450 & -0.220 & -4.957 & 0.125 \\
\hline 0.475 & 0.201 & -4.220 & 0.509 \\
\hline 0.500 & 0.299 & -3.419 & 1.614 \\
\hline 0.525 & -1.185 & -2.983 & 1.748 \\
\hline 0.550 & -1.906 & -1.898 & 2.367 \\
\hline 0.575 & -2.858 & -1.494 & 1.722 \\
\hline 0.600 & -1.910 & -2.088 & 1.953 \\
\hline 0.625 & -1.612 & -3.267 & 1.064 \\
\hline 0.650 & -0.891 & -3.406 & -0.005 \\
\hline 0.675 & -1.052 & -4.085 & -1.264 \\
\hline 0.700 & -0.689 & -4.488 & -2.139 \\
\hline 0.725 & -0.497 & -4.992 & -2.869 \\
\hline
\end{tabular}




\subsection{SCALING RELATIONSHIPS AMONG THE THREE SCALES}

In this section, the scaling among simulations at the full-scale, 120-inch scale and 43.2-inch scale is examined for similarity. Because each case is an exact scale (one third power law was used by the project), the behavior of one scale matches the other two scales. This relationship can be used to extrapolate the results of the denser sensitivity matrix completed for the 120 -inch model to the fullscale and 43.2-inch scale.

\subsection{Theory}

The simulation run table (Table 3-1) supplied for work in FY-2011 assumes a one-third power scaling. Once the geometry scaling is specified as $\alpha$ in EQ 2 and EQ 3 below, the velocity scaling at the output face of the jet-mixer pump can be determined using EQ 4. The assumed GPM and RPM values can also be calculated using a one-third power scale because they conform to EQ 5, EQ 6, and EQ 7.

$$
\begin{aligned}
& \alpha_{s} \equiv \frac{L_{s}}{L_{f s}} \quad E Q 2 \\
& \text { Volume } \Rightarrow \alpha_{s}^{3} \\
& \text { Velocity } \equiv \alpha_{s}^{1 / 3}=\frac{U_{s}}{U_{f s}} \\
& \text { EQ3 } \\
& \frac{W_{s} / T_{s}}{W_{f s} / T_{f s}} \equiv 1 \\
& E Q 4 \\
& W \equiv \frac{K g}{s^{3}} m^{2} \Rightarrow \\
& \left(\frac{K g}{s}\right)_{\text {ratio }}\left(\frac{m}{s}\right)_{\text {ratio }}^{2}=\alpha_{s}^{3} \Rightarrow \quad E Q 10 \\
& \text { Time } \Rightarrow \alpha_{s}^{2 / 3}=\frac{\frac{L_{s}}{L_{f s}}}{\frac{U_{s}}{U_{f s}}}=\alpha_{s} \alpha_{s}^{-1 / 3} \\
& \text { EQ5 } \\
& \frac{U_{s} A_{s} \gamma_{s}}{U_{f s} A_{f s} \gamma_{f s}}\left(\frac{U_{s}}{U_{f s}}\right)^{2}=\alpha_{s}^{3}=\quad E Q 11 \\
& \text { InverseTime } \Rightarrow \alpha_{s}^{-2 / 3}=\frac{r p m_{s}}{r p m_{f s}} \\
& \alpha_{s}^{2}\left(\frac{U_{s}}{U_{f s}}\right)^{3}=\alpha_{s}^{3} \Rightarrow \\
& \frac{G P M_{s}}{G P M_{f s}}=\alpha_{s}^{3} \alpha_{s}^{-2 / 3}=\alpha_{s}^{7 / 3} \\
& \therefore\left(\frac{U_{s}}{U_{f s}}\right)=\alpha_{s}^{1 / 3}
\end{aligned}
$$

Other possible ways to scale other than constant power per unit volume include the time to turn over the tank volume, the time that the jet flow takes to go from the pump to the tank wall, or the circulation time for a pump return circuit. These times are also important in terms of mixing performance. There is no solid phase in the model (it is liquid only), but the time it takes a solid particle to fall the height of the tank would also be unconstrained by the scaling specified. The scaling equations are useful when correcting for small variations in actual flow rate versus intended flow rate in simulations and model test runs. For example, the 120 -inch model run needed to be remapped when scaled to compare with the other two scales because the jet-face velocity was unintentionally too high. Adjustment factors are scaled per EQ 4 to obtain corrected iso-value velocity magnitude and iso-value surface area correlations between full-scale and the smaller 120inch and 43.2-inch models. 
Part of the work in FY-2011 has included testing the hypothesis that if more extensive sensitivity matrices of simulations are carried out at a single scale (120-inch), those results apply at all scales because single-phase flow will follow the scaling laws to sufficient accuracy. More information about the flow response to jet-mixer pumps is obtained by looking at variations in pumping rate, rotation speed and orifice size (velocity at the jet face), than by repeating simulations at precisely the same flow configurations, given precise scaling relationships, in separate models.

For example, if the assumed scaling is not quite right for the actual process (e.g. with solid included), a denser matrix allows interpolation of the results using a different set of scaling equations without re-running all the simulations with differing assumptions.

\subsubsection{Power per Unit Volume}

Besides the straight geometric scaling $(\alpha)$, equal power per volume between the scales was assumed by the project. To see this assumption, a derivation of the one-third scaling of velocity (U) is shown in EQ 8 through EQ 13. The hypothesis is given by EQ 8 where $\mathrm{W}$ is power and $\mathrm{V}$ is volume. The subscripts refer to "scale" and "full-scale." EQ 9 gives the definition of power in more fundamental units. Equation 9 is put in EQ 8 and the distributive and associative properties are used to rearrange it into EQ 10, where the subscript "ratio" means that the same form has an "s" group over an "fs" group. Equation 11 assumes incompressible flow to get the mass flow where " $\mathrm{A}$ " is the area for the nozzle face and $\gamma$ is density (same for all scales). Equation 12 and EQ 13 gather all common terms and show reduction to final form and the deviation is complete. The one-third scaling of velocity is a consequence of the equal power per volume assumption.

\subsection{Full, 120-Inch, and 43.2-Inch Scale Comparison}

Figure 4-1 of the scaled (i.e. using full-scale units) iso-value area versus absolute velocity magnitude (unscaled) shows a single peak of approximately the same magnitude for all three scales. The peak is located further left and becomes sharper (smaller velocity magnitudes) as the size of the model decreases.

Note that Table 4-1, which lists the data using Figure 4-1, has gaps because the mapping used for the smaller scales differ, such that the smaller models hit their scaled version of $0.7 \mathrm{~m} / \mathrm{s}$ at lower absolute values. At that point, the values chosen begin to match those chosen for the full scale (and the gaps in the table disappear). The values at each scale were chosen to make the next step, scaling velocity magnitude, straight forward. 
Figure 4-1. Comparison Cases for each of the Scales (actual simulations).

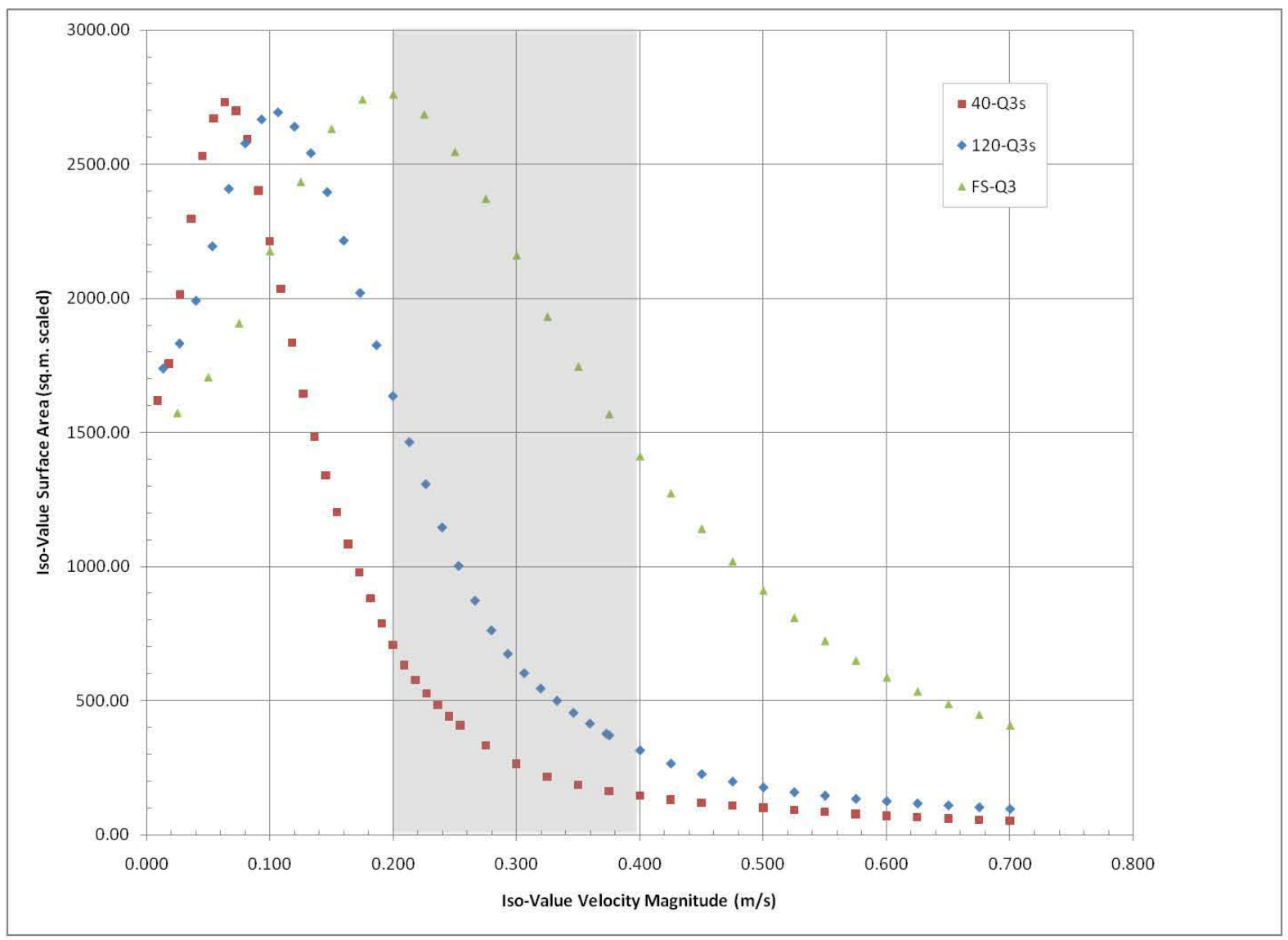


Table 4-1. Iso-Value Surface Area (scaled) versus Velocity Magnitude (3 pages).

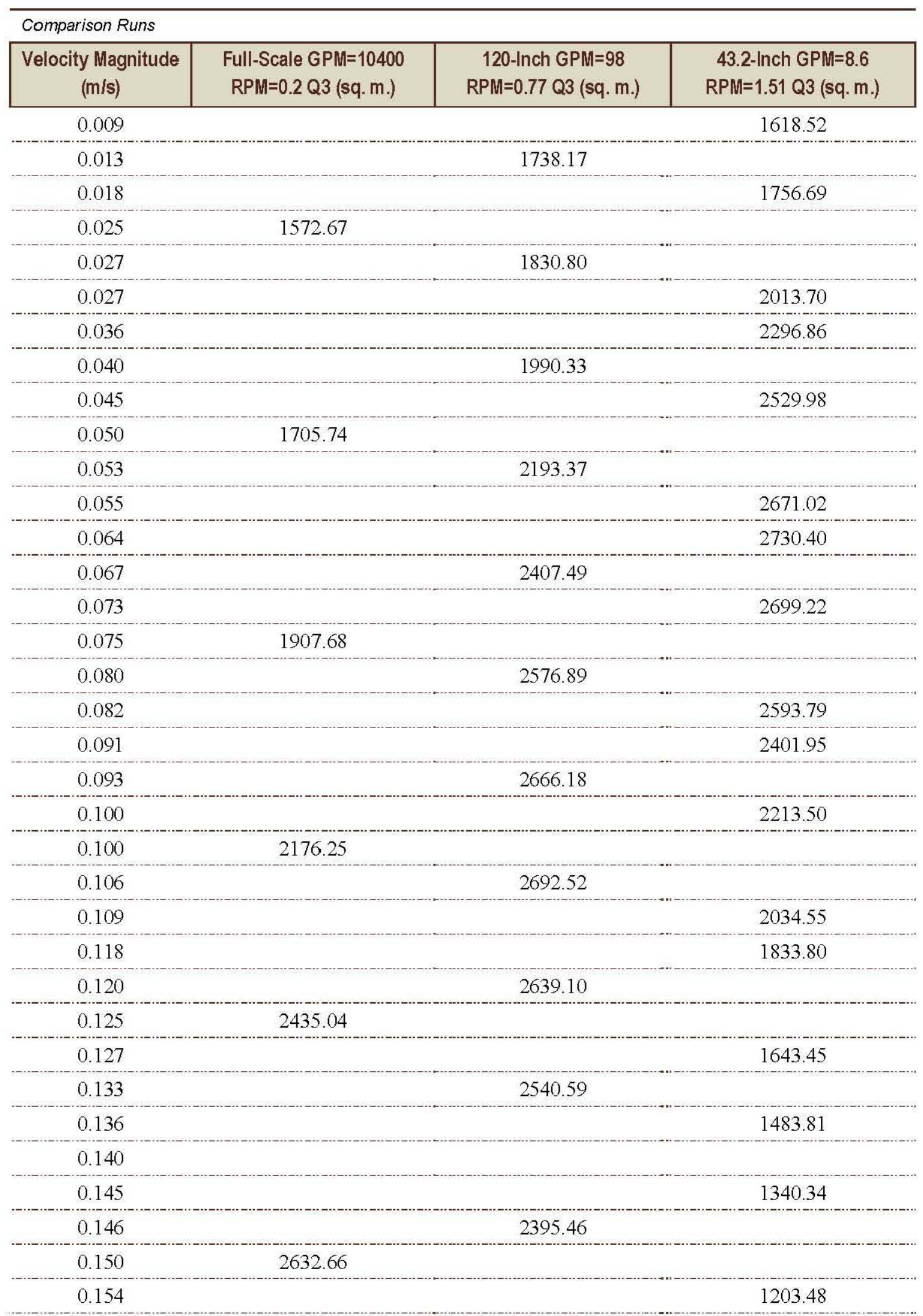


Table 4-1. Iso-Value Surface Area (scaled) versus Velocity Magnitude (3 pages).

\begin{tabular}{|c|c|c|c|}
\hline \multicolumn{4}{|l|}{ Comparison Runs } \\
\hline $\begin{array}{l}\text { Velocity Magnitude } \\
\qquad(\mathrm{m} / \mathrm{s})\end{array}$ & $\begin{array}{l}\text { Full-Scale GPM=10400 } \\
\text { RPM }=0.2 \text { Q3 (sq. m.) }\end{array}$ & $\begin{array}{c}120-\operatorname{Inch} \text { GPM=98 } \\
\mathrm{RPM}=0.77 \mathrm{Q} 3 \text { (sq. m.) }\end{array}$ & $\begin{array}{c}43.2-\operatorname{lnch} \mathrm{GPM}=8.6 \\
\mathrm{RPM}=1.51 \mathrm{Q} 3 \text { (sq. m.) }\end{array}$ \\
\hline 0.160 & & 2214.42 & \\
\hline 0.164 & & & 1084.12 \\
\hline 0.173 & & & 979.02 \\
\hline 0.173 & & 2019.66 & \\
\hline 0.175 & 2742.35 & & \\
\hline 0.182 & & & 881.03 \\
\hline 0.186 & & 1824.75 & \\
\hline 0.191 & & & 788.79 \\
\hline 0.200 & & 1635.10 & \\
\hline 0.200 & & & 706.78 \\
\hline 0.200 & 2761.78 & & \\
\hline 0.209 & & & 632.82 \\
\hline 0.213 & & 1463.80 & \\
\hline 0.218 & & & 576.46 \\
\hline 0.225 & 2687.10 & & \\
\hline 0.226 & & 1306.91 & \\
\hline 0.227 & & & 527.34 \\
\hline 0.236 & & & 483.16 \\
\hline 0.240 & & 1145.59 & \\
\hline 0.245 & & & 441.80 \\
\hline 0.250 & 2547.40 & & \\
\hline 0.253 & & 1002.21 & \\
\hline 0.254 & & & 408.70 \\
\hline 0.266 & & 872.48 & \\
\hline 0.275 & 2372.50 & & 331.95 \\
\hline 0.279 & & 762.02 & \\
\hline 0.293 & & 674.35 & \\
\hline 0.300 & 2161.09 & & 263.97 \\
\hline 0.306 & & 602.60 & \\
\hline 0.319 & & 545.41 & \\
\hline 0.325 & 1931.98 & & 214.92 \\
\hline 0.333 & & 499.48 & \\
\hline 0.346 & & 454.63 & \\
\hline 0.350 & 1746.03 & & 186.63 \\
\hline 0.359 & & 414.62 & \\
\hline
\end{tabular}


Table 4-1. Iso-Value Surface Area (scaled) versus Velocity Magnitude (3 pages).

\begin{tabular}{|c|c|c|c|}
\hline \multicolumn{4}{|l|}{ Comparison Runs } \\
\hline $\begin{array}{l}\text { Velocity Magnitude } \\
\qquad(\mathrm{m} / \mathrm{s})\end{array}$ & $\begin{array}{l}\text { Full-Scale GPM=10400 } \\
\text { RPM }=0.2 \text { Q3 (sq. m.) }\end{array}$ & $\begin{array}{c}120-\text { Inch GPM=98 } \\
\text { RPM }=0.77 \text { Q3 (sq. m.) }\end{array}$ & $\begin{array}{c}\text { 43.2-Inch GPM=8.6 } \\
R P M=1.51 \text { Q3 (sq. m.) }\end{array}$ \\
\hline 0.373 & \multicolumn{3}{|c|}{376.80} \\
\hline 0.375 & 1568.11 & 370.82 & 163.51 \\
\hline 0.400 & 1411.88 & 314.64 & 145.27 \\
\hline 0.425 & 1272.77 & 265.70 & 130.69 \\
\hline 0.450 & 1141.11 & 226.08 & 119.34 \\
\hline 0.475 & 1018.58 & 198.35 & 109.55 \\
\hline 0.500 & 910.44 & 176.60 & 100.80 \\
\hline 0.525 & 808.61 & 158.91 & 92.34 \\
\hline 0.550 & 722.53 & 145.71 & 84.60 \\
\hline 0.575 & 649.08 & 134.01 & 77.56 \\
\hline 0.600 & 586.31 & 125.32 & 70.41 \\
\hline 0.625 & 533.63 & 116.79 & 64.68 \\
\hline 0.650 & $\begin{array}{l}486.96 \\
\end{array}$ & 109.72 & 59.90 \\
\hline 0.675 & 446.74 & 102.53 & 55.86 \\
\hline 0.700 & 406.62 & 96.30 & 51.85 \\
\hline
\end{tabular}

If the iso-value velocity magnitude is also scaled, the curves converge to a reasonable approximation of one another, considering the statistical nature of the process, as shown in Figure 4-2. The process could be made better if the simulations were re-run with exactly the same mesh and corrected velocities at the pump nozzle, etc. For Figure 4-2, both the 43.2-inch tank results and the 120 -inch tank results are scaled up to the full-scale area units to show a comparison. The same set of curves would have been obtained if the full-scale and 120-inch tank results were scaled down to the 43.2-inch tank scale before comparison. The conclusion is that smaller-scale models can "look" the same as full-scale models if scaled properly for single-fluid simulations. This conclusion is used to generate tables at multiple scales from the 120 -inch model sensitivity simulations discussed in Section 3.0 (mainly because the 120 -inch simulations were farther ahead and that particular model was running faster). This extrapolation applies only to the flow of liquid in the tank, because any solid phase will in all likelihood scale differently and respond to absolute velocity, not scaled velocity. In any case, in the current application, the solid phase is not present and all particle motions are assumed based upon defined fluid velocities. However, confidence that has been gained in the present CFD work allows the isolation of the differing scaling presented by inclusion of the solid. Unfortunately, at present, the constitutive relationships between the multiple phases of the full-scale mixture are largely unknown. Further work with CFD may be able to tease out a model for the solid-fluid interaction by analyzing detailed results for the on-going physicalmodel tests. The data used in Figure 4-2 are listed in Table 4-2. 
Figure 4-2. Comparison Cases for All Models

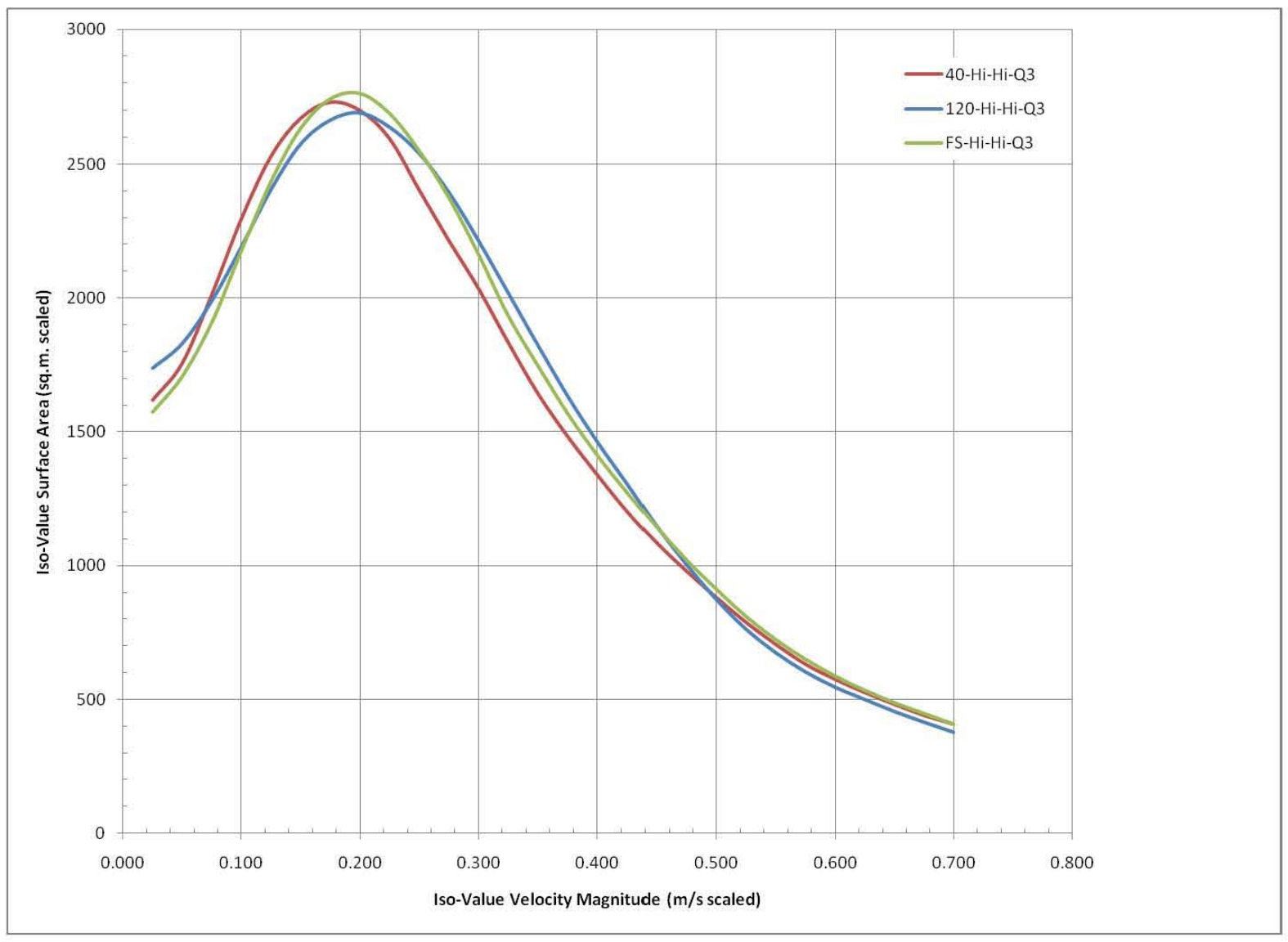

Table 4-2. Iso-Value Surface Area (scaled) versus Velocity Magnitude (scaled) (2pages).

\begin{tabular}{|c|c|c|c|}
\hline \multicolumn{4}{|l|}{ Comparison Runs } \\
\hline $\begin{array}{l}\text { Velocity Magnitude } \\
\qquad(\mathrm{m} / \mathrm{s})\end{array}$ & $\begin{array}{c}\text { Full-Scale } \\
\begin{array}{c}\text { GPM }=10400 / \text { RPM }=0.2 \\
\text { Q3 (sq. m.) }\end{array}\end{array}$ & $\begin{array}{c}120-\text { Inch } \\
\text { GPM=98 } / \text { RPM=0.77 } \\
\text { Q3 (sq. m.) }\end{array}$ & $\begin{array}{c}\text { 43.2-Inch } \\
\text { GPM=8.6 } / \text { RPM=1.51 } \\
\text { Q3 (sq. m.) }\end{array}$ \\
\hline 0.025 & 1572.67 & 1738.17 & 1618.52 \\
\hline 0.050 & 1705.74 & 1830.80 & 1756.69 \\
\hline 0.075 & 1907.68 & 1990.33 & 2013.70 \\
\hline 0.100 & 2176.25 & 2193.37 & 2296.86 \\
\hline 0.125 & 2435.04 & 2407.49 & $\begin{array}{r}2529.98 \\
-3\end{array}$ \\
\hline 0.150 & 2632.66 & 2576.89 & 2671.02 \\
\hline 0.175 & 2742.35 & 2666.18 & 2730.40 \\
\hline 0.200 & 2761.78 & 2692.52 & 2699.22 \\
\hline $\begin{array}{r}0.225 \\
-\end{array}$ & 2687.10 & 2639.10 & $\begin{array}{r}2593.79 \\
-25\end{array}$ \\
\hline 0.250 & 2547.40 & 2540.59 & 2401.95 \\
\hline
\end{tabular}


Table 4-2. Iso-Value Surface Area (scaled) versus Velocity Magnitude (scaled) (2pages).

\begin{tabular}{|c|c|c|c|}
\hline Comparison Runs & & & \\
\hline $\begin{array}{l}\text { Velocity Magnitude } \\
\qquad(\mathrm{m} / \mathrm{s})\end{array}$ & $\begin{array}{c}\text { Full-Scale } \\
\text { GPM }=10400 / \text { RPM }=0.2 \\
\text { Q3 (sq. m.) }\end{array}$ & $\begin{array}{c}\begin{array}{c}120-\operatorname{lnch} \\
\text { GPM }\end{array}=98 / \text { RPM }=0.77 \\
\text { Q3 (sq. m.) }\end{array}$ & $\begin{array}{c}\text { 43.2-Inch } \\
\text { GPM }=8.6 / \text { RPM }=1.51 \\
\text { Q3 (sq. m.) }\end{array}$ \\
\hline 0.275 & 2372.50 & 2395.46 & 2213.50 \\
\hline 0.300 & 2161.09 & 2214.42 & 2034.55 \\
\hline 0.325 & 1931.98 & 2019.66 & 1833.80 \\
\hline 0.350 & 1746.03 & 1824.75 & 1643.45 \\
\hline 0.375 & 1568.11 & 1635.10 & 1483.81 \\
\hline 0.400 & 1411.88 & 1463.80 & 1340.34 \\
\hline 0.425 & 1272.77 & 1306.91 & 1203.48 \\
\hline 0.450 & 1141.11 & 1145.59 & 1084.12 \\
\hline 0.475 & 1018.58 & 1002.21 & 979.02 \\
\hline 0.500 & 910.44 & 872.48 & 881.03 \\
\hline 0.525 & 808.61 & 762.02 & 788.79 \\
\hline 0.550 & 722.53 & 674.35 & 706.78 \\
\hline 0.575 & 649.08 & 602.60 & 632.82 \\
\hline 0.600 & 586.31 & 545.41 & 576.46 \\
\hline 0.625 & 533.63 & 499.48 & 527.34 \\
\hline 0.650 & 486.96 & 454.63 & 483.16 \\
\hline 0.675 & 446.74 & 414.62 & 441.80 \\
\hline 0.700 & 406.62 & 376.80 & 408.70 \\
\hline
\end{tabular}

Figure 4-3 shows the difference among the three scales, after all scaling is done, as a percent change (percent-change does not indicate magnitude of difference, etc.), which emphasizes the small differences seen in Figure 4-2. Small errors still exist due to the inherent variability of the process as well as small differences in intended and resulting injection velocity at the jet faces (the outflow is a pressure condition, uncoupled with the jet face) in the CFD model. The differences are about $10 \%$ or less, even considering the statistical variation. Therefore, scaling from the 120 -inch scale sensitivity cases will be adequate until individual simulations for full-scale and 43.2-inch scale can be completed or the solid phase added to the CFD model. The data used in Figure 4-3 are listed in Table 4-3. 
Figure 4-3. Distribution of Differences Three Cross-Cases.

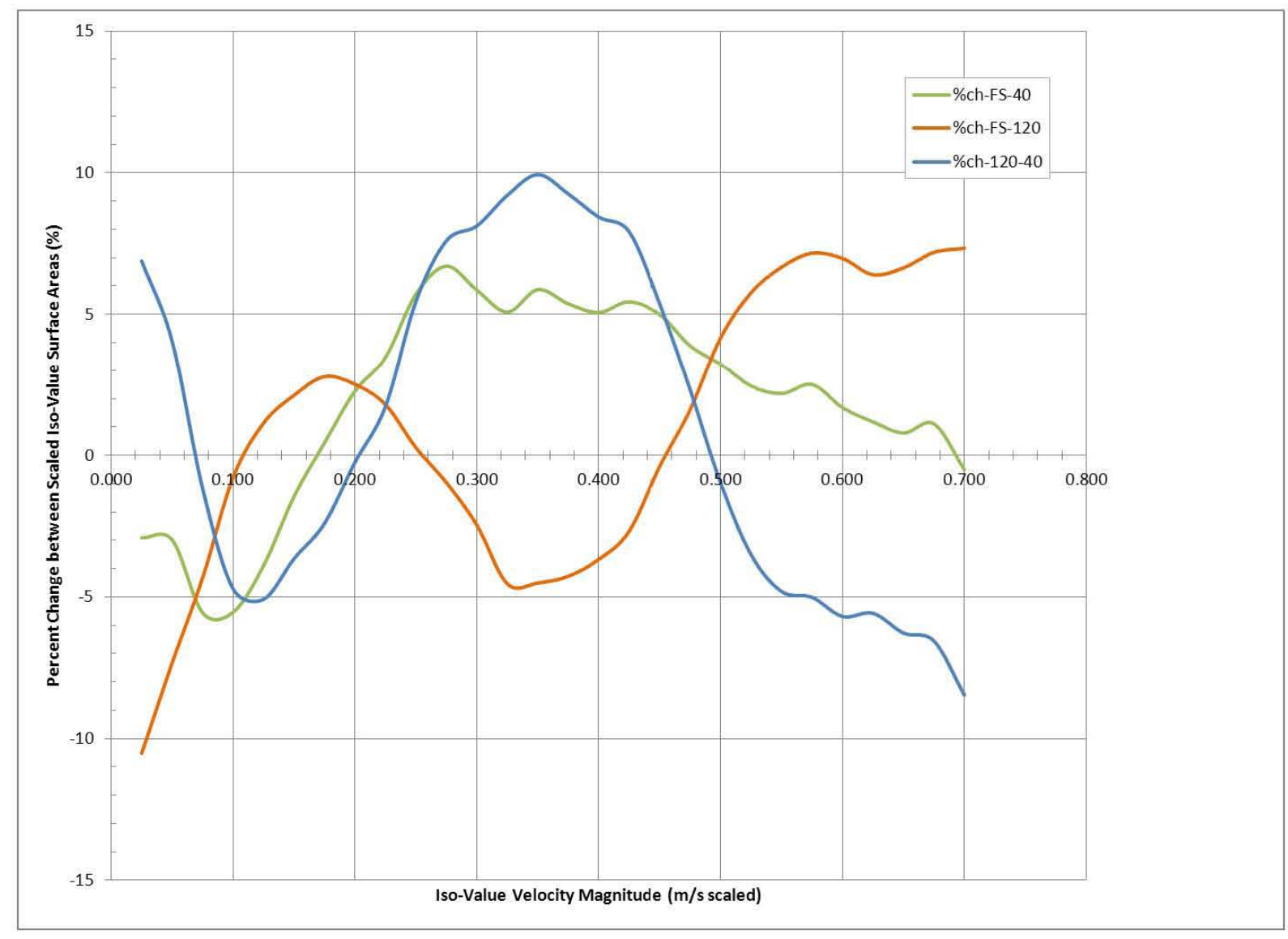

Table 4-3. Percent Change between Comparison Cases (\%) (2 pages).

\begin{tabular}{|c|c|c|c|}
\hline \multicolumn{4}{|c|}{ Calculated from $100^{*}$ (First-Value - Second-Value)/First-Value } \\
\hline $\begin{array}{l}\text { Velocity Magnitude } \\
\qquad(\mathrm{m} / \mathrm{s})\end{array}$ & $\begin{array}{l}\text { Full-Scale vs } \\
43.2-\text { Inch }\end{array}$ & $\begin{array}{l}\text { Full-Scale vs } \\
120 \text {-Inch }\end{array}$ & $\begin{array}{c}\text { 120-Inch vs } \\
\text { 43.2-Inch }\end{array}$ \\
\hline 0.025 & -2.916 & -10.523 & 6.884 \\
\hline 0.050 & -2.987 & -7.332 & 4.048 \\
\hline 0.075 & -5.557 & -4.332 & -1.174 \\
\hline 0.100 & -5.542 & -0.787 & -4.718 \\
\hline 0.125 & -3.899 & 1.131 & -5.088 \\
\hline 0.150 & -1.457 & 2.118 & -3.653 \\
\hline 0.175 & 0.436 & 2.777 & -2.409 \\
\hline 0.200 & 2.266 & 2.508 & -0.249 \\
\hline 0.225 & 3.473 & 1.786 & 1.717 \\
\hline 0.250 & 5.710 & 0.267 & 5.457 \\
\hline 0.275 & 6.702 & -0.968 & 7.596 \\
\hline 0.300 & 5.855 & -2.468 & 8.123 \\
\hline
\end{tabular}


Table 4-3. Percent Change between Comparison Cases (\%) ( 2 pages).

\begin{tabular}{|c|c|c|c|}
\hline \multicolumn{4}{|c|}{ Calculated from $100^{*}$ (First-Value - Second-Value)/First-Value } \\
\hline $\begin{array}{l}\text { Velocity Magnitude } \\
\qquad(\mathrm{m} / \mathrm{s})\end{array}$ & $\begin{array}{l}\text { Full-Scale vs } \\
43.2-\text { Inch }\end{array}$ & $\begin{array}{l}\text { Full-Scale vs } \\
120-\text { Inch }\end{array}$ & $\begin{array}{c}\text { 120-Inch vs } \\
\text { 43.2-Inch }\end{array}$ \\
\hline 0.325 & 5.082 & -4.539 & 9.203 \\
\hline 0.350 & 5.875 & -4.508 & 9.936 \\
\hline 0.375 & 5.376 & -4.272 & 9.253 \\
\hline 0.400 & 5.067 & -3.677 & 8.434 \\
\hline 0.425 & 5.443 & -2.682 & 7.914 \\
\hline 0.450 & 4.994 & -0.393 & 5.366 \\
\hline 0.475 & 3.884 & 1.608 & 2.314 \\
\hline 0.500 & 3.231 & 4.169 & -0.980 \\
\hline 0.525 & 2.451 & 5.761 & -3.513 \\
\hline 0.550 & 2.179 & 6.669 & -4.810 \\
\hline 0.575 & 2.505 & 7.160 & -5.014 \\
\hline 0.600 & 1.679 & 6.975 & -5.694 \\
\hline 0.625 & 1.179 & 6.399 & -5.577 \\
\hline 0.650 & 0.782 & 6.641 & -6.275 \\
\hline 0.675 & 1.106 & 7.190 & -6.555 \\
\hline 0.700 & -0.512 & 7.334 & -8.466 \\
\hline
\end{tabular}

\subsection{Scaling 120-Inch Cases to Full-Scale and 43.2-Inch Scales}

In this section, the 120-inch results are extrapolated to full-scale and 43.2-inch scale by scaling the iso-value surface area, while the iso-value velocity magnitude remains unchanged (but transformed via scaling). The comparison cases discussed in Section 4.2 do not match exactly, because Table 45 and associated figures use straight geometric scaling (used consistently for the 120-inch models), as shown in Equations 2 through 7. Small errors in intended versus actual flow rates in the 120-inch scale are not accounted for (as was done in Section 4.2). This condition makes Table 4-5 and the figures consistent, as all the cases use the same iso-value velocity magnitude mapping, but at odds with Section 4.2, which is addressed in Table 4-4 and Figure 4-4.

Because absolute velocity magnitude is used as a scale, the table has holes again so the curves are shown with symbols since Microsoft Excel seems inadequate to fitting curves through the lines when the values aren't all at the same points on the horizontal axis. 
In Figure 4-4, the same mapping used in Section 4.2 is used to compare extrapolation of the 120inch model in that section with the simulation results for the full-scale and 43.2-inch scales. The data for Figure 4-4 is in Table 4-4.

Figure 4-4. Results at Maximum GPM and Maximum RPM Case (Consistent with Sect. 4.2).

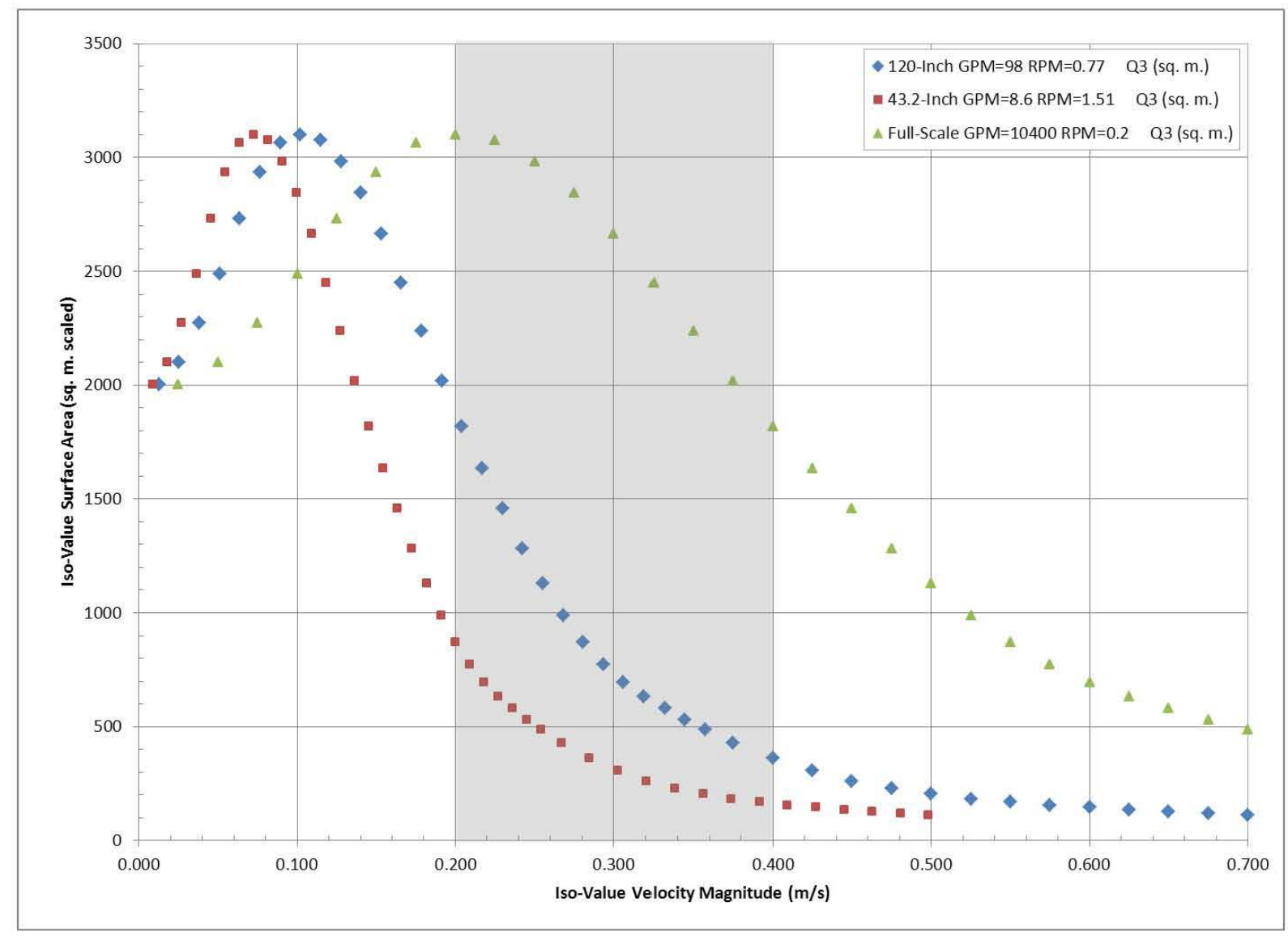

Table 4-4. Iso-Value Surface Area (scaled) versus Velocity Magnitude (4 pages).

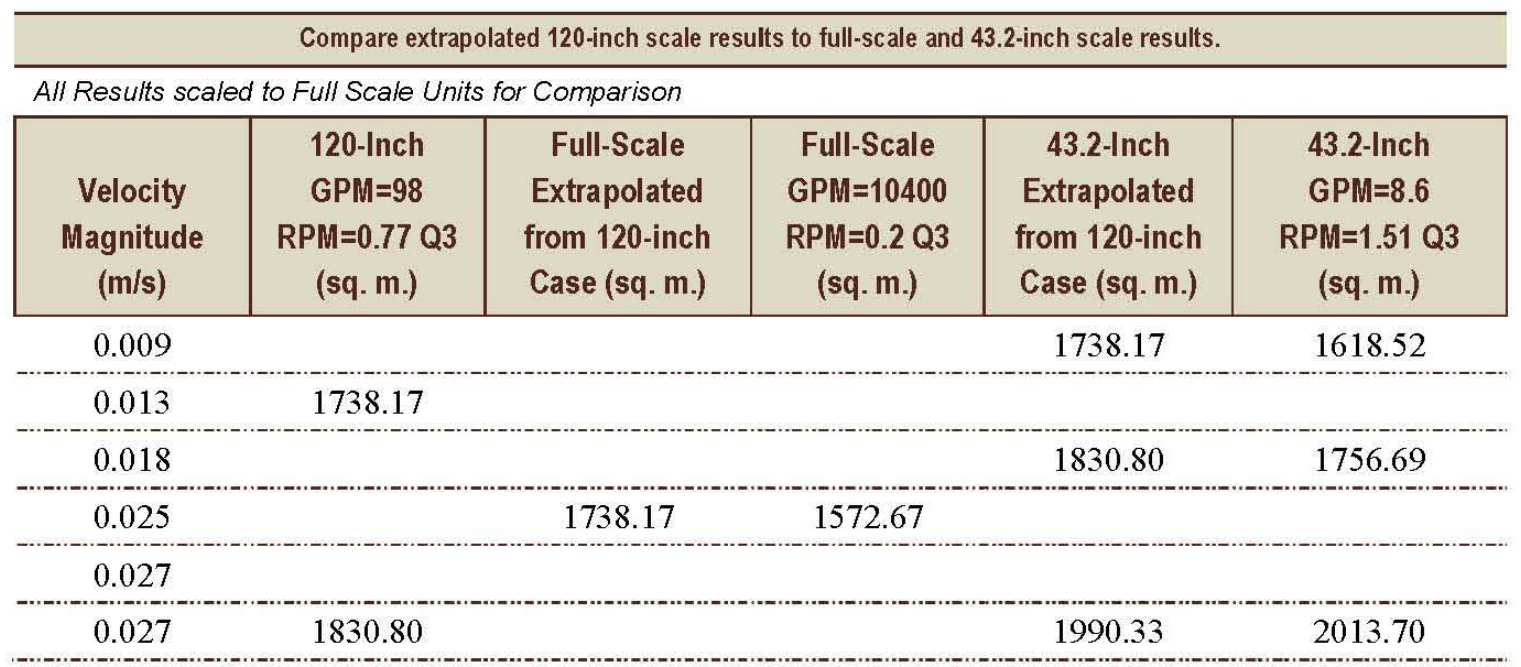


Table 4-4. Iso-Value Surface Area (scaled) versus Velocity Magnitude (4 pages).

\begin{tabular}{|c|c|c|c|c|c|}
\hline \multicolumn{6}{|c|}{ Compare extrapolated 120-inch scale results to full-scale and 43.2-inch scale results. } \\
\hline \multicolumn{6}{|c|}{ All Results scaled to Full Scale Units for Comparison } \\
\hline $\begin{array}{l}\text { Velocity } \\
\text { Magnitude } \\
(\mathrm{m} / \mathrm{s})\end{array}$ & $\begin{array}{c}\text { 120-Inch } \\
\text { GPM=98 } \\
\text { RPM }=0.77 \mathrm{Q} 3 \\
\text { (sq. m.) }\end{array}$ & $\begin{array}{c}\text { Full-Scale } \\
\text { Extrapolated } \\
\text { from } 120 \text {-inch } \\
\text { Case (sq. m.) }\end{array}$ & $\begin{array}{c}\text { Full-Scale } \\
\text { GPM }=10400 \\
\text { RPM }=0.2 \mathrm{Q} 3 \\
\text { (sq. m.) }\end{array}$ & $\begin{array}{c}\text { 43.2-Inch } \\
\text { Extrapolated } \\
\text { from 120-inch } \\
\text { Case (sq. m.) }\end{array}$ & $\begin{array}{c}\text { 43.2-Inch } \\
\text { GPM=8.6 } \\
\text { RPM=1.51 Q3 } \\
\text { (sq. m.) }\end{array}$ \\
\hline 0.036 & & & & 2193.37 & 2296.86 \\
\hline 0.040 & 1990.33 & & & & \\
\hline 0.045 & & & & 2407.49 & 2529.98 \\
\hline 0.050 & & 1830.80 & 1705.74 & & \\
\hline 0.053 & 2193.37 & & & & \\
\hline 0.055 & & & & 2576.89 & 2671.02 \\
\hline 0.064 & & & & 2666.18 & 2730.40 \\
\hline 0.067 & 2407.49 & & & & \\
\hline 0.073 & & & & 2692.52 & 2699.22 \\
\hline 0.075 & & 1990.33 & 1907.68 & & \\
\hline 0.080 & 2576.89 & & & & \\
\hline 0.082 & & & & 2639.10 & 2593.79 \\
\hline 0.091 & & & & 2540.59 & 2401.95 \\
\hline 0.093 & 2666.18 & & & & \\
\hline 0.100 & & 2193.37 & 2176.25 & 2395.46 & 2213.50 \\
\hline 0.106 & 2692.52 & & & & \\
\hline 0.109 & & & & 2214.42 & 2034.55 \\
\hline 0.118 & & & & 2019.66 & 1833.80 \\
\hline 0.120 & 2639.10 & & & & \\
\hline 0.125 & & 2407.49 & 2435.04 & & \\
\hline 0.127 & & & & 1824.75 & 1643.45 \\
\hline 0.133 & 2540.59 & & & & \\
\hline 0.136 & & & & 1635.10 & 1483.81 \\
\hline 0.145 & & & & 1463.80 & 1340.34 \\
\hline 0.146 & 2395.46 & & & & \\
\hline 0.150 & & 2576.89 & 2632.66 & & \\
\hline 0.154 & & & & 1306.91 & 1203.48 \\
\hline 0.160 & 2214.42 & & & & \\
\hline 0.164 & & & & 1145.59 & 1084.12 \\
\hline 0.173 & 2019.66 & & & 1002.21 & 979.02 \\
\hline 0.175 & & 2666.18 & 2742.35 & & \\
\hline 0.182 & & & & 872.48 & 881.03 \\
\hline
\end{tabular}


Table 4-4. Iso-Value Surface Area (scaled) versus Velocity Magnitude (4 pages).

\begin{tabular}{|c|c|c|c|c|c|}
\hline \multicolumn{6}{|c|}{ Compare extrapolated 120 -inch scale results to full-scale and 43.2-inch scale results. } \\
\hline \multicolumn{6}{|c|}{ All Results scaled to Full Scale Units for Comparison } \\
\hline $\begin{array}{l}\text { Velocity } \\
\text { Magnitude } \\
(\mathrm{m} / \mathrm{s})\end{array}$ & $\begin{array}{c}120-\text { Inch } \\
\text { GPM=98 } \\
\text { RPM=0.77 Q3 } \\
\text { (sq. m.) }\end{array}$ & $\begin{array}{c}\text { Full-Scale } \\
\text { Extrapolated } \\
\text { from } 120 \text {-inch } \\
\text { Case (sq. m.) }\end{array}$ & $\begin{array}{c}\text { Full-Scale } \\
\text { GPM }=10400 \\
\text { RPM }=0.2 \mathrm{Q} 3 \\
\text { (sq. m.) }\end{array}$ & $\begin{array}{l}\text { 43.2-Inch } \\
\text { Extrapolated } \\
\text { from } 120 \text {-inch } \\
\text { Case (sq. m.) }\end{array}$ & $\begin{array}{c}\text { 43.2-Inch } \\
\text { GPM=8.6 } \\
\text { RPM=1.51 Q3 } \\
\text { (sq. m.) }\end{array}$ \\
\hline 0.186 & 1824.75 & & & & \\
\hline 0.191 & & & & 762.02 & 788.79 \\
\hline 0.200 & 1635.10 & 2692.52 & 2761.78 & 674.35 & 706.78 \\
\hline 0.209 & & & & 602.60 & 632.82 \\
\hline 0.213 & 1463.80 & & & & \\
\hline 0.218 & & & & 545.41 & 576.46 \\
\hline 0.225 & & 2639.10 & 2687.10 & & \\
\hline 0.226 & 1306.91 & & & & \\
\hline 0.227 & & & & 499.48 & 527.34 \\
\hline 0.236 & & & & 454.63 & 483.16 \\
\hline 0.240 & 1145.59 & & & & \\
\hline 0.245 & & & & 414.62 & 441.80 \\
\hline 0.250 & & 2540.59 & 2547.40 & & \\
\hline 0.253 & 1002.21 & & & & \\
\hline 0.254 & & & & 376.80 & 408.70 \\
\hline 0.256 & & & & 370.82 & \\
\hline 0.266 & 872.48 & & & & \\
\hline 0.273 & & & & 314.64 & \\
\hline 0.275 & & 2395.46 & 2372.50 & & \\
\hline 0.279 & 762.02 & & & & 331.95 \\
\hline 0.290 & & & & 265.70 & \\
\hline 0.293 & 674.35 & & & & \\
\hline 0.300 & & 2214.42 & 2161.09 & & \\
\hline 0.306 & 602.60 & & & & 263.97 \\
\hline 0.307 & & & & 226.08 & \\
\hline 0.319 & 545.41 & & & & \\
\hline 0.324 & & & & 198.35 & \\
\hline 0.325 & & 2019.66 & 1931.98 & & \\
\hline 0.333 & 499.48 & & & & 214.92 \\
\hline 0.341 & & & & 176.60 & \\
\hline 0.346 & 454.63 & & & & \\
\hline 0.350 & & 1824.75 & 1746.03 & & \\
\hline
\end{tabular}


Table 4-4. Iso-Value Surface Area (scaled) versus Velocity Magnitude (4 pages).

\begin{tabular}{|c|c|c|c|c|c|}
\hline \multicolumn{6}{|c|}{ Compare extrapolated 120 -inch scale results to full-scale and 43.2 -inch scale results. } \\
\hline \multicolumn{6}{|c|}{ All Results scaled to Full Scale Units for Comparison } \\
\hline $\begin{array}{l}\text { Velocity } \\
\text { Magnitude } \\
(\mathrm{m} / \mathrm{s})\end{array}$ & $\begin{array}{c}120-\text { Inch } \\
\text { GPM=98 } \\
\text { RPM=0.77 Q3 } \\
\text { (sq. m.) }\end{array}$ & $\begin{array}{l}\text { Full-Scale } \\
\text { Extrapolated } \\
\text { from } 120 \text {-inch } \\
\text { Case (sq. m.) }\end{array}$ & $\begin{array}{c}\text { Full-Scale } \\
\text { GPM }=10400 \\
\text { RPM }=0.2 \mathrm{Q} 3 \\
\text { (sq. m.) }\end{array}$ & $\begin{array}{c}\text { 43.2-Inch } \\
\text { Extrapolated } \\
\text { from } 120 \text {-inch } \\
\text { Case (sq. m.) }\end{array}$ & $\begin{array}{c}\text { 43.2-Inch } \\
\text { GPM=8.6 } \\
\text { RPM=1.51 Q3 } \\
\text { (sq. m.) }\end{array}$ \\
\hline 0.358 & & & & 158.91 & 186.63 \\
\hline 0.359 & 414.62 & & & & \\
\hline 0.373 & 376.80 & & & & \\
\hline 0.375 & 370.82 & 1635.10 & 1568.11 & & \\
\hline 0.376 & & & & 145.71 & 163.51 \\
\hline 0.393 & & & & 134.01 & \\
\hline 0.400 & 314.64 & 1463.80 & 1411.88 & & \\
\hline 0.410 & & & & 125.32 & 145.27 \\
\hline 0.425 & 265.70 & 1306.91 & 1272.77 & & \\
\hline 0.427 & & & & 116.79 & 130.69 \\
\hline 0.444 & & & & 109.72 & \\
\hline 0.450 & 226.08 & 1145.59 & 1141.11 & & \\
\hline 0.461 & & & & 102.53 & 119.34 \\
\hline 0.475 & 198.35 & 1002.21 & 1018.58 & & \\
\hline 0.478 & & & & 96.30 & 109.55 \\
\hline 0.500 & 176.60 & 872.48 & 910.44 & & \\
\hline 0.525 & 158.91 & 762.02 & 808.61 & & 100.80 \\
\hline 0.550 & 145.71 & 674.35 & 722.53 & & 92.34 \\
\hline 0.575 & 134.01 & 602.60 & 649.08 & & 84.60 \\
\hline 0.600 & 125.32 & 545.41 & 586.31 & & 77.56 \\
\hline 0.625 & 116.79 & 499.48 & 533.63 & & 70.41 \\
\hline 0.650 & 109.72 & 454.63 & 486.96 & & 64.68 \\
\hline 0.675 & 102.53 & 414.62 & 446.74 & & 59.90 \\
\hline 0.700 & 96.30 & 376.80 & 406.62 & & 55.86 \\
\hline
\end{tabular}


Figure 4-5 shows the frequency analogy-shift with scale as the scaled 120-inch tank results are transformed to the full-scale and 43.2-inch scale cases at the highest flow rate and fastest pump rotational rate values used for comparison with actual CFD simulations. The values for each scale are listed in the legend. The legend items with - ext are the scaled results and the legend items with Q3 or Q3s are the actual model results. The close correlation between the scaled results and the modeled results demonstrate the functionality of scaling results based on the 120-inch scale model.

Figure 4-5. Extrapolated versus Simulated.

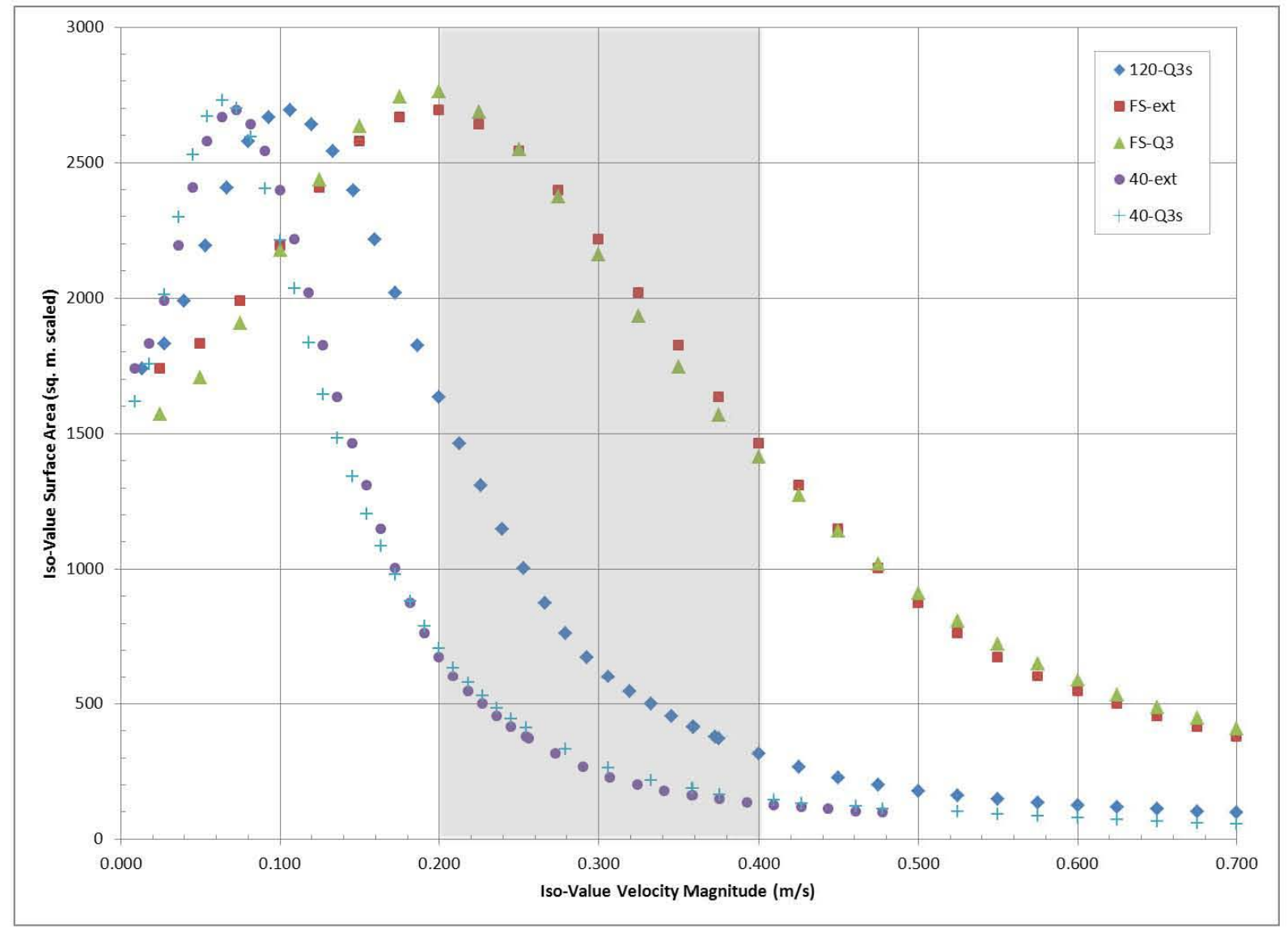


In Figure 4-6, the matching cases for maximum flow rate and minimum rotational rate are shown. The effect is a subtle shift in the peaks toward lower frequency (i.e. iso-value velocity magnitude). The peaks also become slightly sharper.

Figure 4-6. Maximum GPM and Minimum RPM Case.

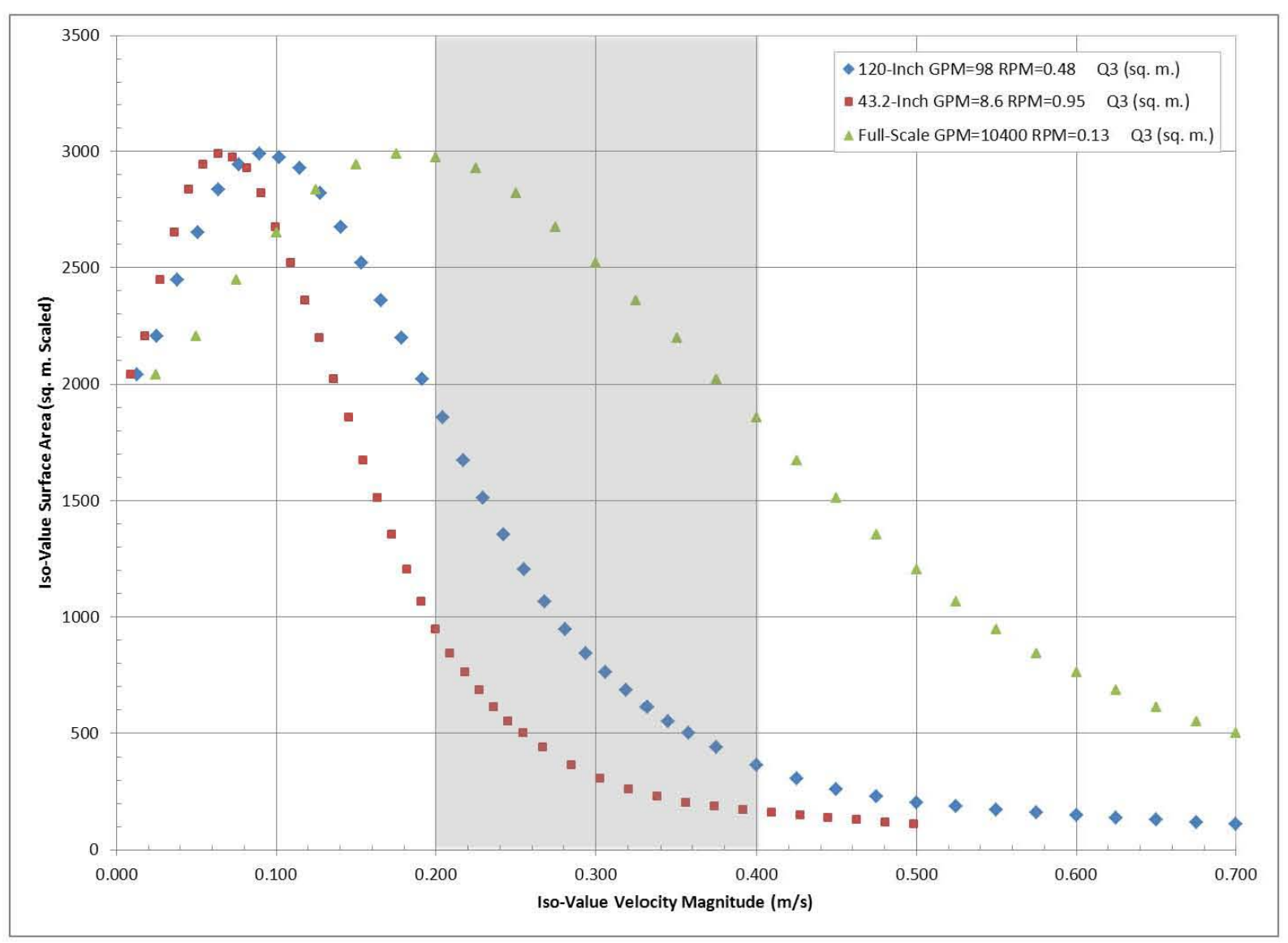


Figure 4-7 shows the medium flow rate, maximum pump rotational rate case, which also emphasizes the leftward shift of the peaks as flow rate decreases. This shift means that the volume of the tank excited to high velocity has decreased and more fluid is circulating at lower average velocities. The magnitude of the peak has fallen as well.

Figure 4-7. Medium GPM and Maximum RPM Case

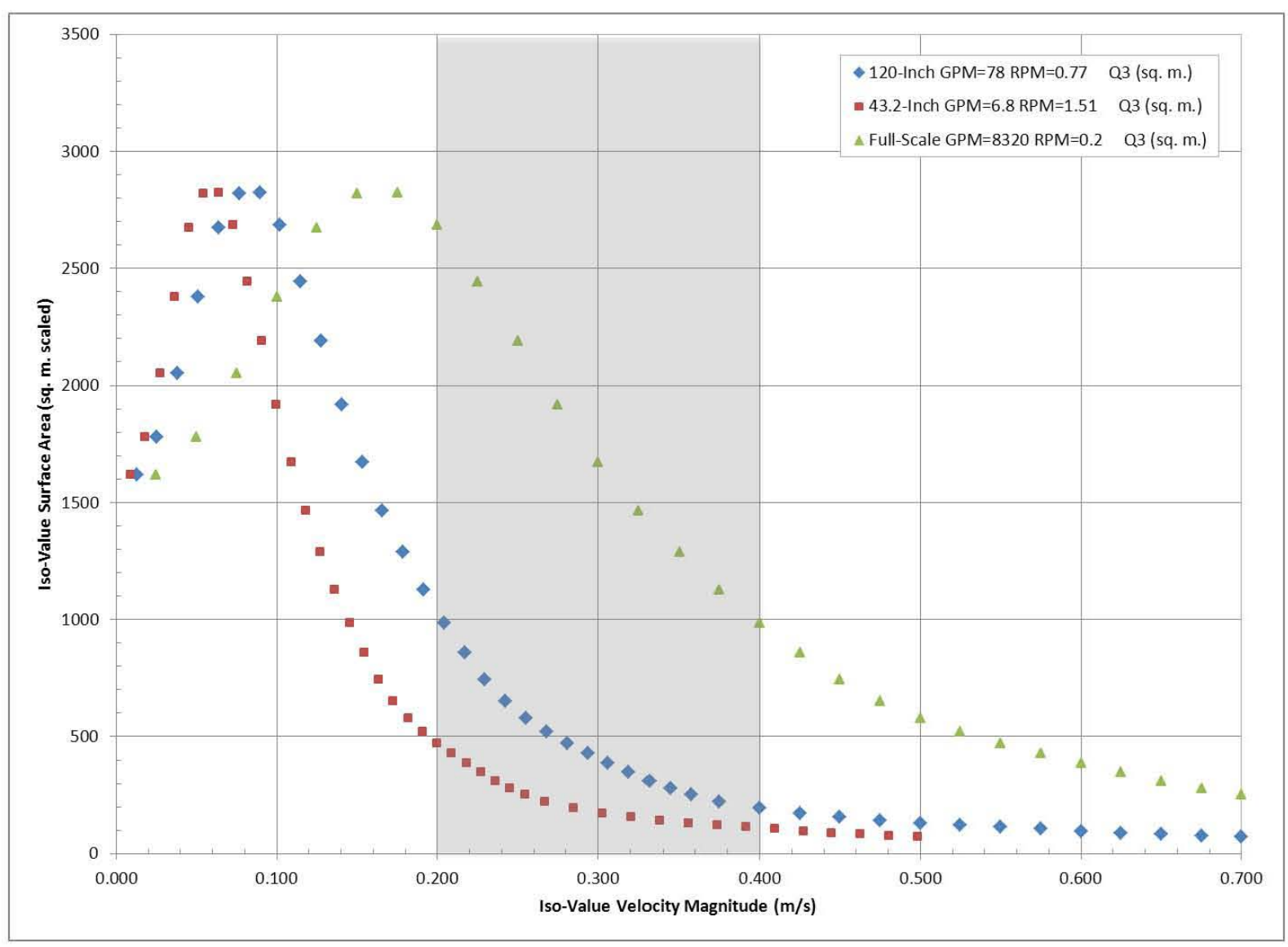


Figure 4-8 shows the effect of reduction in rotation speed when flow rate is at the medium setting. The interesting thing to note in the figure is that more energy is injected in the higher iso-value velocity magnitude level. This high energy can be seen by noting the level at which the full-scale curve crosses the $0.4 \mathrm{~m} / \mathrm{s}$ line in Figure 4-7 versus Figure 4-8. The higher RPM crosses at a lower value of iso-value surface area. Therefore, under these conditions, a slower rotation speed helps spread fluid velocity into more volume of the tank.

Figure 4-8. Medium GPM and Minimum RPM Case.

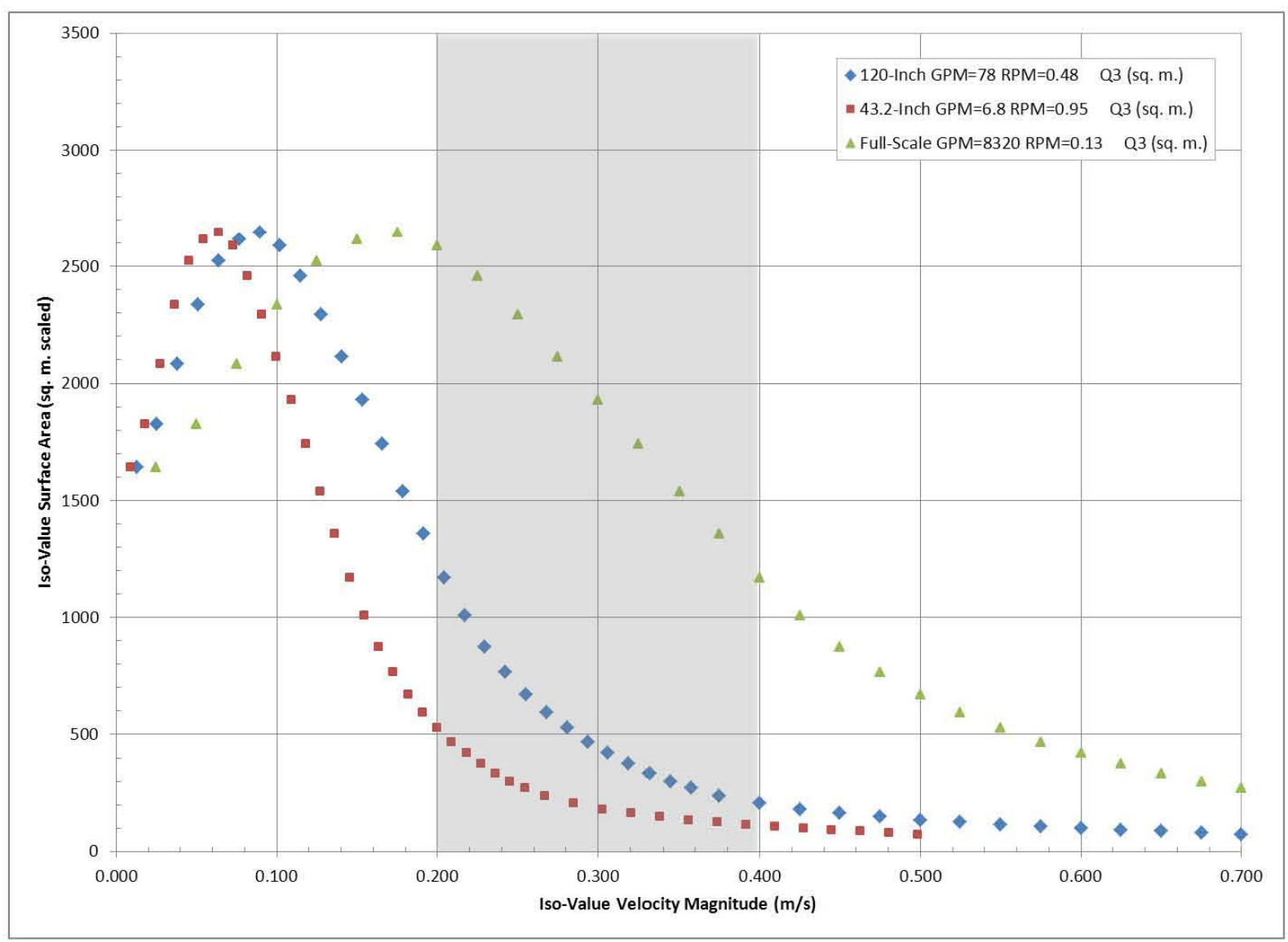


Figure 4-9 and Figure 4-10 show the results of lowering the flow rate to its minimum. Once again, the zero crossing of the full-scale curve at a value of $0.2 \mathrm{~m} / \mathrm{s}$ shows that the lower rotation speed is more effective at pushing higher fluid velocities into the interior. The peaks continue to shift leftward. However, the peaks are quite high because most of the energy put in at the lower flow rate is settling at a relatively low iso-value velocity magnitude.

Figure 4-9. Minimum GPM and Maximum RPM Case.

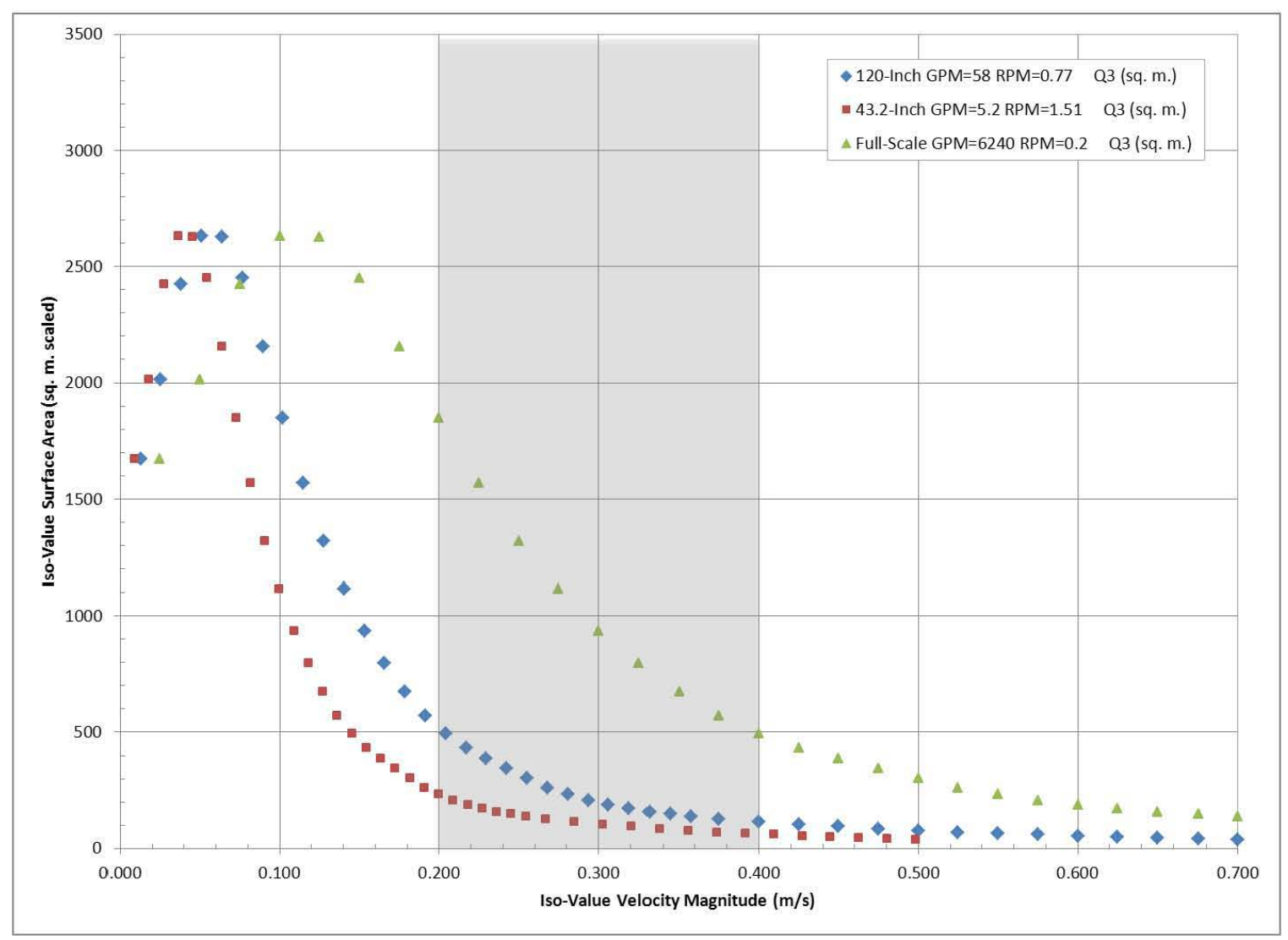


Figure 4-10. Minimum GPM and Minimum RPM Case.

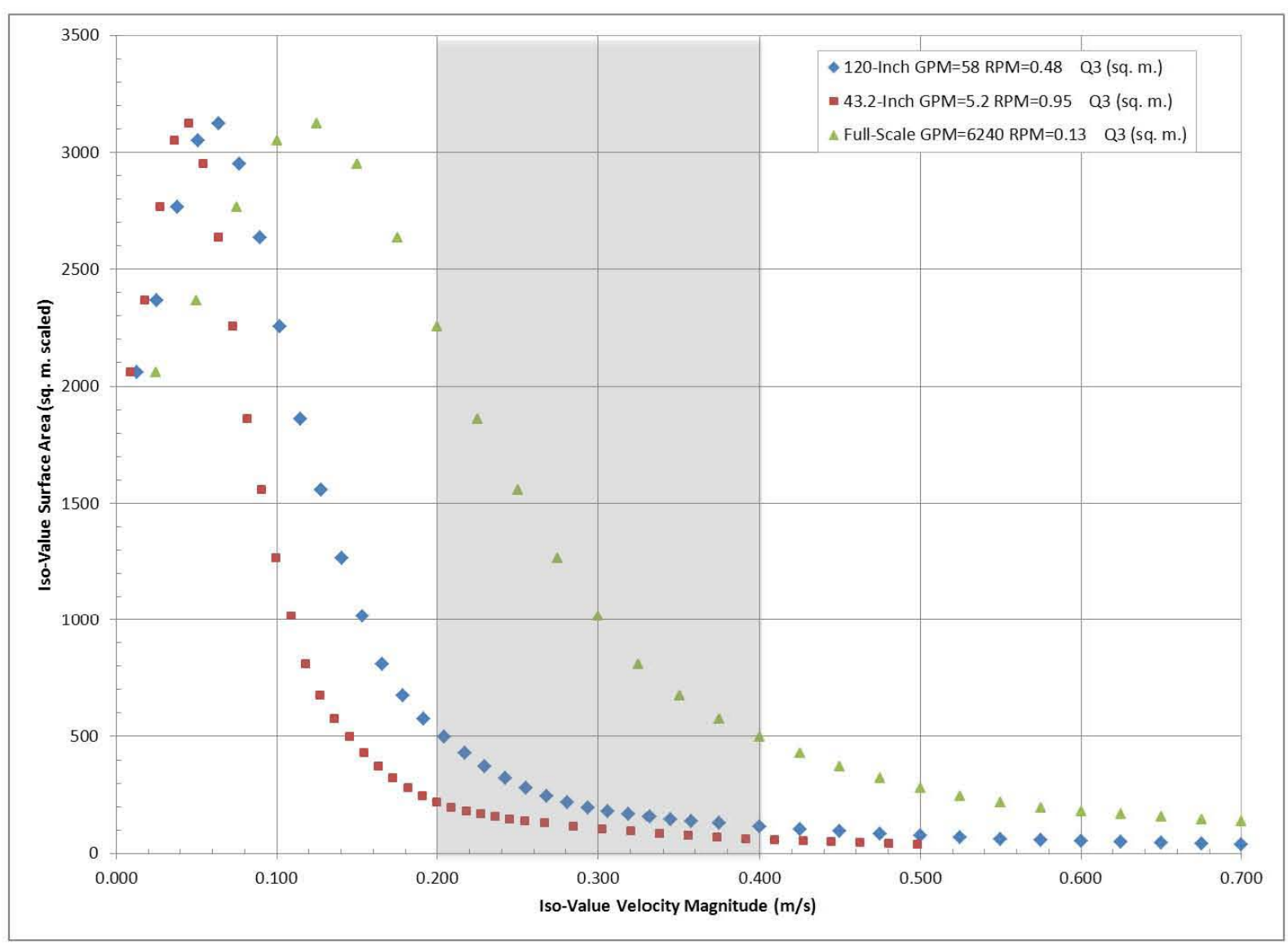

All of the results shown in Figure 4-6 through Figure 4-10 are listed in Table 4-5. There are gaps in the table due to the mapping of iso-value velocity magnitude between the scales. Specifically, the first 28 values of each column represent perfect scaling. This scaling takes the 120-inch model up to the equivalent of 0.7 iso-value velocity magnitude at full-scale. The tail of the 43.2 -inch stops short of this value because values beyond $0.7 \mathrm{~m} / \mathrm{s}$ would need to be computed in the 120 -inch model before it could be extended to higher values in the 43.2-inch scale. However, the tail is essentially flat in this region and has been omitted for it and the full-scale beyond 0.7. In contrast, the results reported in Section 4.2, from actual simulations, has each scale extend to an iso-value velocity magnitude of $0.7 \mathrm{~m} / \mathrm{s}$ in the maximum flow rate, minimum rotation rate case for comparison purposes explained in that section. This extended region was possible because actual FLUENT ${ }^{\circledR}$ edits could be run to provide results at higher values for the 43.2-inch case.

In conclusion, results from the 120-inch scale CFD model can be depicted at the 43.2-inch scale and full-scale with adequate accuracy without actually running the simulators at the other scales. Figure 4-6 through Figure 4-10 showed each of the cases in all scales separated by GPM-RPM pairs. 
Table 4-5. Iso-Value Surface Area (scaled) versus Velocity Magnitude (4 pages).

\begin{tabular}{|c|c|c|c|c|c|c|c|c|c|c|c|c|c|c|c|c|c|c|}
\hline \multicolumn{19}{|c|}{ All 120-Inch Runs scaled to Full Scale and 43.2-Inch } \\
\hline Velocity & $\begin{array}{l}\text { 120-Inch } \\
\text { GPM=98 }\end{array}$ & $\begin{array}{l}\text { 120-Inch } \\
\text { GPM=98 }\end{array}$ & $\begin{array}{l}120-\operatorname{Inch} \\
\text { GPM=78 }\end{array}$ & $\begin{array}{l}\text { 120-Inch } \\
\text { GPM=78 }\end{array}$ & $\begin{array}{l}120-\operatorname{Inch} \\
\text { GPM=58 }\end{array}$ & $\begin{array}{l}\text { 120-Inch } \\
\text { GPM=58 }\end{array}$ & $\begin{array}{l}\text { 43.2-Inch } \\
\text { GPM=8.6 }\end{array}$ & $\begin{array}{l}\text { 43.2-Inch } \\
\text { GPM=8.6 }\end{array}$ & $\begin{array}{l}\text { 43.2-Inch } \\
\text { GPM }=6.8\end{array}$ & $\begin{array}{l}\text { 43.2-Inch } \\
\text { GPM=6.8 }\end{array}$ & $\begin{array}{l}\text { 43.2-Inch } \\
\text { GPM=5.2 }\end{array}$ & $\begin{array}{l}\text { 43.2-Inch } \\
\text { GPM=5.2 }\end{array}$ & $\begin{array}{l}\text { Full-Scale } \\
\text { GPM=10400 }\end{array}$ & $\begin{array}{l}\text { Full-Scale } \\
\text { GPM=10400 }\end{array}$ & $\begin{array}{l}\text { Full-Scale } \\
\text { GPM=8320 }\end{array}$ & $\begin{array}{l}\text { Full-Scale } \\
\text { GPM }=8320\end{array}$ & $\begin{array}{l}\text { Full-Scale } \\
\text { GPM }=6240\end{array}$ & $\begin{array}{l}\text { Full-Scale } \\
\text { GPM }=6240\end{array}$ \\
\hline Magnitud & $\mathrm{RPM}=0.77$ & $\mathrm{RPM}=0.48$ & $\mathrm{RPM}=0.77$ & $\mathrm{RPM}=0.48$ & $\mathrm{RPM}=0.77$ & $\mathrm{RPM}=0.48$ & $\mathrm{RPM}=1.51$ & $\mathrm{RPM}=0.95$ & $\mathrm{RPM}=1.51$ & $\mathrm{RPM}=0.95$ & $\mathrm{RPM}=1.51$ & $\mathrm{RPM}=0.95$ & $\mathrm{RPM}=0.2$ & $R P M=0.13$ & $\mathrm{RPM}=0.2$ & $\mathrm{RPM}=0.13$ & $\mathrm{RPM}=0.2$ & $R P M=0.13$ \\
\hline$e(\mathrm{~m} / \mathrm{s})$ & Q3 (sq. m.) & $Q 3$ (sq. m.) & Q3 (sq. m.) & Q3 (sq. m.) & Q3 (sq. m.) & Q3 (sq. m.) & Q3 (sq. m.) & Q3 (sq. m.) & Q3 (sq. m.) & Q3 (sq. m.) & Q3 (sq. m.) & Q3 (sq. m.) & Q3 (sq. m.) & Q3 (sq. m.) & Q3 (sq. m.) & Q3 (sq. m.) & Q3 (sq. m.) & Q3 (sq. m.) \\
\hline 0.009 & & & & & & & 2004.013 & 2038.907 & 1619.586 & 1641.164 & 1670.774 & 2059.653 & & & & & & \\
\hline 0.013 & 2004.013 & 2038.907 & 1619.586 & 1641.164 & 1670.774 & 2059.653 & & & & & & & & & & & & \\
\hline 0.018 & & & & & & & 2100.903 & 2206.633 & 1778.515 & 1827.187 & 2013.572 & 2366.600 & & & & & & \\
\hline 0.025 & & & & & & & & & & & & & 2004.013 & 2038.907 & 1619.586 & 1641.164 & 1670.774 & 2059.653 \\
\hline 0.026 & 2100.903 & 2206.633 & 1778.515 & 1827.187 & 2013.572 & 2366.600 & & & & & & & & & & & & \\
\hline 0.027 & & & & & & & 2272.750 & 2448.804 & 2053.820 & 2081.506 & 2422.787 & 2764.850 & & & & & & \\
\hline 0.036 & & & & & & & 2487.351 & 2652.104 & 2379.165 & 2335.054 & 2630.955 & 3050.622 & & & & & & \\
\hline 0.038 & 2272.750 & 2448.804 & 2053.820 & 2081.506 & 2422.787 & 2764.850 & & & & & & & & & & & & \\
\hline 0.045 & & & & & & & 2731.388 & 2836.429 & 2674.941 & 2525.109 & 2626.460 & 3122.695 & & & & & & \\
\hline 0.050 & & & & & & & & & & & & & 2100.903 & 2206.633 & 1778.515 & 1827.187 & 2013.572 & 2366.600 \\
\hline 0.051 & 2487.351 & 2652.104 & 2379.165 & 2335.054 & 2630.955 & 3050.622 & & & & & & & & & & & & \\
\hline 0.055 & & & & & & & 2936.583 & 2944.086 & 2820.650 & 2615.650 & 2449.284 & 2951.571 & & & & & & \\
\hline 0.064 & & & & & & & 3063.644 & 2989.847 & 2823.775 & 2645.076 & 2156.496 & 2636.151 & & & & & & \\
\hline 0.064 & 2731.388 & 2836.429 & 2674.941 & 2525.109 & 2626.460 & 3122.695 & & & & & & & & & & & & \\
\hline 0.073 & & & & & & & 3100.494 & 2972.652 & 2683.372 & 2588.980 & 1848.935 & 2255.114 & & & & & & \\
\hline 0.075 & & & & & & & & & & & & & 2272.750 & 2448.804 & 2053.820 & 2081.506 & 2422.787 & 2764.850 \\
\hline 0.077 & 2936.583 & 2944.086 & 2820.650 & 2615.650 & 2449.284 & 2951.571 & & & & & & & & & & & & \\
\hline 0.082 & & & & & & & 3075.872 & 2927.400 & 2441.879 & 2459.173 & 1568.878 & 1860.724 & & & & & & \\
\hline 0.089 & 3063.644 & 2989.847 & 2823.775 & 2645.076 & 2156.496 & 2636.151 & & & & & & & & & & & & \\
\hline 0.091 & & & & & & & 2981.890 & 2819.141 & 2188.980 & 2295.268 & 1318.109 & 1557.669 & & & & & & \\
\hline 0.100 & & & & & & & 2845.865 & 2673.485 & 1916.307 & 2114.857 & 1114.370 & 1266.278 & & & & & & \\
\hline 0.100 & & & & & & & & & & & & & 2487.351 & 2652.104 & 2379.165 & 2335.054 & 2630.955 & 3050.622 \\
\hline 0.102 & 3100.494 & 2972.652 & 2683.372 & 2588.980 & 1848.935 & 2255.114 & & & & & & & & & & & & \\
\hline 0.109 & & & & & & & 2664.136 & 2521.558 & 1670.593 & 1928.195 & 936.676 & 1015.257 & & & & & & \\
\hline 0.115 & 3075.872 & 2927.400 & 2441.879 & 2459.173 & 1568.878 & 1860.724 & & & & & & & & & & & & \\
\hline 0.118 & & & & & & & 2449.202 & 2359.744 & 1465.906 & 1740.923 & 796.247 & 809.417 & & & & & & \\
\hline 0.125 & & & & & & & & & & & & & 2731.388 & 2836.429 & 2674.941 & 2525.109 & 2626.460 & 3122.695 \\
\hline 0.127 & & & & & & & 2237.975 & 2197.827 & 1289.710 & 1538.818 & 673.720 & 675.476 & & & & & & \\
\hline 0.128 & 2981.890 & 2819.141 & 2188.980 & 2295.268 & 1318.109 & 1557.669 & & & & & & & & & & & & \\
\hline 0.136 & & & & & & & 2020.330 & 2019.503 & 1128.899 & 1355.902 & 570.953 & 573.669 & & & & & & \\
\hline 0.140 & 2845.865 & 2673.485 & 1916.307 & 2114.857 & 1114.370 & 1266.278 & & & & & & & & & & & & \\
\hline 0.145 & & & & & & & 1816.844 & 1854.823 & 983.610 & 1170.027 & 493.817 & 496.397 & & & & & & \\
\hline
\end{tabular}


Table 4-5. Iso-Value Surface Area (scaled) versus Velocity Magnitude (4 pages).

\begin{tabular}{|c|c|c|c|c|c|c|c|c|c|c|c|c|c|c|c|c|c|c|}
\hline \multicolumn{19}{|c|}{ All 120-Inch Runs scaled to Full Scale and 43.2-Inch } \\
\hline Velocity & $\begin{array}{l}\text { 120-Inch } \\
\text { GPM=98 }\end{array}$ & $\begin{array}{l}\text { 120-Inch } \\
\text { GPM=98 }\end{array}$ & $\begin{array}{l}120-\operatorname{Inch} \\
\text { GPM=78 }\end{array}$ & $\begin{array}{l}\text { 120-Inch } \\
\text { GPM=78 }\end{array}$ & $\begin{array}{l}\text { 120-Inch } \\
\text { GPM=58 }\end{array}$ & $\begin{array}{l}\text { 120-Inch } \\
\text { GPM=58 }\end{array}$ & $\begin{array}{l}\text { 43.2-Inch } \\
\text { GPM=8.6 }\end{array}$ & $\begin{array}{l}\text { 43.2-Inch } \\
\text { GPM=8.6 }\end{array}$ & $\begin{array}{l}43.2-\operatorname{Inch} \\
\text { GPM=6.8 }\end{array}$ & $\begin{array}{l}\text { 43.2-Inch } \\
\text { GPM=6.8 }\end{array}$ & $\begin{array}{l}\text { 43.2-Inch } \\
\text { GPM=5.2 }\end{array}$ & $\begin{array}{l}\text { 43.2-Inch } \\
\text { GPM=5.2 }\end{array}$ & $\begin{array}{l}\text { Full-Scale } \\
\text { GPM=10400 }\end{array}$ & $\begin{array}{l}\text { Full-Scale } \\
\text { GPM=10400 }\end{array}$ & $\begin{array}{l}\text { Full-Scale } \\
\text { GPM=8320 }\end{array}$ & $\begin{array}{l}\text { Full-Scale } \\
\text { GPM }=8320\end{array}$ & $\begin{array}{l}\text { Full-Scale } \\
\text { GPM }=6240\end{array}$ & $\begin{array}{l}\text { Full-Scale } \\
\text { GPM }=6240\end{array}$ \\
\hline Magnitud & $\mathrm{RPM}=0.77$ & $\mathrm{RPM}=0.48$ & $\mathrm{RPM}=0.77$ & $\mathrm{RPM}=0.48$ & $\mathrm{RPM}=0.77$ & $\mathrm{RPM}=0.48$ & $\mathrm{RPM}=1.51$ & $\mathrm{RPM}=0.95$ & $\mathrm{RPM}=1.51$ & $\mathrm{RPM}=0.95$ & $\mathrm{RPM}=1.51$ & $\mathrm{RPM}=0.95$ & $\mathrm{RPM}=0.2$ & $R P M=0.13$ & $\mathrm{RPM}=0.2$ & $\mathrm{RPM}=0.13$ & $\mathrm{RPM}=0.2$ & $R P M=0.13$ \\
\hline$e(\mathrm{~m} / \mathrm{s})$ & Q3 (sq. m.) & $Q 3$ (sq. m.) & Q3 (sq. m.) & Q3 (sq. m.) & Q3 (sq. m.) & Q3 (sq. m.) & Q3 (sq. m.) & Q3 (sq. m.) & Q3 (sq. m.) & Q3 (sq. m.) & Q3 (sq. m.) & Q3 (sq. m.) & Q3 (sq. m.) & Q3 (sq. m.) & Q3 (sq. m.) & Q3 (sq. m.) & Q3 (sq. m.) & Q3 (sq. m.) \\
\hline 0.150 & & & & & & & & & & & & & 2936.583 & 2944.086 & 2820.650 & 2615.650 & 2449.284 & 2951.571 \\
\hline 0.153 & 2664.136 & 2521.558 & 1670.593 & 1928.195 & 936.676 & 1015.257 & & & & & & & & & & & & \\
\hline 0.154 & & & & & & & 1633.914 & 1672.361 & 860.001 & 1008.154 & 433.109 & 428.860 & & & & & & \\
\hline 0.164 & & & & & & & 1458.616 & 1512.702 & 742.865 & 874.848 & 387.016 & 370.252 & & & & & & \\
\hline 0.166 & 2449.202 & 2359.744 & 1465.906 & 1740.923 & 796.247 & 809.417 & & & & & & & & & & & & \\
\hline 0.173 & & & & & & & 1283.875 & 1354.235 & 650.569 & 767.708 & 345.527 & 322.196 & & & & & & \\
\hline 0.175 & & & & & & & & & & & & & 3063.644 & 2989.847 & 2823.775 & 2645.076 & 2156.496 & 2636.151 \\
\hline 0.179 & 2237.975 & 2197.827 & 1289.710 & 1538.818 & 673.720 & 675.476 & & & & & & & & & & & & \\
\hline 0.182 & & & & & & & 1128.435 & 1203.066 & 579.446 & 671.124 & 301.031 & 280.167 & & & & & & \\
\hline 0.191 & & & & & & & 986.651 & 1065.039 & 521.642 & 594.939 & 261.178 & 245.049 & & & & & & \\
\hline 0.191 & 2020.330 & 2019.503 & 1128.899 & 1355.902 & 570.953 & 573.669 & & & & & & & & & & & & \\
\hline 0.200 & & & & & & & 869.717 & 948.068 & 470.747 & 528.521 & 232.213 & 217.064 & & & & & & \\
\hline 0.200 & & & & & & & & & & & & & 3100.494 & 2972.652 & 2683.372 & 2588.980 & 1848.935 & 2255.114 \\
\hline 0.204 & 1816.844 & 1854.823 & 983.610 & 1170.027 & 493.817 & 496.397 & & & & & & & & & & & & \\
\hline 0.209 & & & & & & & 773.177 & 844.274 & 429.531 & 468.766 & 207.934 & 196.607 & & & & & & \\
\hline 0.217 & 1633.914 & 1672.361 & 860.001 & 1008.154 & 433.109 & 428.860 & & & & & & & & & & & & \\
\hline 0.218 & & & & & & & 694.436 & 761.654 & 385.858 & 420.260 & 187.802 & 180.621 & & & & & & \\
\hline 0.225 & & & & & & & & & & & & & 3075.872 & 2927.400 & 2441.879 & 2459.173 & 1568.878 & 1860.724 \\
\hline 0.227 & & & & & & & 631.182 & 684.033 & 346.988 & 375.032 & 170.867 & 167.664 & & & & & & \\
\hline 0.230 & 1458.616 & 1512.702 & 742.865 & 874.848 & 387.016 & 370.252 & & & & & & & & & & & & \\
\hline 0.236 & & & & & & & 580.066 & 614.903 & 311.330 & 333.813 & 157.922 & 155.942 & & & & & & \\
\hline 0.242 & 1283.875 & 1354.235 & 650.569 & 767.708 & 345.527 & 322.196 & & & & & & & & & & & & \\
\hline 0.245 & & & & & & & 530.691 & 551.650 & 278.338 & 299.190 & 147.636 & 146.292 & & & & & & \\
\hline 0.250 & & & & & & & & & & & & & 2981.890 & 2819.141 & 2188.980 & 2295.268 & 1318.109 & 1557.669 \\
\hline 0.254 & & & & & & & 485.329 & 503.493 & 252.143 & 272.296 & 138.512 & 137.941 & & & & & & \\
\hline 0.255 & 1128.435 & 1203.066 & 579.446 & 671.124 & 301.031 & 280.167 & & & & & & & & & & & & \\
\hline 0.267 & & & & & & & 428.055 & 440.297 & 223.140 & 238.310 & 127.520 & 127.914 & & & & & & \\
\hline 0.268 & 986.651 & 1065.039 & 521.642 & 594.939 & 261.178 & 245.049 & & & & & & & & & & & & \\
\hline 0.275 & & & & & & & & & & & & & 2845.865 & 2673.485 & 1916.307 & 2114.857 & 1114.370 & 1266.278 \\
\hline 0.281 & 869.717 & 948.068 & 470.747 & 528.521 & 232.213 & 217.064 & & & & & & & & & & & & \\
\hline 0.285 & & & & & & & 363.204 & 362.658 & 193.736 & 205.088 & 114.268 & 115.574 & & & & & & \\
\hline 0.294 & 773.177 & 844.274 & 429.531 & 468.766 & 207.934 & 196.607 & & & & & & & & & & & & \\
\hline
\end{tabular}


Table 4-5. Iso-Value Surface Area (scaled) versus Velocity Magnitude (4 pages).

\begin{tabular}{|c|c|c|c|c|c|c|c|c|c|c|c|c|c|c|c|c|c|c|}
\hline \multicolumn{19}{|c|}{ All 120-Inch Runs scaled to Full Scale and 43.2-Inch } \\
\hline Velocity & $\begin{array}{l}\text { 120-Inch } \\
\text { GPM=98 }\end{array}$ & $\begin{array}{l}\text { 120-Inch } \\
\text { GPM=98 }\end{array}$ & $\begin{array}{l}120-\operatorname{Inch} \\
\text { GPM=78 }\end{array}$ & $\begin{array}{l}\text { 120-Inch } \\
\text { GPM=78 }\end{array}$ & $\begin{array}{l}120-\operatorname{Inch} \\
\text { GPM=58 }\end{array}$ & $\begin{array}{l}\text { 120-Inch } \\
\text { GPM=58 }\end{array}$ & $\begin{array}{l}\text { 43.2-Inch } \\
\text { GPM=8.6 }\end{array}$ & $\begin{array}{l}\text { 43.2-Inch } \\
\text { GPM=8.6 }\end{array}$ & $\begin{array}{l}43.2-\operatorname{Inch} \\
G P M=6.8\end{array}$ & $\begin{array}{l}\text { 43.2-Inch } \\
\text { GPM }=6.8\end{array}$ & $\begin{array}{l}\text { 43.2-Inch } \\
\text { GPM }=5.2\end{array}$ & $\begin{array}{l}\text { 43.2-Inch } \\
\text { GPM=5.2 }\end{array}$ & $\begin{array}{l}\text { Full-Scale } \\
\text { GPM=10400 }\end{array}$ & $\begin{array}{l}\text { Full-Scale } \\
\text { GPM=10400 }\end{array}$ & $\begin{array}{l}\text { Full-Scale } \\
\text { GPM=8320 }\end{array}$ & $\begin{array}{l}\text { Full-Scale } \\
\text { GPM=8320 }\end{array}$ & $\begin{array}{l}\text { Full-Scale } \\
\text { GPM= } 6240\end{array}$ & $\begin{array}{l}\text { Full-Scale } \\
\text { GPM }=6240\end{array}$ \\
\hline Magnitud & $\mathrm{RPM}=0.77$ & $\mathrm{RPM}=0.48$ & $\mathrm{RPM}=0.77$ & $\mathrm{RPM}=0.48$ & $\mathrm{RPM}=0.77$ & $\mathrm{RPM}=0.48$ & $\mathrm{RPM}=1.51$ & $\mathrm{RPM}=0.95$ & $\mathrm{RPM}=1.51$ & $\mathrm{RPM}=0.95$ & $\mathrm{RPM}=1.51$ & $\mathrm{RPM}=0.95$ & $\mathrm{RPM}=0.2$ & $\mathrm{RPM}=0.13$ & $\mathrm{RPM}=0.2$ & $\mathrm{RPM}=0.13$ & $\mathrm{RPM}=0.2$ & $\mathrm{RPM}=0.13$ \\
\hline$e(\mathrm{~m} / \mathrm{s})$ & Q3 (sq. m.) & Q3 (sq. m.) & Q3 (sq. m.) & Q3 (sq. m.) & Q3 (sq. m.) & Q3 (sq. m.) & Q3 (sq. m.) & Q3 (sq. m.) & Q3 (sq. m.) & Q3 (sq. m.) & Q3 (sq. m.) & Q3 (sq. m.) & Q3 (sq. m.) & Q3 (sq. m.) & Q3 (sq. m.) & Q3 (sq. m.) & Q3 (sq. m.) & Q3 (sq. m.) \\
\hline 0.300 & & & & & & & & & & & & & 2664.136 & 2521.558 & 1670.593 & 1928.195 & 936.676 & 1015.257 \\
\hline 0.303 & & & & & & & 306.710 & 304.954 & 171.889 & 179.802 & 103.483 & 103.489 & & & & & & \\
\hline 0.306 & 694.436 & 761.654 & 385.858 & 420.260 & 187.802 & 180.621 & & & & & & & & & & & & \\
\hline 0.319 & 631.182 & 684.033 & 346.988 & 375.032 & 170.867 & 167.664 & & & & & & & & & & & & \\
\hline 0.320 & & & & & & & 260.971 & 261.546 & 154.877 & 162.554 & 93.562 & 93.445 & & & & & & \\
\hline 0.325 & & & & & & & & & & & & & 2449.202 & 2359.744 & 1465.906 & 1740.923 & 796.247 & 809.417 \\
\hline 0.332 & 580.066 & 614.903 & 311.330 & 333.813 & 157.922 & 155.942 & & & & & & & & & & & & \\
\hline 0.338 & & & & & & & 228.968 & 228.507 & 142.017 & 148.011 & 84.269 & 83.841 & & & & & & \\
\hline 0.345 & 530.691 & 551.650 & 278.338 & 299.190 & 147.636 & 146.292 & & & & & & & & & & & & \\
\hline 0.350 & & & & & & & & & & & & & 2237.975 & 2197.827 & 1289.710 & 1538.818 & 673.720 & 675.476 \\
\hline 0.356 & & & & & & & 203.861 & 203.250 & 130.797 & 135.269 & 76.466 & 75.232 & & & & & & \\
\hline 0.357 & 485.329 & 503.493 & 252.143 & 272.296 & 138.512 & 137.941 & & & & & & & & & & & & \\
\hline 0.374 & & & & & & & 183.430 & 185.603 & 121.093 & 124.704 & 69.650 & 68.432 & & & & & & \\
\hline 0.375 & 428.055 & 440.297 & 223.140 & 238.310 & 127.520 & 127.914 & & & & & & & & & & & & \\
\hline 0.375 & & & & & & & & & & & & & 2020.330 & 2019.503 & 1128.899 & 1355.902 & 570.953 & 573.669 \\
\hline 0.392 & & & & & & & 168.197 & 171.403 & 112.897 & 115.040 & 63.869 & 62.358 & & & & & & \\
\hline 0.400 & 363.204 & 362.658 & 193.736 & 205.088 & 114.268 & 115.574 & & & & & & & & & & & & \\
\hline 0.400 & & & & & & & & & & & & & 1816.844 & 1854.823 & 983.610 & 1170.027 & 493.817 & 496.397 \\
\hline 0.409 & & & & & & & 154.696 & 159.117 & 104.915 & 106.483 & 58.643 & 57.634 & & & & & & \\
\hline 0.425 & 306.710 & 304.954 & 171.889 & 179.802 & 103.483 & 103.489 & & & & & & & & & & & & \\
\hline 0.425 & & & & & & & & & & & & & 1633.914 & 1672.361 & 860.001 & 1008.154 & 433.109 & 428.860 \\
\hline 0.427 & & & & & & & 144.657 & 147.420 & 96.902 & 98.925 & 53.476 & 52.432 & & & & & & \\
\hline 0.445 & & & & & & & 134.816 & 136.989 & 89.119 & 92.031 & 48.633 & 48.115 & & & & & & \\
\hline 0.450 & 260.971 & 261.546 & 154.877 & 162.554 & 93.562 & 93.445 & & & & & & & & & & & & \\
\hline 0.450 & & & & & & & & & & & & & 1458.616 & 1512.702 & 742.865 & 874.848 & 387.016 & 370.252 \\
\hline 0.463 & & & & & & & 126.654 & 127.783 & 82.719 & 85.536 & 44.197 & 44.199 & & & & & & \\
\hline 0.475 & 228.968 & 228.507 & 142.017 & 148.011 & 84.269 & 83.841 & & & & & & & & & & & & \\
\hline 0.475 & & & & & & & & & & & & & 1283.875 & 1354.235 & 650.569 & 767.708 & 345.527 & 322.196 \\
\hline 0.481 & & & & & & & 118.358 & 119.604 & 76.235 & 79.349 & 40.023 & 40.529 & & & & & & \\
\hline 0.498 & & & & & & & 111.157 & 111.923 & 70.644 & 73.814 & 36.291 & 37.067 & & & & & & \\
\hline 0.500 & 203.861 & 203.250 & 130.797 & 135.269 & 76.466 & 75.232 & & & & & & & & & & & & \\
\hline 0.500 & & & & & & & & & & & & & 1128.435 & 1203.066 & 579.446 & 671.124 & 301.031 & 280.167 \\
\hline
\end{tabular}


Table 4-5. Iso-Value Surface Area (scaled) versus Velocity Magnitude (4 pages).

\begin{tabular}{|c|c|c|c|c|c|c|c|c|c|c|c|c|c|c|c|c|c|c|}
\hline \multicolumn{19}{|c|}{ All 120-Inch Runs scaled to Full Scale and 43.2-Inch } \\
\hline Velocity & $\begin{array}{l}120-\text { Inch } \\
\text { GPM=98 }\end{array}$ & $\begin{array}{l}120-\operatorname{Inch} \\
\text { GPM=98 }\end{array}$ & $\begin{array}{l}\text { 120-Inch } \\
\text { GPM=78 }\end{array}$ & $\begin{array}{l}\text { 120-Inch } \\
\text { GPM=78 }\end{array}$ & $\begin{array}{l}120 \text {-Inch } \\
\text { GPM=58 }\end{array}$ & $\begin{array}{l}\text { 120-Inch } \\
\text { GPM=58 }\end{array}$ & $\begin{array}{l}\text { 43.2-Inch } \\
\text { GPM=8.6 }\end{array}$ & $\begin{array}{l}\text { 43.2-Inch } \\
\text { GPM=8.6 }\end{array}$ & $\begin{array}{l}\text { 43.2-Inch } \\
\text { GPM=6.8 }\end{array}$ & $\begin{array}{l}\text { 43.2-Inch } \\
\text { GPM=6.8 }\end{array}$ & $\begin{array}{l}\text { 43.2-Inch } \\
\text { GPM=5.2 }\end{array}$ & $\begin{array}{l}\text { 43.2-Inch } \\
\text { GPM=5.2 }\end{array}$ & $\begin{array}{l}\text { Full-Scale } \\
\text { GPM=10400 }\end{array}$ & $\begin{array}{l}\text { Full-Scale } \\
\text { GPM=10400 }\end{array}$ & $\begin{array}{l}\text { Full-Scale } \\
\text { GPM }=8320\end{array}$ & $\begin{array}{l}\text { Full-Scale } \\
\text { GPM=8320 }\end{array}$ & $\begin{array}{l}\text { Full-Scale } \\
\text { GPM= } 6240\end{array}$ & $\begin{array}{l}\text { Full-Scale } \\
G P M=6240\end{array}$ \\
\hline Magnitud & $\mathrm{RPM}=0.77$ & $\mathrm{RPM}=0.48$ & $\mathrm{RPM}=0.77$ & $\mathrm{RPM}=0.48$ & $\mathrm{RPM}=0.77$ & $\mathrm{RPM}=0.48$ & $\mathrm{RPM}=1.51$ & $\mathrm{RPM}=0.95$ & $\mathrm{RPM}=1.51$ & $\mathrm{RPM}=0.95$ & $\mathrm{RPM}=1.51$ & $\mathrm{RPM}=0.95$ & $\mathrm{RPM}=0.2$ & $\mathrm{RPM}=0.13$ & $\mathrm{RPM}=0.2$ & $\mathrm{RPM}=0.13$ & $\mathrm{RPM}=0.2$ & $\mathrm{RPM}=0.13$ \\
\hline$e(\mathrm{~m} / \mathrm{s})$ & Q3 (sq. m.) & Q3 (sq. m.) & Q3 (sq. m.) & Q3 (sq. m.) & Q3 (sq. m.) & Q3 (sq. m.) & Q3 (sq. m.) & Q3 (sq. m.) & Q3 (sq. m.) & Q3 (sq. m.) & Q3 (sq. m.) & Q3 (sq. m.) & Q3 (sq. m.) & Q3 (sq. m.) & Q3 (sq. m.) & Q3 (sq. m.) & Q3 (sq. m.) & Q3 (sq. m.) \\
\hline 0.525 & 183.430 & 185.603 & 121.093 & 124.704 & 69.650 & 68.432 & & & & & & & & & & & & \\
\hline 0.525 & & & & & & & & & & & & & 986.651 & 1065.039 & 521.642 & 594.939 & 261.178 & 245.049 \\
\hline 0.550 & 168.197 & 171.403 & 112.897 & 115.040 & 63.869 & 62.358 & & & & & & & & & & & & \\
\hline 0.550 & & & & & & & & & & & & & 869.717 & 948.068 & 470.747 & 528.521 & 232.213 & 217.064 \\
\hline 0.575 & 154.696 & 159.117 & 104.915 & 106.483 & 58.643 & 57.634 & & & & & & & & & & & & \\
\hline 0.575 & & & & & & & & & & & & & 773.177 & 844.274 & 429.531 & 468.766 & 207.934 & 196.607 \\
\hline 0.600 & 144.657 & 147.420 & 96.902 & 98.925 & 53.476 & 52.432 & & & & & & & & & & & & \\
\hline 0.600 & & & & & & & & & & & & & 694.436 & 761.654 & 385.858 & 420.260 & 187.802 & 180.621 \\
\hline 0.625 & 134.816 & 136.989 & 89.119 & 92.031 & 48.633 & 48.115 & & & & & & & & & & & & \\
\hline 0.625 & & & & & & & & & & & & & 631.182 & 684.033 & 346.988 & 375.032 & 170.867 & 167.664 \\
\hline 0.650 & 126.654 & 127.783 & 82.719 & 85.536 & 44.197 & 44.199 & & & & & & & & & & & & \\
\hline 0.650 & & & & & & & & & & & & & 580.066 & 614.903 & 311.330 & 333.813 & 157.922 & 155.942 \\
\hline 0.675 & 118.358 & 119.604 & 76.235 & 79.349 & 40.023 & 40.529 & & & & & & & & & & & & \\
\hline 0.675 & & & & & & & & & & & & & 530.691 & 551.650 & 278.338 & 299.190 & 147.636 & 146.292 \\
\hline 0.700 & 111.157 & 111.923 & 70.644 & 73.814 & 36.291 & 37.067 & & & & & & & & & & & & \\
\hline 0.700 & & & & & & & & & & & & & 485.329 & 503.493 & 252.143 & 272.296 & 138.512 & 137.941 \\
\hline 0.735 & & & & & & & & & & & & & 428.055 & 440.297 & 223.140 & 238.310 & 127.520 & 127.914 \\
\hline 0.784 & & & & & & & & & & & & & 363.204 & 362.658 & 193.736 & 205.088 & 114.268 & 115.574 \\
\hline 0.833 & & & & & & & & & & & & & 306.710 & 304.954 & 171.889 & 179.802 & 103.483 & 103.489 \\
\hline 0.882 & & & & & & & & & & & & & 260.971 & 261.546 & 154.877 & 162.554 & 93.562 & 93.445 \\
\hline 0.931 & & & & & & & & & & & & & 228.968 & 228.507 & 142.017 & 148.011 & 84.269 & 83.841 \\
\hline 0.980 & & & & & & & & & & & & & 203.861 & 203.250 & 130.797 & 135.269 & 76.466 & 75.232 \\
\hline 1.029 & & & & & & & & & & & & & 183.430 & 185.603 & 121.093 & 124.704 & 69.650 & 68.432 \\
\hline 1.077 & & & & & & & & & & & & & 168.197 & 171.403 & 112.897 & 115.040 & 63.869 & 62.358 \\
\hline 1.126 & & & & & & & & & & & & & 154.696 & 159.117 & 104.915 & 106.483 & 58.643 & 57.634 \\
\hline 1.175 & & & & & & & & & & & & & 144.657 & 147.420 & 96.902 & 98.925 & 53.476 & 52.432 \\
\hline 1.224 & & & & & & & & & & & & & 134.816 & 136.989 & 89.119 & 92.031 & 48.633 & 48.115 \\
\hline 1.273 & & & & & & & & & & & & & 126.654 & 127.783 & 82.719 & 85.536 & 44.197 & 44.199 \\
\hline 1.322 & & & & & & & & & & & & & 118.358 & 119.604 & 76.235 & 79.349 & 40.023 & 40.529 \\
\hline 1.371 & & & & & & & & & & & & & 111.157 & 111.923 & 70.644 & 73.814 & 36.291 & 37.067 \\
\hline
\end{tabular}


Figure 4-11 and Figure 4-12 show all six cases at the same scale, and are the same data in Figure 3-4 scaled to the other scales. Note that the "98 GPM, 0.77 RPM" case will not exactly correspond to the curve in Section 4.2, but matches that discussed in Section 3.0 (depicted in Figure 3-4). The case corresponding to Section 4.2 is shown in Figure 3-4.

The data for these figures comes from Table 4-5 (see Figure 4-5) with the blanks removed since they use consistent velocity-magnitude maps for each individual curve. The velocity-magnitude axis is the one at full-scale or absolute units (unscaled), which is the reason the 43.2-inch curve stops short of $0.7 \mathrm{~m} / \mathrm{s}$. The range of particular interest is shaded, and is beyond the peak in each curve.

Since the range of interest shows very different behavior on each of the scales, the solid-fluid interaction may be different on each scale, too. For example, at the 43.2-inch scale the solid could be hurled into the interior by the pump relatively further than at the full-scale (i.e. momentum rather than convection dominated) so that actual experiments at this scale could overstate the ability to move solid at full-scale. Unfortunately, this parameter is one of the time based factors that isn't scaled in favor of equal power per volume, so this effect should be evaluated in light of the final scale-up effort applied to the experiment results in further work. 
Figure 4-11. Results from 120-inch Cases Presented in Full-Scale Units.

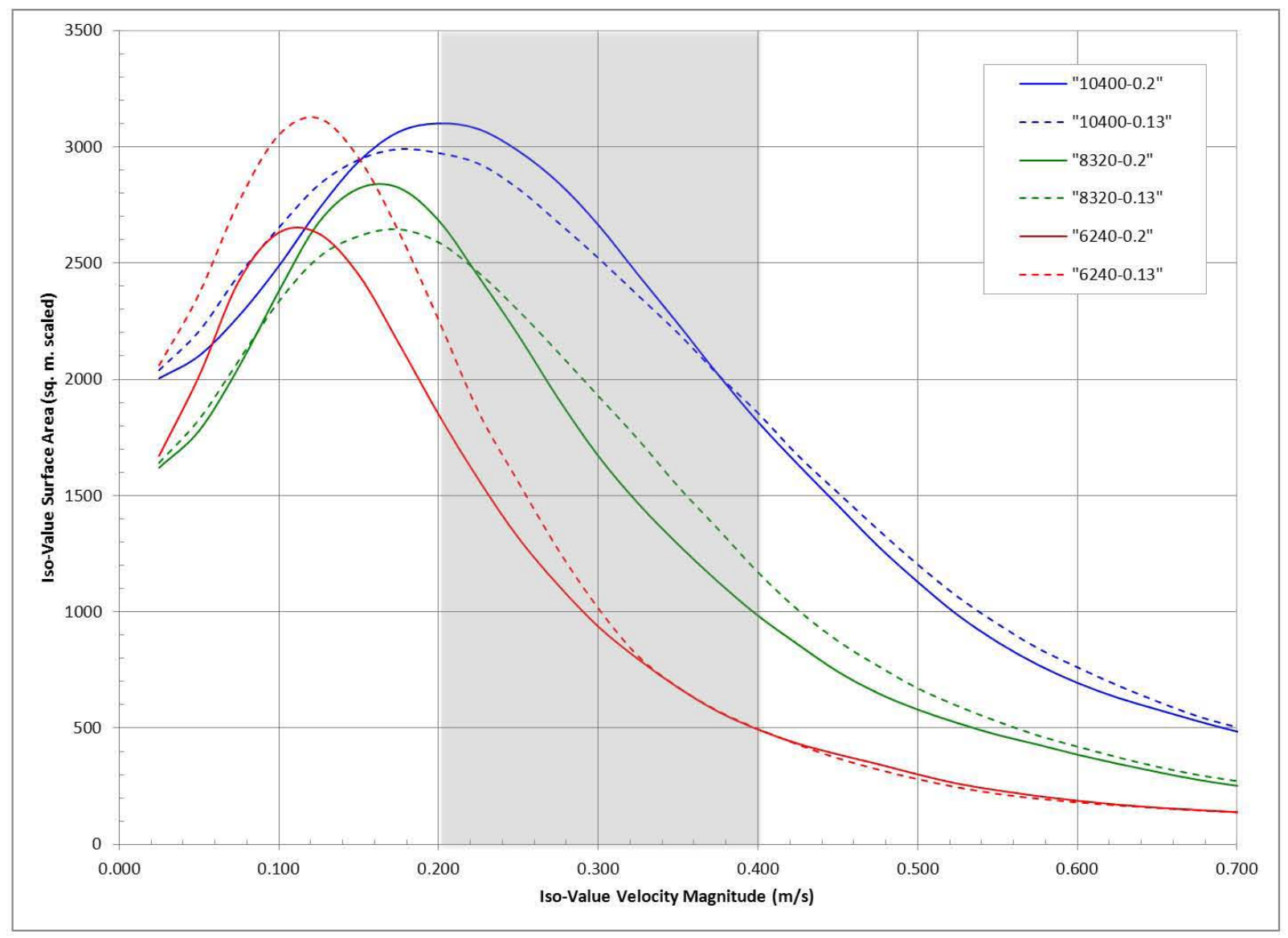


Figure 4-12. Results from 120-inch Cases Presented in 43.2-Inch Units.

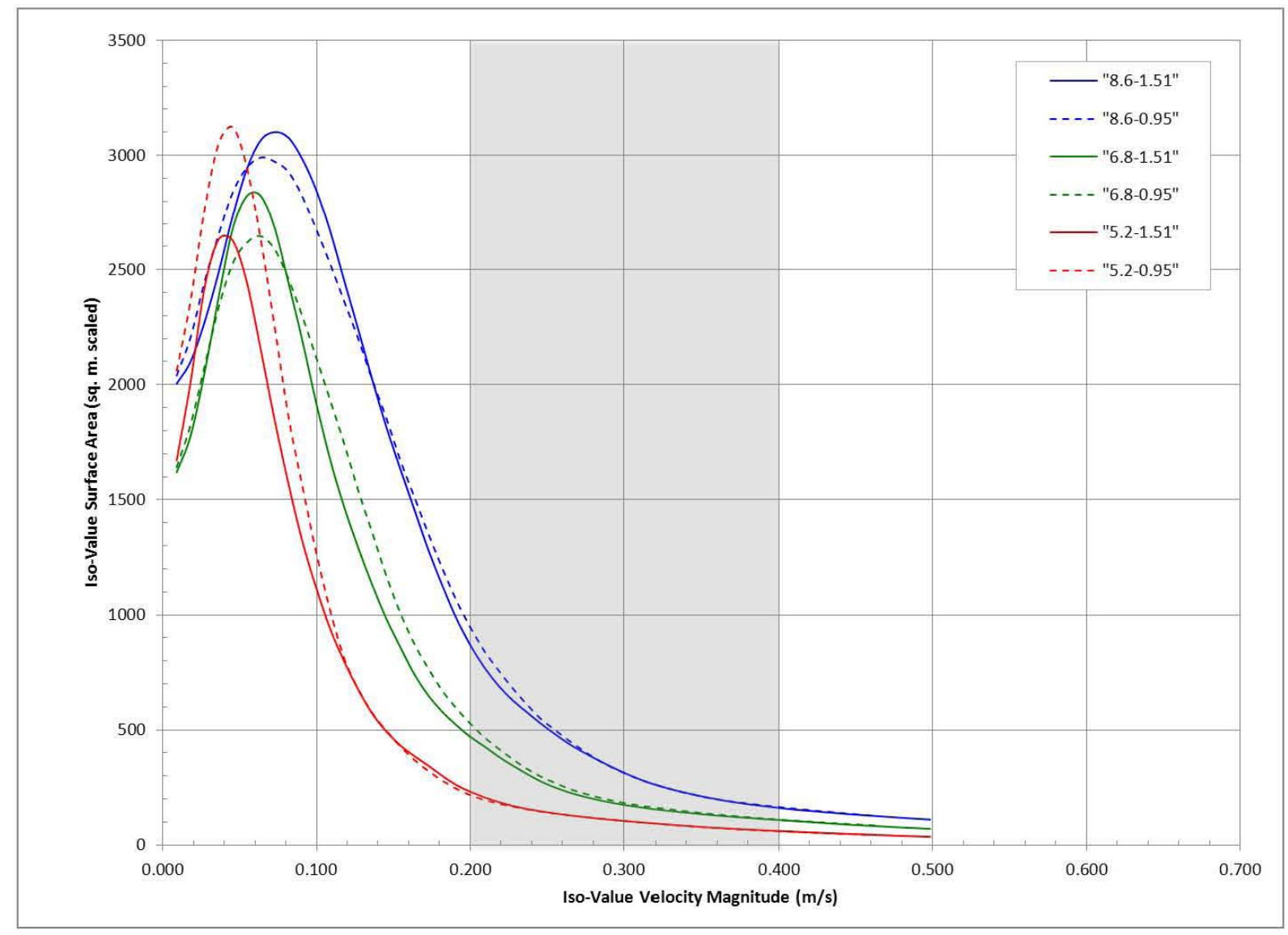




\subsection{CONCLUSIONS}

The CFD modeling of the DST mixing process that was planned for Tank AY-102 has shown benefit in evaluating various operating scenarios and enhancing the understanding of the mixing impacts. The three major objectives were accomplished. They are listed below along with their outcomes.

1. Demonstrate that the modeled jet velocities are equivalent to the jet velocities measured in the SSMD 120-inch tank. Comparisons of the SSMD impellor measurements and the CFD model velocities were sufficient in the region exceeding 20 nozzle diameters, indicating that the CFD fluid parameters match those occurring in the SSMD tanks.

2. Evaluate the impact of the jet, in terms of its flow rate and rotational rate, on the mixing performance at each of the three scale -- 43.2-inch, 120-inch, and full-scale. Mixing performance comparisons were developed at all three scales presenting the impacts of changes in flow rate and rotational rate on the mixing performance. At all scales, increasing the flow rate increases the volume of the tank that has an absolute velocity of 0.2 to $0.4 \mathrm{~m} / \mathrm{s}$. In some instances, the iso-area increase can be as large as $70 \%$. Rotational rate is a secondary but important factor, especially at the larger scales and the lower flow rates. The large scales and lower flow rates need additional time for the jet to fully penetrate. Therefore the lower rotational rate allows the jet to fully expand and reach further into the tank interior.

3. Evaluate the correlations that occur between the various scales for a defined particle suspension range of 0.2 to $0.4 \mathrm{~m} / \mathrm{s}$, as well as the parameter's impacts on mixing performance. At each of the three tank scales, the mixing performance in terms of the velocity range of interest $(0.2$ to 0.4 $\mathrm{m} / \mathrm{s}$ ) was compared. As the tank scale increased, larger portions of the tank had velocity within the range of interest. This result is partly due to the higher jet velocities utilized in the large scales, but does suggest that mixing performance and distribution of solids can be expected to improve as scales get larger. The influence of actual solid particles in these fluid-only simulation streams should be considered when predicting mixing performance.

These results are based upon a sensitivity study of the jet velocity and the rotational rate. These studies have been accomplished using a CFD model that has been tuned to produce jet velocities within the 120-inch tank that compare favorably with the actual jet velocities measured in the 120 -inch scale SSMD tank. The same turbulence parameters that were utilized for the 120 -inch tank scale have been applied to the 43.2-inch and full-scale CFD tank models.

Using the tuned CFD models, a sensitivity study of the impacts of three jet velocity levels and two rotational rates was performed. Since the CFD model was only analyzing a single fluid model, the results from the 120 -inch tank scale could be calculated, with scaling relations used to determine the tank results for the 43.2-inch and full-scale tanks. To confirm the scaling relationships, one CFD model each at 43.2 -inch and one at full-scale were generated to compare to the scaled results. These runs compared favorably to the scaled runs, demonstrating an understanding of the scaling relationships for liquid flow between the multiple scales. This understanding has been utilized to scale the 120-inch tank results to the 43.2-inch tank scale and the full-scale to complete the sensitivity matrix.

The fluid-only CFD work is consistent for a range of scaling laws because, locally, the fluid behaves the same in all the models. For example, density or temperature gradients that would 
cause the force of gravity to distinguish between scales have been ignored. Thus, the fact that the models are consistent, as demonstrated in Section 4.2, cannot be used to prove that the apriori choice of one-third power scaling is the correct choice since other assumptions would be just as consistent.

Using the results from the complete sensitivity matrix across all scales, the effects of jet velocity and rotational rate have been studied. In all cases, a change in jet velocity has a much larger impact on mixing than changes in rotational rate. For some of the lower jet velocity cases, the rotation rate can be moderately significant. However, as the jet velocity increases the impact of rotational rate decreases. In terms of the expected key particle movement velocities of 0.2 to 0.4 $\mathrm{m} / \mathrm{s}$, the small scale is relatively insensitive to jet velocity. This insensitivity is due to a majority of the tank operating at much lower velocity and the peak iso-areas being well to the left of this velocity range. As the tank scale increases, the iso-area peaks will shift to the right, increasing the mixing impact for a given change in jet velocity. At the full-scale, the iso-area peaks are very near the velocity of interest range of 0.2 to $0.4 \mathrm{~m} / \mathrm{s}$, indicating larger changes in mixing performance for a change in jet velocity.

To properly model the solids mixing process, a constitutive model for the solid mixture needs to be combined with the liquid constitutive model used in this study. A constitutive model, in this application, mostly describes momentum transfer between the phases, which ideally should be deduced from experiments at the two physical test stands in the program. Understanding the solid-liquid interaction in sufficient detail will provide confidence in scale-up predictions of the DST mixing process to full-scale using CFD. 


\subsection{REFERENCES}

24590-WTP-ICD-MG-01-019, 2008, ICD-19 - Interface Control Document for Waste Feed, Rev. 4, U.S. Department of Energy, Office of River Protection, Richland, Washington.

Abramovich, G. N., 1963, The Theory of Turbulent Jets, The MIT Press, Cambridge, Massachusetts.

H-2-34669, Coil Assembly, October 1969, Hanford Site Drawing, Richland, Washington.

H-2-34690, Dome Plan Penetration Tank-102-AY, March 1971, Hanford Site Drawing, Richland, Washington.

H-2-64447, Tank Plan and Penetration Schedule, January 1967, Hanford Site Drawing, Richland, Washington.

Lee, S.Y., R. A. Leishear, R. A. Dimenna, D. B. Stefanko, 2004, "Mixing in Large Scale Tanks Part I - Flow Modeling of Turbulent Mixing Jets", 2004 ASME Heat Transfer/Fluids Engineering Summer Conference, Charlotte, North Carolina, July 11-15, HT-FED200456228.

Lee, S. Y., R. A. Dimenna, R. A. Leishear, D. B. Stefanko, 2008, "Analysis of Turbulent Mixing Jets in a Large Scale Tank", ASME Journal of Fluids Engineering, Volume 130, Number 1 ,

PL-SSMD-EG-0001, RPP-44650, Rev. 0, 2010, Waste Feed Delivery Small Scale Mixing Demonstration Plan, E. Straalsund, Energy Solutions Engineering and Technology, Richland, Washington.

RPP-48055, 2010, Computational Fluid Dynamics Modeling of Scaled Hanford Double Shell Tank Mixing, Fiscal Year 2010 Model Development Results (VET-1667-RPT-001), Vista Engineering Technologies, LLC, Richland Washington.

RPP-44619, 2010, Computational Fluid Dynamics Modeling for Double-Shell Tank Mixing Demonstration Project Work Plan (VET-1667-PLN-001) Rev. 1, Washington River Protection Solutions, Richland, Washington. 


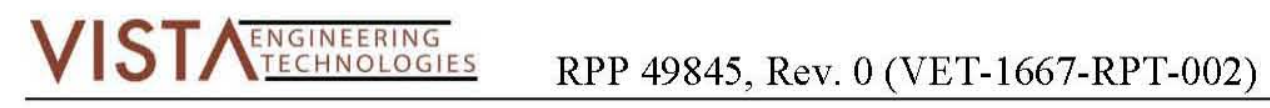

APPENDIX A: PROCESS MOVIE ON CD 